\title{
Stereospecific Synthesis of Carbanucleotides Designed for Antisense Methodology
}

by Xue-Feng Zhu' ${ }^{1}$ ), Freddy Nydegger, and Albert Gossauer*

Department of Chemistry of the University of Fribourg, Chemin du Musée 9, CH-1700 Fribourg

\begin{abstract}
A short stereospecific synthesis of the carbocyclic 2'-deoxynucleoside analogues $\mathbf{3 6}$ and $\mathbf{3 7}$ (Schemes 2 and 5) and $\mathbf{4 5}$ and $\mathbf{4 6}$ (Schemes 2 and 6) starting from optically active 8,9,10-trinorborn-5-en-2-one (1) is described. As two functional groups capable to react with each other are present in the same molecule of the synthetic carbanucleosides, the latter can form polymers similar to oligonucleotides.
\end{abstract}

Introduction. - Since the first report on the specific inhibition of gene expression by an oligonucleotide by Zamecnik and Stephenson in 1978 [1][2], antisense oligonucleotide methodology has become a promising tool in chemotherapy because of its specificity and manifold applications [3-5]. However, although some naturally occurring phosphodiester oligonucleosides have been shown to inhibit the replication of viruses in cell culture, the key to a wide application of oligonucleotide therapeutics resides in the development of modified oligonucleotides, which should be more resistent to degradation by naturally occurring nucleases. Actually, to achieve the desired biological effects, synthetic oligonucleotides must meet the following requirements: $i$ ) their half-life in the biological medium must be long enough for the desired action to take place inside the cell; $i i$ ) they must be able to penetrate the cell membrane to reach their objectives, and iii) they must bind strongly enough to the targeted nucleic acid sequence.

In principle, any one of the molecular components of an oligonucleotide (i.e., base, sugar, or phosphodiester backbone) can be modified to obtain an antisense nucleotide with specific affinity to a given segment of the targeted nucleic acid. Among these different kinds of modifications, the replacement of a cycloalkane for the ribose moiety is particularly promising since the synthetic nucleoside analogs - so-called carbanucleosides - are resistent against acids and phosphorylase enzymes that cleave the glycosidic linkage of normal nucleosides. Furthermore, the comparatively higher lipophilicity of carbanucleosides is potentially advantageous for facilitating oral administration and cell-wall penetration [6-9]. On the other hand, since the isolation of $(-)-(S)$-aristeromycin from Streptomyces citricolor [10] and (-)-neplanocin A from Ampullariella regularis [11], the interest in this class of compounds has grown rapidly, and other carbocyclic analogues of purine and pyrimidine nucleosides have been the subject of a great deal of synthetic and biological study in the last decade.

1) Present address: Isis Pharmaceuticals, Inc., Carlsbad, California, USA. 
By analogy to the enzymatic synthesis of nucleic acids, a particularly straightforward approach to antisense oligonucleotides is based on the polymerization of monomers containing two functional groups in the same molecule capable to react together in the presence of a catalyst. In making the choice of the most appropriate functional groups that meet this condition, it is obvious to consider first those which lead to macromolecules of the types commonly synthesized in polymer chemistry, i.e., polycarboxylates and polyamides. On the other hand, the length of the chains joining the carbanucleoside units must be appropriate to assure an intramolecular separation between the monomer units in the polymer chain as similar as possible to that present in nucleic acids. As a result of these considerations, the syntheses of three carbadinucleotides of the type $\mathbf{4}, \mathbf{5}$, and $\mathbf{1 0}$ were designed, which should be accessible from monomeric building blocks of the type represented by $\mathbf{2}, \mathbf{3}, \mathbf{7}$ (from $\mathbf{6}$ ), and $\mathbf{9}$ (from $(+)-8)$, and $\mathbf{9}$ (Scheme 1).

A straightforward synthesis of $r a c-2$ and $r a c-3$ (both as butyl esters bearing a protecting group at the primary alcohol function) from rac-bicyclo[2.2.1]hept-5-en-2one (rac-1; short form: norbornenone) was carried out some years ago in our laboratory, affording in a four-step sequence both epimers in an overall yield of $43 \%$ each [12]. This approach proved to be more advantageous than an alternative synthesis reported previously by Jenny et al., who obtained the methyl ester of rac-3 in $24 \%$ yield in six reaction steps starting from racemic exo-norbornene-2-carbaldehyde [13][14]. The present communication describes an improved procedure for the synthesis of enantiomerically pure (+)-norbornenone $\mathbf{1}$, as well as stereospecific syntheses of $\mathbf{2}$ and $\mathbf{7}$ therefrom. The latter is the appropriate counterpart to carbanucleoside $\mathbf{9}$ for the construction of carbadinucleotide 10, as the smallest self-replicating unit suitable for the synthesis of polycarbanucleotides, the length of which should enable hybridization with natural DNA or RNA fragments. Carbanucleoside 9 should be readily accessible from enantiomerically pure $(+)-\mathbf{8}$, which has been obtained by enzymatic resolution of the racemate [15]. Ultimately, the syntheses of $\mathbf{2}$ and $\mathbf{7}$ described in the present work take advantage of the fact that their common optically active cyclopentanone precursor 6 posses a $C_{2}$ symmetry axis, giving rise to a sole enantiomer on reduction of the carbonyl group.

Results and Discussion. - Synthesis of Carbanucleosides $\mathbf{4 5}$ and $\mathbf{4 6}$. The Concept ... The $(1 R, 2 R)$-isomer of $\mathbf{6}$ should be accessible from $(+)$-norbornenone $\mathbf{1}$ by means of the conventional methodology of opening the bicyclo[2.2.1]heptane skeleton by Baeyer-Villiger oxidation of the norbornanone derivative 12a (Scheme 2). Thus, the key step of the reaction sequence represented by the framed formulae in Scheme 2 is the introduction of the acetic acid chain at $\mathrm{C}(2)$ of the cyclopentane ring. This goal should be achieved by cyclopropanation of the $\mathrm{C}=\mathrm{C}$ bond of $\mathbf{1}$ with a diazoacetate and subsequent regioselective opening of the cyclopropane ring of $\mathbf{1 1}$ by cleaving the $\mathrm{C}-\mathrm{C}$ bond vicinal to the carbonyl group. Depending on the diazocarboxylate used for the cyclopropanation reaction, chemoselective transformation of the ester group of $\mathbf{1 3}$ ( $\rightarrow$ 14) prior to cleavage of the lactone ring enables to differentiate between both side chains at $\mathrm{C}(1)$ and $\mathrm{C}(2)$. After cleavage of the lactone ring, the $\mathrm{OH}$ group of the obtained hydroxycyclopentanediacetate is $c i s$ with respect to the acetic acid moiety originating from the norbornenone skeleton (cf. $\mathbf{1 5}$ in Scheme 2) so that nucleophilic 
Scheme 1
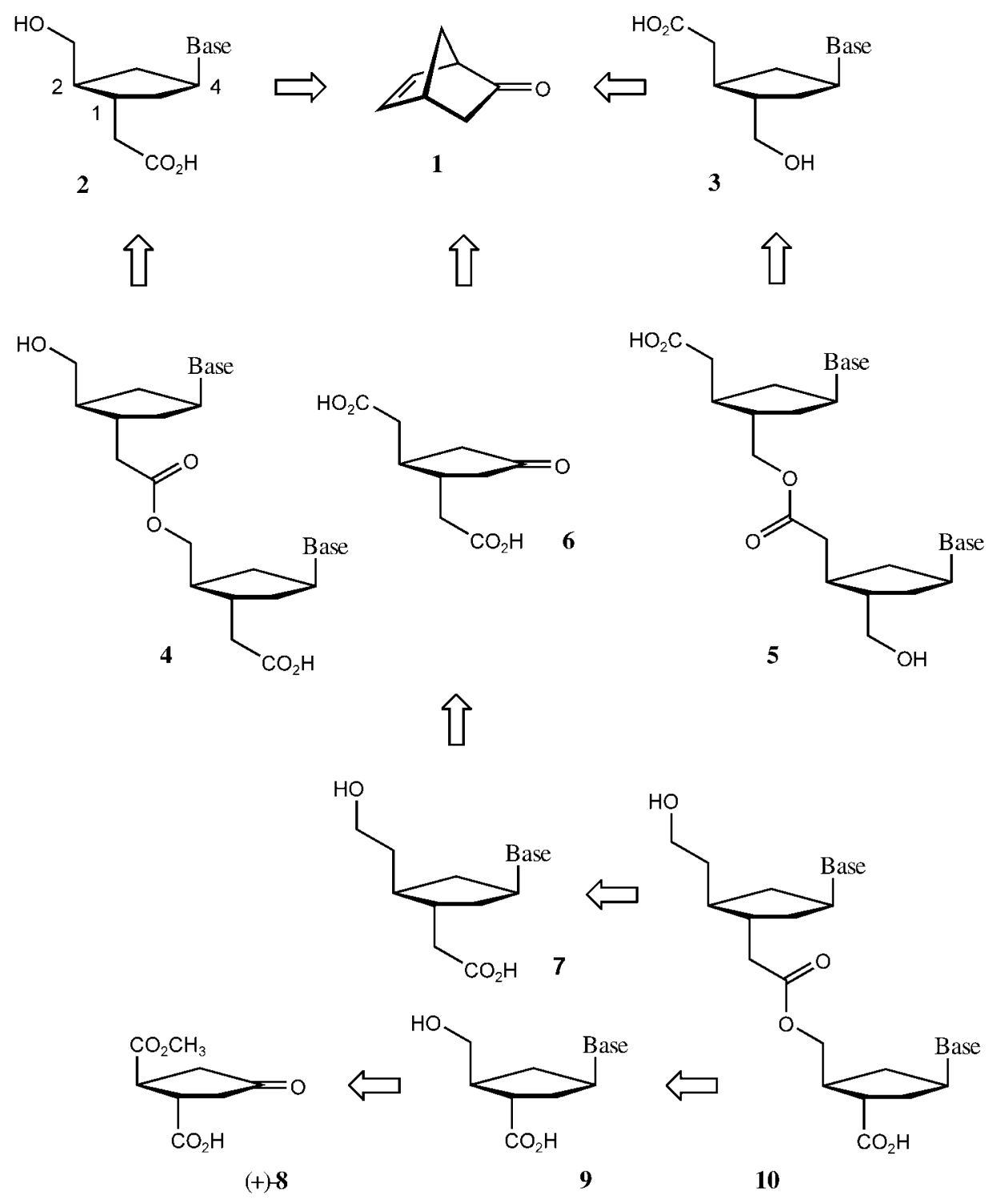

substitution of the $\mathrm{OH}$ group by a nucleobase affords the corresponding carbanucleoside with the nucleobase cis to the modified acetic acid chain (cf. below, Scheme 6).

... and Its Realization. (+)-Norbornenone $\mathbf{1}$ was obtained by asymmetrically catalyzed Diels-Alder cycloaddition of $\alpha$-bromoacrylaldehyde to cyclopentadiene as reported by Corey and co-workers [16] [17] (Scheme 3). In contrast to Corey's method, however, the preparation diol 19 via epoxide 18 [18] proved to be more efficient and reproducible than either the direct transformation of bromohydrine $\mathbf{1 7}$ [18] into 19 or 
Scheme $2^{2}$ )

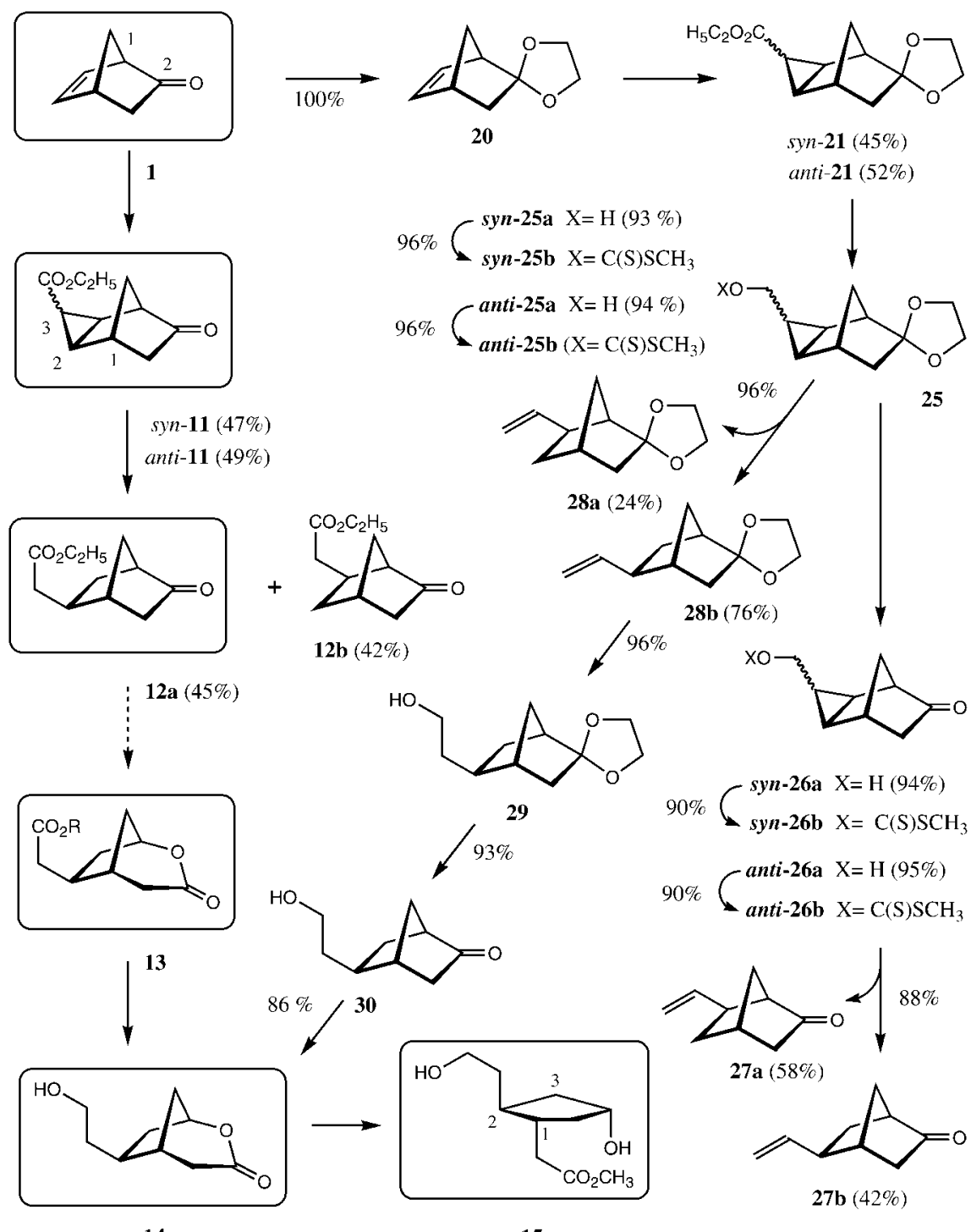

14

the transformation of $\mathbf{1 6}$ into the corresponding cyanohydrine via the oxime of the former. Moreover, only negligible quantities of by-products were formed during the synthesis of 18 and 19 (see Exper. Part). Finally, diol 19 was transformed into optically pure (e.e. $>97 \%$ ) (+)-norbornenone $\mathbf{1}$ by oxidation with sodium periodate following the procedure described by Helmchen and co-workers [19].

The success of the next reaction step, cyclopropanation of the $\mathrm{C}=\mathrm{C}$ bond of $\mathbf{1}$, is strongly dependent on the catalyst used (see Table). Actually, according to Hubert's 
Scheme 3

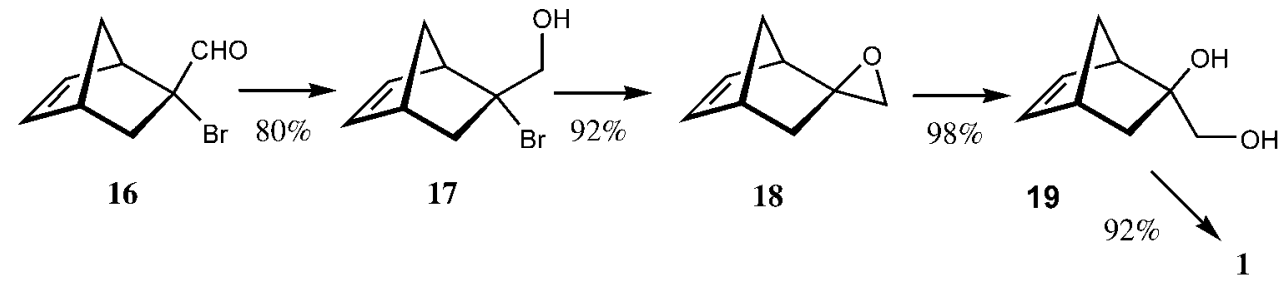

Table. Dependence of the Yield and syn/anti Stereoselectivity of the Cyclopropanation Reaction of $\mathbf{1}$ and $\mathbf{2 0}$ with Ethyl Diazoacetate (EDA) on the Reaction Conditions

\begin{tabular}{|c|c|c|c|c|c|c|c|}
\hline Catalyst & Substrate & $\begin{array}{l}\text { Catal./substr. } \\
\text { ratio }\end{array}$ & $\begin{array}{l}\text { EDA/substr. } \\
\text { ratio }^{\text {a) }}\end{array}$ & Temp. $\left[{ }^{\circ}\right]$ & Time $\left.[\mathrm{h}]^{\mathrm{b}}\right)$ & Yield $[\%]^{\mathrm{c}}$ ) & $\begin{array}{l}\text { anti/syn } \\
\text { Ratio }^{\mathrm{d}} \text { ) }\end{array}$ \\
\hline$\left[\mathrm{Rh}_{2}(\mathrm{OAc})_{4}\right]$ & 20 & $200: 1$ & $1: 1$ & 23 & 1.5 & 30 & 1.46 \\
\hline$\left[\mathrm{Rh}_{2}(\mathrm{OAc})_{4}\right]$ & 20 & $100: 1$ & $1: 1$ & 45 & 1 & 50 & 1.80 \\
\hline$\left[\mathrm{Cu}(\mathrm{OTf})_{2}\right]$ & 20 & $100: 1$ & $1: 1$ & 23 & 1.5 & 38 & 2.33 \\
\hline$\left[\mathrm{Cu}(\mathrm{OTf})_{2}\right]$ & 20 & $100: 1$ & $1: 1$ & 45 & 1 & 68 & 2.41 \\
\hline$\left[\mathrm{Pd}(\mathrm{OAc})_{2}\right]$ & 20 & $100: 1$ & $1: 1$ & 23 & 1.5 & 83 & 1.38 \\
\hline$\left[\mathrm{Pd}(\mathrm{OAc})_{2}\right]$ & 20 & $100: 1$ & $1: 1$ & 45 & 1 & 90 & 1.16 \\
\hline$\left[\mathrm{Pd}(\mathrm{OAc})_{2}\right]$ & 20 & $50: 1$ & $1: 1$ & 45 & 1 & 87 & 1.23 \\
\hline$\left[\mathrm{Pd}(\mathrm{OAc})_{2}\right]$ & 20 & $100: 1$ & $1.2: 1$ & 45 & 1 & 100 & 1.16 \\
\hline$\left[\mathrm{Pd}(\mathrm{OAc})_{2}\right]$ & 1 & $100: 1$ & $1: 1$ & 45 & 1 & 94 & 1.05 \\
\hline$\left[\mathrm{Pd}(\mathrm{OAc})_{2}\right]$ & 1 & $100: 1$ & $1.2: 1$ & 45 & 1 & 100 & 1.05 \\
\hline
\end{tabular}

a) A solution of $\operatorname{EDA}(0.5 \mathrm{mmol})$ in dry $\mathrm{CH}_{2} \mathrm{Cl}_{2}(12 \mathrm{ml})$ was added, under Ar, at constant flow rate during $2 \mathrm{~h}$ to a stirred solution of the alkene $(0.05 \mathrm{mmol})$ in $\mathrm{CH}_{2} \mathrm{Cl}_{2}(5 \mathrm{ml})$ containing the catalyst. $\left.{ }^{\mathrm{b}}\right)$ Time after the addition of EDA was completed. ${ }^{c}$ ) Yield of crude product before chromatographic separation. ${ }^{\mathrm{d}}$ ) As determined by ${ }^{1} \mathrm{H}-\mathrm{NMR}$ spectroscopy.

study on the mechanism of the reaction of $\alpha$-diazo esters with olefins [20], catalysts that favor the formation of a metal-olefin complex, which subsequently reacts with the diazo compound, rather than the formation of a metal-carbene complex, reduce the rate of dimerization of the carbenoid equivalent of the diazo compound, which is the main undesired side reaction in this kind of cyclopropane synthesis. Both (+)norbornenone $\mathbf{1}$ and ethane-1,2-diyl ketal $\mathbf{2 0}$ react in the presence of a palladium catalysts yielding the corresponding cyclopropane derivative in high yield (Scheme 2). As expected, carbene addition to the endocyclic $\mathrm{C}=\mathrm{C}$-bond takes place from the sterically less-hindered exo-side, although it lacks stereoselectivity in terms of the synor anti-position of the carboxylate group with respect to the methano bridge of the bicyclic substrate ${ }^{2}$ ). In the case of ethane-1,2-diyl ketal 21 the exo-configuration of the cyclopropane moiety could be unequivocally demonstrated for both the syn- and antiisomer by NMR data.

No nuclear Overhauser effect (NOE) on the protons of the $\mathrm{CH}_{2}(8)$ group of the tricycle of syn-and anti-21 was observed upon irradiation either of $\mathrm{H}-\mathrm{C}(2)$ or of $\mathrm{H}-\mathrm{C}(4)$. As both syn- and anti-21 can be transformed by deprotection of the carbonyl group into the corresponding cyclopropanonorbornanone derivatives 11, the latter

2) The designation syn/anti refers to the position of the substituent at $\mathrm{C}(3)$ of the tricycle with respect to the main-bridge atom $\mathrm{C}(8)$, i.e., less/more remote from $\mathrm{C}(8)$. 
must be also exo-configurated. Moreover, the assignment of the syn- and anti-configuration to the isomers of ketal 21 was also possible by NOE difference spectroscopy, since the enhancement by $23.5 \%$ of the intensity of the resonance signal at $1.77 \mathrm{ppm}$ assigned to $\mathrm{H}-\mathrm{C}(3)$ of the tricycle observed on irradiation at $\mathrm{H}-\mathrm{C}(8)$ of anti21 requires a 'cis'-arrangement of the involved $\mathrm{H}$-atoms. On the other hand, the measured coupling constants $\left({ }^{3} \mathrm{~J}(\mathrm{H}, \mathrm{H})=2.6 \mathrm{~Hz}\right)$ between $\mathrm{H}-\mathrm{C}(3)$ and $\mathrm{H}-\mathrm{C}(2)$ or $\mathrm{H}-\mathrm{C}(4)$ are consistent with a trans-arrangement of the coupling protons in anti-21 (a corresponding cis-arrangement usually results in ${ }^{3} J(\mathrm{H}, \mathrm{H})=10 \pm 2 \mathrm{~Hz}$ ) [21].

Unfortunately, however, reductive cleavage of the cyclopropane ring, which was attempted by catalytic hydrogenation of the mixture of syn- and anti-stereoisomers of 11 (both as racemates), was not regioselective: the reaction product consisted of a mixture of the desired 5-oxonorbornane-2-acetate rac-12a and its isomer rac-12b in a ratio of roughly 1:1 (Scheme 2). In view of this difficulty, we next attempted a regioselective cleavage of the cyclopropane ring in consideration of the well-known tendency of cyclopropylmethyl radicals to isomerize, yielding butene radicals [22]. As a matter of fact, rearrangement of the cyclopropylmethyl radical 22, derived from $\mathbf{1 1}$, may produce the two radicals $\mathbf{2 3}$ and $\mathbf{2 4 ,} \mathbf{2 3}$ being homoconjugated with the carbonyl group of the norbornanone skeleton (Scheme 4). Although, a priori, the preparation of radical 27 does not require the separation of syn- and anti-11 since the cyclopropanering opening cancels the chirality of its $\mathrm{C}(2)$ atom, the following transformations were carried out with the separated stereoisomers, thereby simplifying the characterization of the obtained products. Thus, the ester groups of the ketals syn- and anti-21 were reduced with $\mathrm{LiAlH}_{4}$ to yield the primary alcohols syn- and anti-25a, respectively (Scheme 2). Following deprotection of the carbonyl group led to the corresponding hydroxy ketones syn- and anti-26a, respectively, which were transformed subsequently into the corresponding xanthates syn- and anti-26b. Radical-induced deoxygenation of the latter ( $c f$. [23]) led to a mixture of the 6- and 5-vinylnorbornanones $\mathbf{2 7} \mathbf{a}$ and $\mathbf{2 7 b}$, respectively, with a low preference ( $58 \mathrm{vs} .42 \%$ ) for the undesired isomer $27 \mathbf{a}$. This result agrees with the calculated heats of formation of radicals centered at the $\mathrm{C}(5)$ and $\mathrm{C}(6)$ atoms of norcamphor (= bicyclo[2.2.1]heptane-2-one), which are practically identical within the margin of error of the MNDO method [24]. On the contrary, radical-induced deoxygenation of the xanthates syn- and anti-25b, derived from the ketals syn- and anti-25a, respectively, proceeded with a marked preference for the 5vinyl isomer $\mathbf{2 8 b}$, which was obtained in a $3: 1$ ratio with respect to the (undesired) 6vinyl isomer 28a. Although not completely regioselective, the above reaction sequence provides access (via $\mathbf{2 9}$ and $\mathbf{3 0}$ ) to hydroxy lactone $\mathbf{1 4}$ as a single isomer that could be transformed in two steps into the desired carbanucleosides 45 and 46 (cf. below, Scheme 6).

Stereospecific Synthesis of Carbanucleosides $\mathbf{3 6}$ and 37. Moreover, vinyl derivative 28b serves as an intermediate for the synthesis of carbanucleosides $\mathbf{3 6}$ and $\mathbf{3 7}$

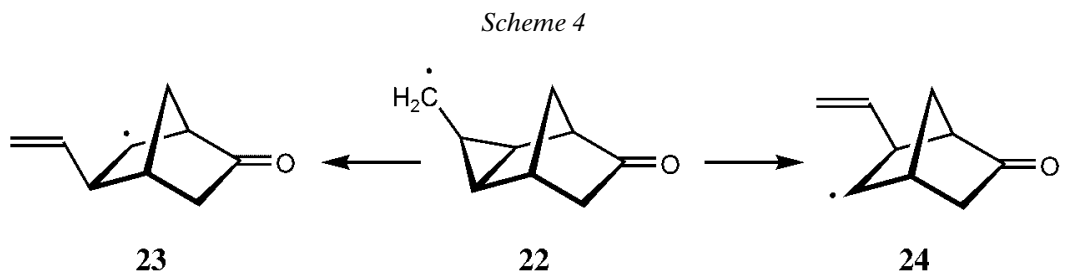


<smiles>C=CC1C2CC1C1(C2)OCCO1</smiles>

$28 \mathrm{~b}$
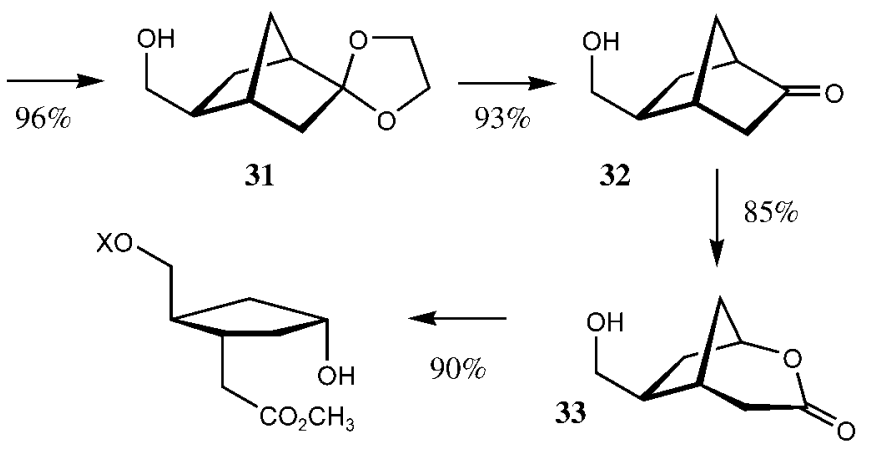

$70 \%$

34a $(X=H)$

$34 b\left(X={ }^{t} \mathrm{BuPh}_{2} \mathrm{Si}\right.$

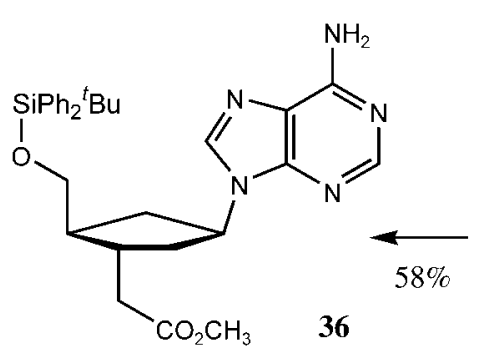

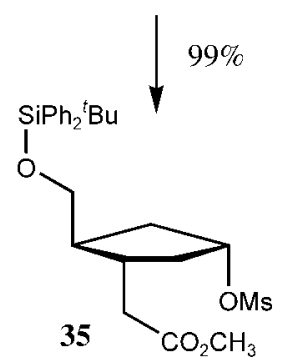

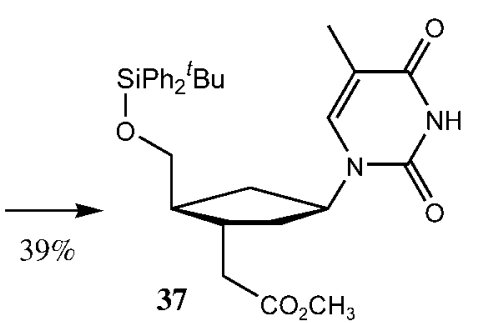

(Scheme 5) as it can be easily transformed by ozonolysis and subsequent reduction of the obtained aldehyde into 31, the methanol analogue of ethanol 29. Thus, after deprotection of the carbonyl group, Baeyer-Villiger oxidation of the norcampher derivative $\mathbf{3 2}$ afforded hydroxy lactone $\mathbf{3 3}$, which was transformed by methanolysis into the hydroxy cyclopentaneacetate 34a. Following the usual procedure, the primaryalcohol group of 34a was selectively protected as (tert-butyl)diphenylsilyl ether $\mathbf{3 4 \mathbf { b }}$ and, after transformation of the secondary-alcohol group into the corresponding mesylate $(\rightarrow \mathbf{3 5})$, the latter was reacted either with adenine or with thymine to yield the corresponding carbanucleosides $\mathbf{3 6}$ and $\mathbf{3 7}$, respectively. The same compounds (bearing different protecting groups for the primary-alcohol and carboxylic acid functions) had been obtained earlier, as racemates, by a different route [12].

Stereospecific Synthesis of Carbanucleosides $\mathbf{4 5}$ and 46. The unsatisfactory regioselectivity observed in our attempts to cleave the cyclopropane ring of $\mathbf{1 1}$ and 25b by catalytic hydrogenation and radical-induced deoxygenation, respectively, prompted us to postpone the ring opening to the next step of the originally intended reaction sequence, namely the Baeyer-Villiger oxidation of the carbonyl group of $\mathbf{1 1}$ (Scheme 6). However, when lactone syn-38 was hydrogenated on $\mathrm{Pd} / \mathrm{C}$, only a low yield $(25 \%)$ of the undesired ring-opened isomer $\mathbf{3 9}$ was obtained, probably due to the competitive reduction of the lactone moiety under these reaction conditions. 
Scheme $6^{2}$ )
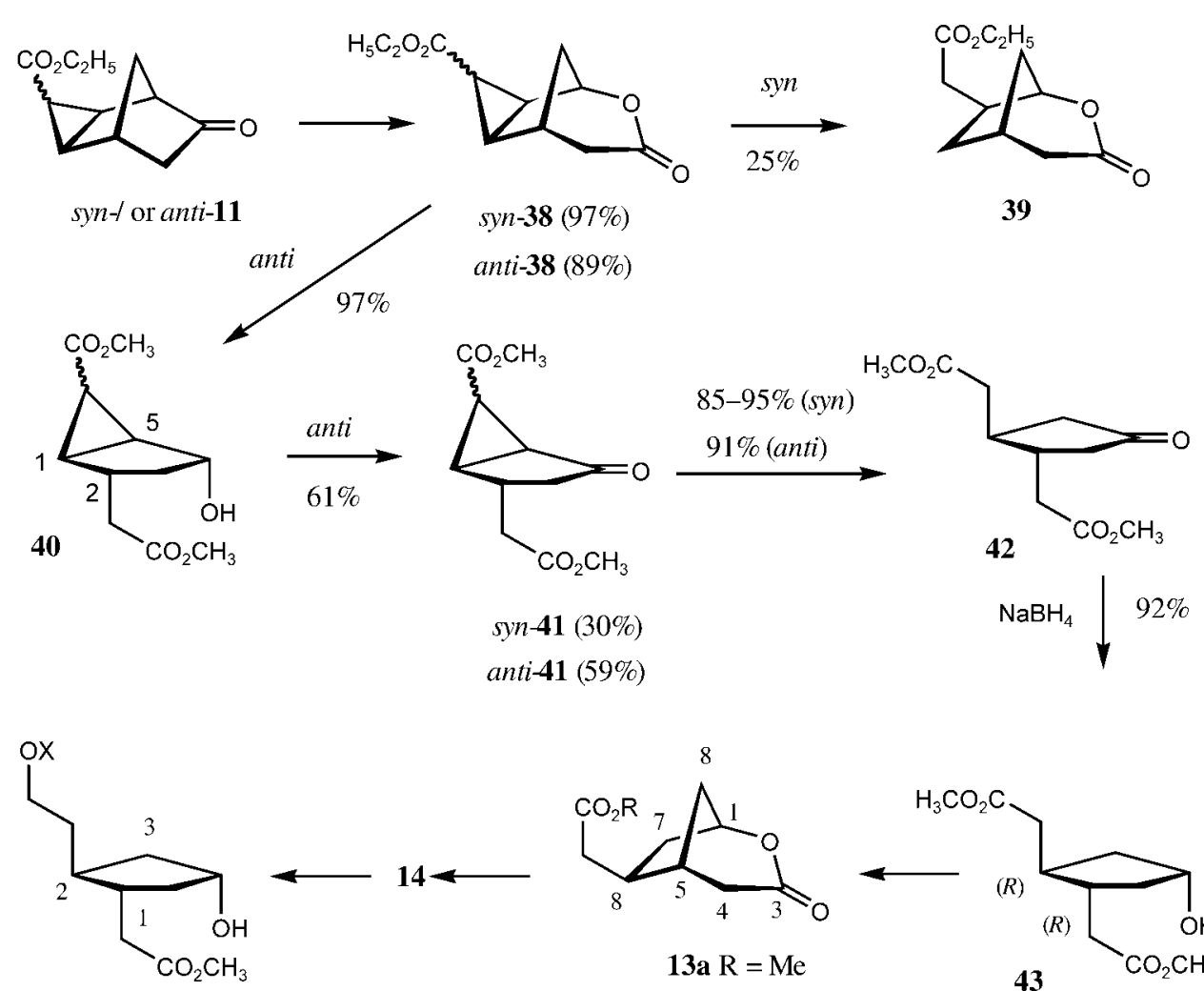

$$
\begin{aligned}
& \text { 15a } X=\mathrm{H} \\
& \text { 15b } X={ }^{t} \mathrm{BuPh}_{2} \mathrm{Si}
\end{aligned}
$$

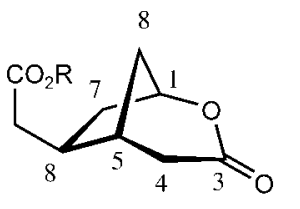

$$
\begin{aligned}
\text { 13a } \mathrm{R} & =\mathrm{Me} \\
\text { b } \mathrm{R} & =\mathrm{PhCH}_{2} \\
\text { c } \mathrm{R} & =\mathrm{H}
\end{aligned}
$$

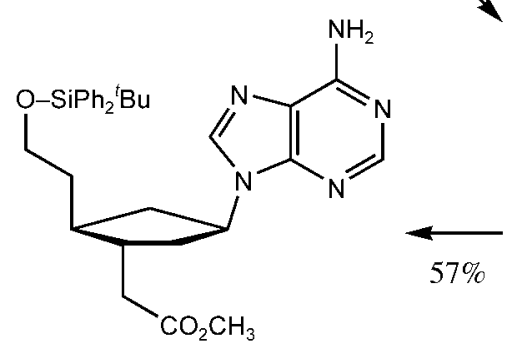

45

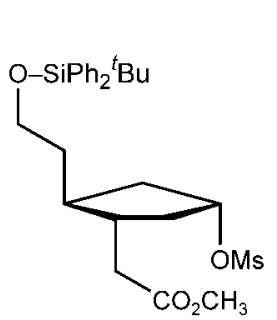

44

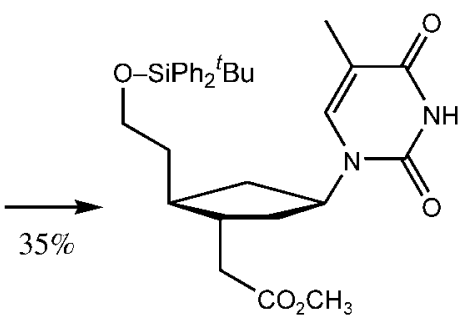

46

According to a study of the regioselectivity of reductive cleavage of the cyclopropane ring by Musso and co-workers [25][26], electron-withdrawing substituents weaken the $\mathrm{C}-\mathrm{C}$ bond adjacent to the substituted $\mathrm{C}$-atom, thus facilitating its hydrogenolytic cleavage. Thus, it appeared advantageous to modify the proposed 
synthetic pathway including ketones syn- and anti-41 as intermediates (Scheme 6). Both bicyclo[3.1.0] hexanones were readily accessible by oxidation of the corresponding secondary alcohols syn- and anti-40, respectively. The latter were obtained on methanolysis of the lactone moiety of syn- and anti-38, which took place under transesterification of the carboxylate group at the cyclopropane ring. As expected, hydrogenolytic cleavage of the cyclopropane ring of both syn-and anti-41 occurred at the $\sigma$-bond adjacent to the carbonyl group yielding the $C_{2}$-symmetric cyclopentanone derivative $\mathbf{4 2}$ regioselectively. Racemic $\mathbf{4 2}$ (as the diethyl ester) has previously been prepared in four steps starting with cyclopent-2-enone ( $c f$. [27][28]). Borohydride reduction of $\mathbf{4 2}$ afforded the desired secondary alcohol $\mathbf{4 3}$ as a single isomer. It must be pointed out that this outcome of the synthesis of $\mathbf{4 3}$ confirms unequivocally the relative trans-configuration at the $\mathrm{C}(1)$ and $\mathrm{C}(2)$ atoms, since a cis-isomer resulting from an endo-cyclopropanonorbornanone derivative would afford two diastereomeric cyclopentanol derivatives with opposite configuration at the pseudoasymmetric $\mathrm{C}(4)$ atom.

A manifest advantage of the above synthetic strategy is the $C_{2}$ symmetry of intermediate $\mathbf{4 2}$, which prevents the formation of stereoisomers on replacement of the carbonyl group by a tetragonal C-atom. Moreover, the same strategy offers a simple possibility to differentiate between the two acetic acid chains at $\mathrm{C}(1)$ and $\mathrm{C}(2)$, since lactonization of $\mathbf{4 3}$ yields a single product, 13a, which, on transesterification with benzylic alcohol and subsequent hydrogenolysis of the benzyl ester group, affords the monocarboxylic acid 13c (Scheme 6). Diborane reduction of the carboxylic acid group of 13c took place chemoselectively, thus yielding the primary alcohol 14, which was finally transformed into 15a by methanolysis of the lactone ring. After protecting the primary alcohol function of $\mathbf{1 5 a}$, the resulting silyl ether $\mathbf{1 5 b}$ was transformed with methanesulfonyl chloride to the mesylate $\mathbf{4 4}$, which was subjected to nucleophilic substitution with either adenine or thymine to yield the carbanucleosides $\mathbf{4 5}$ and $\mathbf{4 6}$, respectively.

Conclusions. - In summary, the present work describes a straightforward stereospecific synthesis of the four carbanucleosides 36, 37, $\mathbf{4 5}$, and $\mathbf{4 6}$ from optical active norbornen-2-one $\mathbf{1}$ as a readily accessible starting material. As in each carbanucleoside the two functional groups $(\mathrm{OH}$ and $\mathrm{COOH})$ can be deprotected selectively, the monomeric building blocks are suitable for the direct synthesis of polyester analogs of nucleotides or, alternatively, for the stepwise synthesis of heteromeric polynucleotide analogs.

Financial support of this work by the Swiss National Science Foundation (Project No. 20-49507.96) is gratefully acknowledged. NMR Spectra were recorded by F. Fehr.

\section{Experimental Part}

General. Solvents were generally dried and distilled prior to use. All air- and $\mathrm{H}_{2} \mathrm{O}$-sensitive reactions were carried out under Ar. The 3-chloroperbenzoic acid (MCPBA), N,N-dimethylpyridin-4-amine (DMAP), tetrahydrofuran (THF), pyridinium chlorochromate (PCC), and other reagents were purchased from Fluka Chemie AG, CH-9471 Buchs. TLC (reaction monitoring): E. Merck silica-gel $60 F_{254}(0.2 \mathrm{~mm})$ precoated aluminium plates $(20 \times 20 \mathrm{~cm})$; detection by UV light $(254$ and $366 \mathrm{~nm})$ or $1 \%$ aq. 2,4-dinitrophenylhydrazine soln. (prepared by dissolving $0.4 \mathrm{~g}$ of 2,4-dinitrophenylhydrazine in $100 \mathrm{ml}$ of $2 \mathrm{~N} \mathrm{HCl}$ ), or alkaline $\mathrm{KMnO}_{4}$ soln. (prepared by dissolving $3 \mathrm{~g}$ of $\mathrm{KMnO}_{4}$ and $20 \mathrm{~g}$ of $\mathrm{K}_{2} \mathrm{CO}_{3}$ in $300 \mathrm{ml}$ of $\mathrm{H}_{2} \mathrm{O}$, followed by addition of $3 \mathrm{ml}$ of $5 \%$ 
aq. $\mathrm{NaOH}$ soln.). Column chromatography (CC) and flash column chromatography (FC): silica gel 60 (0.063$0.200 \mathrm{~mm}, 700-230 \mathrm{mesh})$ and silica gel 60 (0.040-0.063 mm, 230-400 mesh), respectively, from E. Merck AG.

M.p.s: Kofler hot-stage apparatus (Thermovar, C. Reichert $A G$, Vienna) equipped with a digital thermometer; uncorrected. Optical rotations $[\alpha]_{\mathrm{D}}$ : Perkin-Elmer-241-MV polarimeter; in deg $\left.\mathrm{ml} \mathrm{g}^{-1} \mathrm{dm}^{-1}\right), c$ in $\mathrm{g} / 100 \mathrm{ml}$. UV/VIS Spectra: Hewlett-Packard-8452A diode array spectrophotometer; $\lambda_{\max }(\varepsilon)$ in $\mathrm{nm}$. IR Spectra: Mattison 5000 FT-IR; $\tilde{v}$ in $\mathrm{cm}^{-1}$. NMR Spectra: Varian-Gemini-200 $\left(200.00\left({ }^{1} \mathrm{H}\right)\right.$ and $\left.50.30 \mathrm{MHz}\left({ }^{13} \mathrm{C}\right)\right)$, Bruker-AM-360 (360.14 $\left({ }^{1} \mathrm{H}\right)$ and $\left.90.57 \mathrm{MHz}\left({ }^{13} \mathrm{C}\right)\right)$, and Bruker-Advance-DRX-500 $\left(500.13\left({ }^{1} \mathrm{H}\right)\right.$ and $\left.125.76 \mathrm{MHz}\left({ }^{13} \mathrm{C}\right)\right)$ spectrometer; $\mathrm{CDCl}_{3}$ solns., when not given otherwise; chemical shifts $\delta$ in ppm rel. to $\mathrm{Me}_{4} \mathrm{Si}$ as internal standard, $J$ values in $\mathrm{Hz}$; assignments based on homonuclear COSY; ${ }^{1} \mathrm{H}\left\{{ }^{1} \mathrm{H}\right\} \mathrm{NOE}$ difference correlations attached proton test (APT) and/or chemical shifts; NOE: indication of $\delta$ of enhanced signal (\% enhancement, irradiated $\delta$ ). MS: Vacuum Generator Micromass 7070 E; EI (electron ionization) at $70 \mathrm{eV}$; in $m / z$ (rel. \%). High-resolution (HR) MS: Bruker 4.7T-BioApexII (FT-MS). Combustion analyses were carried out by Ilse Beetz, Microanalytical Laboratory, Kronach, Germany.

(+)-(1R,4R)-Bicyclo[2.2.1]hept-5-en-2-one (1). Oxidation of $\mathbf{1 9}$ with sodium periodate according to [19] gave 1. Colorless oil. $[\alpha]_{\mathrm{D}}^{26}=+1107.2\left(c=0.41, \mathrm{CHCl}_{3}\right)\left([29]:[\alpha]_{\mathrm{D}}^{23}=+1033\left(c=1.01, \mathrm{CHCl}_{3}\right)\right)$.

Ethyl (1R,2R,3R,4R,5R)- and (1R,2R,3S,4R,5R)-6-Oxotricyclo[3.2.1.0 2.4 Joctane-3-carboxylate (syn- and anti-11). A mixture of $\mathbf{1}(9.73 \mathrm{~g}, 90 \mathrm{mmol})$ ( $c f$. [19]) and [Pd(OAc) $)_{2}$ ( $\left.202 \mathrm{mg}, 0.9 \mathrm{mmol}\right)$ in dry freshly distilled $\mathrm{CH}_{2} \mathrm{Cl}_{2}(400 \mathrm{ml})$ was stirred at high speed and heated to rapid reflux in a round-bottomed flask equipped with a high-dilution adapter $\left(\right.$ Aldrich $^{\circledast}, Z$ 22,330-1) while a soln. of ethyl diazoacetate $(92 \% ; 13.4 \mathrm{~g}, 108 \mathrm{mmol})$ in $\mathrm{CH}_{2} \mathrm{Cl}_{2}(400 \mathrm{ml})$ was added dropwise at a rate of $1 / 20$ of the refluxing flow. After the addition was complete $(4 \mathrm{~h})$, the mixture was refluxed for additional $2 \mathrm{~h}$. The residue obtained after evaporation was separated by FC (silica gel, AcOEt/petroleum ether 1:4): $8.15 \mathrm{~g}(47 \%)$ of $\operatorname{syn-11}\left(R_{\mathrm{f}} 0.31\right)$ and $8.64 \mathrm{~g}(49 \%)$ of anti-11 $\left(R_{\mathrm{f}} 0.44\right)$, both as colorless oils.

Data of syn-11: $[\alpha]_{\mathrm{D}}^{21}=+274.1\left(c=0.63, \mathrm{CHCl}_{3}\right)$. IR $\left(\mathrm{CHCl}_{3}\right): 1746,1724 .{ }^{1} \mathrm{H}-\mathrm{NMR}\left(500.13 \mathrm{MHz}, \mathrm{CDCl}_{3}\right)$ : $4.18\left(q, J=7.13, \mathrm{MeCH}_{2} \mathrm{O}\right) ; 2.86(m, 1 \mathrm{H}) ; 2.84(m, 1 \mathrm{H}) ; 2.09(d d m, J=17.06,3.50,1 \mathrm{H}-\mathrm{C}(7)) ; 2.00(d d, J=$ $17.06,4.54,1 \mathrm{H}-\mathrm{C}(7)) ; 1.81(d d, J=7.72,7.66, \mathrm{H}-\mathrm{C}(3)) ; 1.53(d d m, J=7.72,6.49,1 \mathrm{H}) ; 1.35(d d m, J=7.66$, $6.49,1 \mathrm{H}) ; 1.29\left(t, J=7.13, \mathrm{Me} \mathrm{CH}_{2} \mathrm{O}\right) ; 1.24(d m, J=12.65,1 \mathrm{H}-\mathrm{C}(8)) ; 1.16(d m, J=12.65,1 \mathrm{H}-\mathrm{C}(8))$. ${ }^{13} \mathrm{C}-\mathrm{NMR}\left(50.3 \mathrm{MHz}, \mathrm{CDCl}_{3}\right): 212.92(\mathrm{C}(6)) ; 171.09(\mathrm{CO}) ; 61.03\left(\mathrm{MeCH}_{2} \mathrm{O}\right) ; 48.40(\mathrm{C}(5)) ; 44.39(\mathrm{C}(7)) ; 34.97$ $(\mathrm{C}(1)) ; 27.65(\mathrm{C}(8)) ; 25.81(\mathrm{C}(3)) ; 23.17(\mathrm{C}(2)) ; 16.23(\mathrm{C}(4)) ; 13.97\left(\mathrm{MeCH}_{2} \mathrm{O}\right)$. CI-MS $\left(\mathrm{CH}_{4}\right): 223(7,[M+$ $\left.29]^{+}\right), 196\left(12,[M+2]^{+}\right), 195\left(100,[M+1]^{+}\right), 177(2), 167(5), 166(5), 149(47), 121(22), 95(4), 93(3), 79(5)$. Anal. calc. for $\mathrm{C}_{11} \mathrm{H}_{14} \mathrm{O}_{3}$ : C 68.02, H 7.27; found: $\mathrm{C} 67.96, \mathrm{H} 7.31$.

Data of anti-11: $[\alpha]_{\mathrm{D}}^{20}=+303.9\left(c=0.80, \mathrm{CHCl}_{3}\right)$. IR $\left(\mathrm{CHCl}_{3}\right): 1744,1724 .{ }^{1} \mathrm{H}-\mathrm{NMR}\left(500.13 \mathrm{MHz}, \mathrm{CDCl}_{3}\right)$ : $4.13\left(q, J=7.14, \mathrm{MeCH}_{2} \mathrm{O}\right) ; 2.70-2.73(m, \mathrm{H}-\mathrm{C}(1), \mathrm{H}-\mathrm{C}(5)) ; 2.09(d d, J=2.60,2.46, \mathrm{H}-\mathrm{C}(3)) ; 2.05-2.03$ $(m, 2 \mathrm{H}-\mathrm{C}(7)) ; 1.75(d m, J=7.20,1 \mathrm{H}) ; 1.57(d m, J=7.00,1 \mathrm{H}) ; 1.30(m, 1 \mathrm{H}-\mathrm{C}(8)) ; 1.26(t, J=7.14$, $\left.3 \mathrm{MeCH}_{2} \mathrm{O}\right) ; 1.21(d m, J=11.81,1 \mathrm{H}-\mathrm{C}(8)) \cdot{ }^{13} \mathrm{C}-\mathrm{NMR}\left(50.3 \mathrm{MHz}, \mathrm{CDCl}_{3}\right): 212.68(\mathrm{C}(6)) ; 171.95(\mathrm{CO}) ; 60.73$ $\left(\mathrm{MeCH}_{2} \mathrm{O}\right) ; 48.05(\mathrm{C}(5)) ; 43.28(\mathrm{C}(7)) ; 34.48(\mathrm{C}(1)) ; 26.94(\mathrm{C}(8)) ; 26.07(\mathrm{C}(2)) ; 19.95(\mathrm{C}(3)) ; 19.59(\mathrm{C}(4))$; $14.17\left(\mathrm{MeCH} \mathrm{CH}_{2} \mathrm{O}\right)$. CI-MS $\left(\mathrm{CH}_{4}\right): 223\left(10,[M+29]^{+}\right), 195\left(100,[M+1]^{+}\right), 194\left(19, M^{+}\right), 166(11), 165(2), 149$ (52), $121(13), 93$ (3), 79 (3). EI-MS: $195\left(2,[M+1]^{+}\right), 194\left(11, M^{+}\right), 166(14), 165(6), 149(10), 148(20), 121$ (26), 120 (48), 119 (23), 93 (33), 91 (68), 79 (100), 78 (40), 77 (72), 65 (18), 51 (20), 39 (42). Anal. calc. for $\mathrm{C}_{11} \mathrm{H}_{14} \mathrm{O}_{3}$ : C 68.02, H 7.27; found: C 67.63, H 7.27.

Ethyl 5-Oxobicyclo[2.2.1]heptane-2-acetate (rac-12a) and Ethyl 6-Oxobicyclo[2.2.1]heptane-2-acetate (rac12b). A soln. of racemic syn-11 (550 mg, $2.83 \mathrm{mmol})$ in $\mathrm{MeOH}(30 \mathrm{ml})$ was hydrogenated at r.t./1 atm over $10 \%$ $\mathrm{Pd} / \mathrm{C}(204 \mathrm{mg}$ ) for $40 \mathrm{~h}$. Then the catalyst was filtered off, the filtrate evaporated, and the residue subjected to CC (silica gel, AcOEt/petroleum ether 1:16): $250 \mathrm{mg}$ (45\%) of rac-12a and $233.3 \mathrm{mg}(42 \%)$ of $\mathrm{rac}-\mathbf{1 2 b}$ as colorless oils.

Data of rac-12a: ${ }^{1} \mathrm{H}-\mathrm{NMR}\left(500.13 \mathrm{MHz}, \mathrm{CDCl}_{3}\right): 4.18\left(q, J=7.16, \mathrm{MeCH}_{2} \mathrm{O}\right) ; 2.59(m, 1 \mathrm{H}) ; 2.46(m, 1 \mathrm{H})$; $2.44(d d, J=15.49,8.00,1 \mathrm{H}) ; 2.33(d d, J=15.49,7.58,1 \mathrm{H}) ; 2.19(d d d, J=15.92,7.96,4.92,1 \mathrm{H}) ; 2.11(d d, J=$ $17.85,4.63,1 \mathrm{H}) ; 1.98(d d d, J=17.85,3.56,0.97,1 \mathrm{H}) ; 1.84(d d d, J=13.30,8.32,1.41,1 \mathrm{H}) ; 1.70-1.68(m, 2 \mathrm{H})$; $1.40(d d d, J=13.30,4.80,4.80,1 \mathrm{H}) ; 1.27\left(t, J=7.16, M e \mathrm{CH}_{2} \mathrm{O}\right) .{ }^{13} \mathrm{C}-\mathrm{NMR}\left(50.3 \mathrm{MHz}, \mathrm{CDCl}_{3}\right): 217.07(\mathrm{C}(5))$; $172.22(\mathrm{CO}) ; 60.45\left(\mathrm{MeCH}_{2} \mathrm{O}\right) ; 50.25(\mathrm{C}(4))$; $45.37(\mathrm{C}(6)) ; 40.87\left(\mathrm{CH}_{2} \mathrm{COOEt}\right) ; 40.03(\mathrm{C}(2)) ; 36.57(\mathrm{C}(1))$; 34.57, $31.54(\mathrm{C}(3), \mathrm{C}(7))$; $14.22\left(\mathrm{MeCH}_{2} \mathrm{O}\right)$. CI-MS $\left(\mathrm{CH}_{4}\right): 237\left(4,[M+41]^{+}\right), 225\left(14,[M+29]^{+}\right), 198(14$, $\left.[M+2]^{+}\right), 197\left(100,[M+1]^{+}\right), 169(6), 168(4), 151(10), 123(4)$

Data of rac-12b: ${ }^{1} \mathrm{H}-\mathrm{NMR}\left(500.13 \mathrm{MHz}, \mathrm{CDCl}_{3}\right): 4.14\left(q, J=7.16, \mathrm{MeCH}_{2} \mathrm{O}\right) ; 2.70(m, \mathrm{H}-\mathrm{C}(2)) ; 2.44-$ $2.26(m, 4 \mathrm{H}) ; 2.06(d m, J=17.84,1 \mathrm{H}) ; 1.86(d d, J=17.84,3.96,1 \mathrm{H}) ; 1.82(d d d, J=12.57,7.48,2.15,1 \mathrm{H}) ; 1.72$ $(d m, J=11.12,1 \mathrm{H}, \mathrm{H}-\mathrm{C}(7)) ; 1.67(d m, J=11.12,1 \mathrm{H}-\mathrm{C}(7)) ; 1.40(d m, J=12.57,1 \mathrm{H}) ; 1.26(t, J=7.16$, $\left.\mathrm{MeCH}_{2} \mathrm{O}\right) .{ }^{13} \mathrm{C}-\mathrm{NMR}\left(50.3 \mathrm{MHz}, \mathrm{CDCl}_{3}\right): 216.52(\mathrm{C}(6)) ; 171.76(\mathrm{CO}) ; 60.53\left(\mathrm{MeCH}_{2} \mathrm{O}\right) ; 54.60(\mathrm{C}(1)) ; 44.22$ 
$(\mathrm{C}(5)) ; 39.82\left(\mathrm{CH}_{2} \mathrm{COOEt}\right) ; 35.78(\mathrm{C}(4))$; 35.63, $34.62(\mathrm{C}(3), \mathrm{C}(7)) ; 32.94(\mathrm{C}(2)) ; 14.20\left(\mathrm{MeCH}_{2} \mathrm{O}\right)$. CI-MS $\left(\mathrm{CH}_{4}\right): 237\left(4,[M+41]^{+}\right), 225\left(12,[M+29]^{+}\right), 198\left(11,[M+2]^{+}\right), 197\left(97,[M+1]^{+}\right), 179(4), 169(5), 168(18)$, $153(14), 152(13), 150(100), 123(4), 79$ (3).

Methyl (1R,5R,6R)-2-Oxa-3-oxobicyclo[3.2.1] octane-6-acetate (13a). A mixture of $\mathbf{4 3}$ (200 mg, $86.8 \mathrm{mmol}$ ) and $\mathrm{Pb}_{3} \mathrm{O}_{4}\left(3 \mathrm{mg}\right.$ ) was heated at $190-200^{\circ} / 200 \mathrm{mbar}$ for $1 \mathrm{~h}$. Then the mixture was bulb-to-bulb distilled at $0.1 \mathrm{mbar}$, and the thus obtained crude product $(155 \mathrm{mg}, 90 \%)$ was recrystallized from hexane/ $\mathrm{Et}_{2} \mathrm{O}: 110 \mathrm{mg}$ $(64 \%)$ of 13a. Colorless crystals. M.p. $78-79.5^{\circ}$. $[\alpha]_{\mathrm{D}}^{20}=+18.0\left(c=0.521, \mathrm{CHCl}_{3}\right) .{ }^{1} \mathrm{H}-\mathrm{NMR}\left(\mathrm{CDCl}_{3}\right): 4.85$ $(m, \mathrm{H}-\mathrm{C}(1)) ; 3.69(s, \mathrm{MeO}) ; 2.75(d d, J=18.50,5.02,1 \mathrm{H}-\mathrm{C}(4)) ; 2.61(d d d, J=18.62,2.06,2.06,1 \mathrm{H}-\mathrm{C}(4))$; $2.53-2.42\left(m, \mathrm{CH}_{2}\right) ; 2.40-2.25(m, 1 \mathrm{H}-\mathrm{C}(7), \mathrm{H}-\mathrm{C}(6), \mathrm{H}-\mathrm{C}(5)) ; 1.94(d m, J=13.13,1 \mathrm{H}-\mathrm{C}(8)) ; 1.79$ $(d m, J=13.14,1 \mathrm{H}-\mathrm{C}(8)) ; 1.55-1.47(m, 1 \mathrm{H}-\mathrm{C}(7)) \cdot{ }^{13} \mathrm{C}-\mathrm{NMR}$ (APT): 172.76, 170.21, (2 CO); $81.30(\mathrm{C}(1))$; $52.11(\mathrm{MeO}) ; 41.24,40.68,40.19(\mathrm{C}(4), \mathrm{C}(7), \mathrm{C}(8))$; $39.05(\mathrm{C}(5)) ; 37.37(\mathrm{C}(6))$; $33.66\left(\mathrm{CH}_{2}\right)$. EI-MS: 199 (37, $\left.[M+1]^{+}\right), 181(100), 167(16), 153(17), 139(28)$. HR-ESI-MS: $221.0783\left([M+\mathrm{Na}]^{+}, \mathrm{C}_{10} \mathrm{H}_{14} \mathrm{O}_{4} \mathrm{Na}^{+}\right.$; calc. 221.0784).

Benzyl (1R,5R,6R)-2-Oxa-3-oxobicyclo[3.2.1]octane-6-acetate (13b). A soln. of benzyl alcohol (11 mg, $0.10 \mathrm{mmol})$ in dry THF $(3 \mathrm{ml})$ was cooled to $0^{\circ}$ before $1.6 \mathrm{M} \mathrm{BuLi}$ in hexane $(65 \mu \mathrm{l})$ was added. After $10 \mathrm{~min}$ stirring, the mixture was added dropwise to a stirred soln. of $13 \mathbf{a}(20 \mathrm{mg}, 0.10 \mathrm{mmol})$ in dry THF $(5 \mathrm{ml})$ at $0^{\circ}$. Stirring was continued for $2 \mathrm{~h}$ at $0^{\circ}$ before the mixture was poured into $\mathrm{H}_{2} \mathrm{O}(50 \mathrm{ml})$ and extracted with $\mathrm{CH}_{2} \mathrm{Cl}_{2}$. The combined org. phase was dried $\left(\mathrm{Na}_{2} \mathrm{SO}_{4}\right)$ and evaporated and the residue purified by prep. TLC (AcOEt/ hexane 1:1): $7.5 \mathrm{mg}(27 \%)$ of 13b. Colorless oil. ${ }^{1} \mathrm{H}-\mathrm{NMR}\left(\mathrm{CDCl}_{3}\right)$ : $7.40-7.31(\mathrm{~m}, 5 \mathrm{arom} . \mathrm{H}) ; 5.14(A$ of $\left.A B, J=12.21,1 \mathrm{H}, \mathrm{PhCH}_{2}\right) ; 5.10\left(B\right.$ of $\left.A B, J=12.21,1 \mathrm{H}, \mathrm{PhCH}_{2}\right) ; 4.83(m, \mathrm{H}-\mathrm{C}(1)) ; 2.71(d d, J=18.62,4.89$, $1 \mathrm{H}-\mathrm{C}(4)) ; 2.56(d d d, J=18.61,2.14,2.14,1 \mathrm{H}-\mathrm{C}(4)) ; 2.52-2.43\left(m, \mathrm{CH}_{2}\right) ; 2.42-2.22(m, 1 \mathrm{H}-\mathrm{C}(7)$, $\mathrm{H}-\mathrm{C}(6), \quad \mathrm{H}-\mathrm{C}(5)) ; 1.91 \quad(d m, J=13.12,1 \mathrm{H}-\mathrm{C}(8)) ; 1.76 \quad(d m, J=13.13,1 \mathrm{H}-\mathrm{C}(8)) ; 1.55-1.45$ $(m, 1 \mathrm{H}-\mathrm{C}(7)) .{ }^{13} \mathrm{C}-\mathrm{NMR}$ (APT): 171.73, $169.86(2 \mathrm{CO}) ; 135.63$ (arom. C); 128.67, 128.57, 128.48, 128.37, 128.27 (5 arom. CH), $80.95(\mathrm{C}(1))$; $66.54\left(\mathrm{PhCH}_{2}\right) ; 40.89,40.64,39.86(\mathrm{C}(4), \mathrm{C}(7), \mathrm{C}(8)) ; 38.79(\mathrm{C}(5)) ; 37.02$ $(\mathrm{C}(6)) ; 33.33\left(\mathrm{CH}_{2}\right)$. HR-ESI-MS: $297.1093\left([M+\mathrm{Na}]^{+}, \mathrm{C}_{16} \mathrm{H}_{18} \mathrm{O}_{4} \mathrm{Na}^{+}\right.$; calc. 297.1097).

(1R,5R,6R)-2-Oxa-3-oxobicyclo[3.2.1] octane-6-acetic Acid (13c). A stirred soln. of 13b $(7.5 \mathrm{mg}$, $0.027 \mathrm{mmol})$ in AcOEt $(1 \mathrm{ml})$ was hydrogenated over $10 \% \mathrm{Pd} / \mathrm{C}(2 \mathrm{mg})$ at r.t./1 atm until the uptake of $\mathrm{H}_{2}$ ceased $(1 \mathrm{~h})$. The catalyst was filtered off, the filtrate evaporated, and the residue recrystallized from $\mathrm{Et}_{2} \mathrm{O} /$ hexane: $3 \mathrm{mg}(60 \%)$ of 13c. Colorless crystals. M.p. $123-125^{\circ} .{ }^{1} \mathrm{H}-\mathrm{NMR}\left(\mathrm{CDCl}_{3}\right): 10.3$ (br. $\left.s, \mathrm{COOH}\right) ; 4.86$ $(m, \mathrm{H}-\mathrm{C}(1)) ; 2.76(d d, J=18.58,4.89,1 \mathrm{H}-\mathrm{C}(4)) ; 2.62(d d d, J=18.58,1.96,1.96,1 \mathrm{H}-\mathrm{C}(4)) ; 2.56-2.45$ $\left(m, \mathrm{CH}_{2}\right) ; 2.43-2.28(m, 1 \mathrm{H}-\mathrm{C}(7), \mathrm{H}-\mathrm{C}(6), \mathrm{H}-\mathrm{C}(5)) ; 1.96(d m, J=13.20,1 \mathrm{H}-\mathrm{C}(8)) ; 1.80(d m, J=13.20$, $1 \mathrm{H}-\mathrm{C}(8)) ; 1.57-1.50(m, 1 \mathrm{H}-\mathrm{C}(7)) .{ }^{13} \mathrm{C}-\mathrm{NMR}$ (APT): $176.88(\mathrm{COOH}) ; 169.88(\mathrm{CO}) ; 80.91(\mathrm{C}(1)) ; 40.89$, 40.09, $39.88(\mathrm{C}(4), \mathrm{C}(7), \mathrm{C}(8))$; $38.47(\mathrm{C}(5))$; $37.06(\mathrm{C}(6))$; $33.32\left(\mathrm{CH}_{2}\right)$. HR-ESI-MS: $207.0622\left([\mathrm{M}+\mathrm{Na}]^{+}\right.$, $\mathrm{C}_{9} \mathrm{H}_{12} \mathrm{O}_{4} \mathrm{Na}^{+}$; calc. 207.0627).

(1R,5R,6R)-6-(2-Hydroxyethyl)-2-oxabicyclo[3.2.1]octan-3-one (14). a) A soln. of 13c (3 mg, $0.016 \mathrm{mmol}$ ) in dry THF $(2 \mathrm{ml})$ was cooled to $0^{\circ}$ before $1 \mathrm{M} \mathrm{BH}_{3}$ in THF $(70 \mu \mathrm{l})$ was added. The mixture was stirred for $7 \mathrm{~h}$ at $0^{\circ}$, then diluted with $\mathrm{H}_{2} \mathrm{O}(1 \mathrm{ml})$ and shaken with $\mathrm{CH}_{2} \mathrm{Cl}_{2}(10 \mathrm{ml})$. The org. layer was dried $\left(\mathrm{Na}_{2} \mathrm{SO}_{4}\right)$ and evaporated, and the residue purified by prep. TLC (AcOEt/hexane/EtOH $10: 10: 1$ ): $1.3 \mathrm{mg}$ (47\%) of 14). Colorless oil.

b) A mixture of 30, $(5.18 \mathrm{~g}, 33.6 \mathrm{mmol}), \mathrm{NaHCO}_{3}(5.65 \mathrm{~g}, 67.2 \mathrm{mmol})$, and $c a .55 \% \mathrm{MCPBA}(21.14 \mathrm{~g}$, $67.2 \mathrm{mmol})$ in $\mathrm{CH}_{2} \mathrm{Cl}_{2}(460 \mathrm{ml})$ was stirred at r.t. until the starting material had completely disappeared $(c a .2 \mathrm{~h}$, TLC monitoring). The mixture was then filtered, the solid washed with $\mathrm{CH}_{2} \mathrm{Cl}_{2}$, and the combined filtrate shaken several times with small volumes of cold $10 \%$ aq. $\mathrm{Na}_{2} \mathrm{SO}_{3}$ soln. until the starch/ $\mathrm{I}_{2}$ test of the org. layer was negative. Then the combined aq. phase was extracted with $\mathrm{CH}_{2} \mathrm{Cl}_{2}(6 \times 100 \mathrm{ml})$, the combined org. soln. dried $\left(\mathrm{Na}_{2} \mathrm{SO}_{4}\right)$ and evaporated, and the residue purified by CC ( $\left.\mathrm{AcOEt} / \mathrm{CH}_{2} \mathrm{Cl}_{2} / \mathrm{EtOH} 10: 10: 1\right): 4.92 \mathrm{~g}(86 \%)$ of $\mathbf{1 4}$. $R_{\mathrm{f}}$ 0.39. Colorless oil. $[\alpha]_{\mathrm{D}}^{20}=+31.9\left(c=1.88, \mathrm{CHCl}_{3}\right)$. IR $\left(\mathrm{CHCl}_{3}\right): 1726 .{ }^{1} \mathrm{H}-\mathrm{NMR}\left(\mathrm{CDCl}_{3}\right): 4.85(m, \mathrm{H}-\mathrm{C}(1))$; $3.72-3.62\left(m, \mathrm{CH}_{2} \mathrm{CH}_{2} \mathrm{OH}\right) ; 2.74(d d, J=18.48,5.03,1 \mathrm{H}-\mathrm{C}(4)) ; 2.55(d d d, J=18.57,2.09,2.09,1 \mathrm{H}-\mathrm{C}(4))$; $2.44(d d d, J=14.91,8.60,2.65,1 \mathrm{H}-\mathrm{C}(7)) ; 2.27(m, \mathrm{H}-\mathrm{C}(5)) ; 2.14(m, \mathrm{H}-\mathrm{C}(6)) ; 1.93(d m, J=13.08$, $1 \mathrm{H}-\mathrm{C}(8)) ; 1.80(d m, J=13.00,1 \mathrm{H}-\mathrm{C}(8)) ; 1.68\left(m, 1 \mathrm{H}, \mathrm{CH}_{2} \mathrm{CH}_{2} \mathrm{OH}\right) ; 1.58$ (br. $\left.s, 1 \mathrm{H}, \mathrm{CH}_{2} \mathrm{CH}_{2} \mathrm{OH}\right)$; $1.55-1.47\left(m, 2 \mathrm{H}, 1 \mathrm{H}-\mathrm{C}(7), \mathrm{CH}_{2} \mathrm{CH}_{2} \mathrm{OH}\right) .{ }^{13} \mathrm{C}-\mathrm{NMR}$ (APT): 170.25 (CO); 81.14 (C(1)); 61.18 $\left(\mathrm{CH}_{2} \mathrm{CH}_{2} \mathrm{OH}\right) ; 41.17(\mathrm{C}(4)) ; 40.27\left(\mathrm{CH}_{2} \mathrm{CH}_{2} \mathrm{OH}\right) ; 39.30(\mathrm{C}(7)) ; 39.04(\mathrm{C}(6)) ; 37.08(\mathrm{C}(5)) ; 33.48(\mathrm{C}(8))$. EIMS: $171\left(23,[M+1]^{+}\right), 153(63), 135$ (21), 125 (24), 111 (100), 107 (27), 93 (49), 81 (10), 79 (10), 67 (6), 61 (10). HR-ESI-MS: $193.0836\left([M+\mathrm{Na}]^{+}, \mathrm{C}_{9} \mathrm{H}_{14} \mathrm{O}_{3} \mathrm{Na}^{+} ;\right.$calc. 193.0835).

Methyl (1R,2S,4S)-4-Hydroxy-2-(2-hydroxyethyl)cyclopentaneacetate (15a). A soln. of $\mathbf{1 4}$ (5.8 g, $34 \mathrm{mmol})$ in $\mathrm{MeOH}(200 \mathrm{ml})$ containing $37 \%$ aq. $\mathrm{HCl}$ soln. $(1.9 \mathrm{ml}, 23 \mathrm{mmol})$ was refluxed for $20 \mathrm{~h}$ and then cooled, before $10 \%$ aq. $\mathrm{NaHCO}_{3}$ soln. $(40 \mathrm{ml})$ was added. The resulting mixture was extracted with AcOEt $(8 \times 100 \mathrm{ml})$, the 
combined org. extract dried $\left(\mathrm{Na}_{2} \mathrm{SO}_{4}\right)$ and evaporated, and the slightly yellow oil $(6.19 \mathrm{~g}, \mathrm{ca} .90 \%)$ was used without further purification for the next step. ${ }^{1} \mathrm{H}-\mathrm{NMR}\left(500.13 \mathrm{MHz}, \mathrm{CDCl}_{3}\right): 4.34(m, \mathrm{H}-\mathrm{C}(4)) ; 3.74-3.61$ $\left(m, \mathrm{HOCH}_{2} \mathrm{CH}_{2} \mathrm{OH}\right) ; 3.68(s, \mathrm{MeO}) ; 2.60\left(d d, J=15.66,4.86,1 \mathrm{H}, \mathrm{CH}_{2} \mathrm{CO}_{2} \mathrm{Me}\right) ; 2.36(d d, J=15.66,8.18,1 \mathrm{H}$, $\left.\mathrm{CH}_{2} \mathrm{CO}_{2} \mathrm{Me}\right) ; 2.29(d d d, J=14.02,8.51,6.01,1 \mathrm{H}) ; 1.99-1.93(m, 2 \mathrm{H}) ; 1.91(m, 1 \mathrm{H}) ; 1.79(m, 1 \mathrm{H}) ; 1.68$ (br., $2 \mathrm{OH}) ; 1.49-1.40(m, 2 \mathrm{H}) ; 1.37(d d d d, J=13.96,7.08,3.48,1.67,1 \mathrm{H}) .{ }^{13} \mathrm{C}-\mathrm{NMR}\left(50.3 \mathrm{MHz}, \mathrm{CDCl}_{3}\right): 173.88$ $(\mathrm{CO}) ; 72.50(\mathrm{C}(4)) ; 61.75\left(\mathrm{CH}_{2} \mathrm{CH}_{2} \mathrm{OH}\right) ; 51.51(\mathrm{MeO}) ; 42.34,41.62(\mathrm{C}(3), \mathrm{C}(5)) ; 40.55,39.61(\mathrm{C}(1), \mathrm{C}(2))$; $39.20\left(\mathrm{CH}_{2} \mathrm{CH}_{2} \mathrm{OH}\right) ; 37.46\left(\mathrm{CH}_{2} \mathrm{CO}_{2} \mathrm{Me}\right)$. CI-MS $\left(\mathrm{CH}_{4}\right): 231\left(13,[M+29]^{+}\right), 217\left(1,[M+15]^{+}\right), 203(17,[M+$ $\left.1]^{+}\right), 201\left(2,[M-1]^{+}\right), 185(47), 171(7), 168(13), 167(100), 153(87), 135(47), 125(16), 111(56), 107(34), 93$ (26).

Methyl (1R,2S,4S)-2-\{2-\{[(tert-Butyl)diphenylsilyl]oxy\}ethyl\}-4-hydroxycyclopentaneacetate (15b). A soln. of $15 \mathrm{a}(6.27 \mathrm{~g}, 31 \mathrm{mmol})$ in anh. DMF $(60 \mathrm{ml})$ containing $1 H$-imidazole $(5.28 \mathrm{~g}, 77.5 \mathrm{mmol})$, and (tertbutyl)chlorodiphenylsilane $(10.23 \mathrm{~g}, 37.2 \mathrm{mmol})$ was stirred for $40 \mathrm{~h}$ at r.t. and then poured into AcOEt (1.2 l). The resulting soln. was shaken successively with $1 \mathrm{M} \mathrm{HCl}(12 \mathrm{ml}), \mathrm{H}_{2} \mathrm{O}(120 \mathrm{ml})$ and sat. aq. $\mathrm{NaHCO}_{3}$ soln. $(120 \mathrm{ml})$, dried $\left(\mathrm{Na}_{2} \mathrm{SO}_{4}\right)$ and evaporated and the residue purified by $\mathrm{FC}\left(\mathrm{AcOEt} / \mathrm{CH}_{2} \mathrm{Cl}_{2} 1: 8\right): 11.1 \mathrm{~g}(74 \%$ from 15a) of 15b $\left(R_{\mathrm{f}} 0.44\right)$. Colorless syrup. $[\alpha]_{\mathrm{D}}^{23}=+27.1\left(c=0.78, \mathrm{CHCl}_{3}\right)$. IR $\left(\mathrm{CHCl}_{3}\right): 1728$. ${ }^{1} \mathrm{H}-\mathrm{NMR}$ $\left(360 \mathrm{MHz}, \mathrm{CDCl}_{3}\right): 7.68-7.63(m, 4$ arom. $\mathrm{H}) ; 7.46-7.35(m, 6$ arom. $\mathrm{H}) ; 4.27(m, \mathrm{H}-\mathrm{C}(4)) ; 3.74-3.59$ $\left(m, \mathrm{CH}_{2} \mathrm{CH}_{2} \mathrm{O}\right) ; 3.66(s, \mathrm{MeO}) ; 2.56\left(d d, J=15.75,4.36,1 \mathrm{H}, \mathrm{CH}_{2} \mathrm{CO}_{2} \mathrm{Me}\right) ; 2.34-2.21(m, 2 \mathrm{H}) ; 1.96-1.74$ $(m, 4 \mathrm{H}) ; 1.67$ (br., $\mathrm{OH}) ; 1.41-1.29(m, 3 \mathrm{H}) ; 1.04\left(s,{ }^{t} \mathrm{Bu}\right) .{ }^{13} \mathrm{C}-\mathrm{NMR}\left(50.3 \mathrm{MHz}, \mathrm{CDCl}_{3}\right): 173.68(\mathrm{CO}) ; 135.51$, 133.91, 129.52, 127.56 (12 arom. C); $72.38(\mathrm{C}(4)) ; 62.85\left(\mathrm{CH}_{2} \mathrm{CH}_{2} \mathrm{O}\right) ; 51.37(\mathrm{MeO}) ; 42.25,41.56(\mathrm{C}(3), \mathrm{C}(5))$; 40.63, $39.66(\mathrm{C}(1), \mathrm{C}(2)) ; 39.02\left(\mathrm{CH}_{2} \mathrm{CH}_{2} \mathrm{OH}\right) ; 37.23\left(\mathrm{CH}_{2} \mathrm{CO}_{2} \mathrm{Me}\right) ; 26.83\left(\mathrm{Me}_{3} \mathrm{C}\right) ; 19.11\left(\mathrm{Me}_{3} \mathrm{C}\right)$. FAB-MS: 463 $\left(6,[M+\mathrm{Na}]^{+}\right), 441\left(7,[M+1]^{+}\right), 423(2), 383(56), 363(22), 345(20), 319(4), 305(3), 273(8), 253(7), 239$ (11), 213 (73), 199 (100), 183 (52), 167 (60), 153 (36), 135 (100), 121 (50). Anal. calc. for $\mathrm{C}_{26} \mathrm{H}_{36} \mathrm{O}_{4} \mathrm{Si}: \mathrm{C} 70.87$, H 8.23; found: C 71.14, H 8.03 .

Ethyl (1'R,2'R,3'R,4'R,5'R)- and (1'R,2'R,3'S,4'R,5'R)-Spiro[1,3-dioxolane-2,6'-tricyclo[3.2.1.0 2,4 ]octane]$3^{\prime}$-carboxylate (syn- and anti-21). A soln. of $20\left(83.70 \mathrm{~g}, 0.55 \mathrm{~mol} ;[\alpha]_{\mathrm{D}}^{23}=+168.2\left(c=0.85, \mathrm{CHCl}_{3}\right)\right.$; prepared like the racemate [30][31]) in dry, freshly distilled $\mathrm{CH}_{2} \mathrm{Cl}_{2}(750 \mathrm{ml})$ was treated in the presence of [Pd(OAc) $)_{2}$ ] $(1.23 \mathrm{~g}, 5.54 \mathrm{mmol})$ with a soln. of $92 \%$ ethyldiazoacetate $81.90 \mathrm{~g}, 0.66 \mathrm{~mol}$ ) diluted to $750 \mathrm{ml}$ with $\mathrm{CH}_{2} \mathrm{Cl}_{2}$ under the same conditions as described for 11. After the addition was complete $(7 \mathrm{~h})$, the mixture was refluxed for additional $2 \mathrm{~h}$. The residue obtained after evaporation was separated by FC (silica gel, AcOEt/petroleum ether 1:8): $58.98 \mathrm{~g}(45 \%)$ of syn-21 $\left(R_{\mathrm{f}} 0.24\right)$ and $68.15 \mathrm{~g}(52 \%)$ of anti-21 $\left(R_{\mathrm{f}} 0.27\right)$

Data of syn-21: Colorless solid. M.p. 47.5-49.5 $.[\alpha]_{\mathrm{D}}^{23}=-6.2\left(c=0.78, \mathrm{CHCl}_{3}\right)$. IR $\left(\mathrm{CHCl}_{3}\right): 1723$. ${ }^{1} \mathrm{H}-\mathrm{NMR}\left(500.13 \mathrm{MHz}, \mathrm{CDCl}_{3}\right): 4.14\left(q, J=7.14, \mathrm{MeCH}_{2} \mathrm{O}\right) ; 3.97-3.86\left(m, 4 \mathrm{H}, \mathrm{OCH}_{2} \mathrm{CH}_{2} \mathrm{O}\right) ; 2.53$ $\left(m, \mathrm{H}-\mathrm{C}\left(1^{\prime}\right)\right) ; 2.43\left(m, \mathrm{H}-\mathrm{C}\left(5^{\prime}\right)\right) ; 1.83\left(d d, J=12.90,4.05,1 \mathrm{H}-\mathrm{C}\left(7^{\prime}\right)\right) ; 1.61\left(d d, J=12.90,3.84,1 \mathrm{H}-\mathrm{C}\left(7^{\prime}\right)\right)$; $1.57\left(d d, J=7.96,7.96, \mathrm{H}-\mathrm{C}\left(3^{\prime}\right)\right) ; 1.48\left(d d m, J=7.96,6.72, \mathrm{H}-\mathrm{C}\left(4^{\prime}\right)\right) ; 1.30\left(d d m, J=7.96,6.72, \mathrm{H}-\mathrm{C}\left(2^{\prime}\right)\right) ; 1.27$ $\left(t, J=7.14, \mathrm{MeCH}_{2} \mathrm{O}\right) ; 1.20\left(d m, J=12.35,1 \mathrm{H}-\mathrm{C}\left(8^{\prime}\right)\right) ; 0.81\left(d m, J=12.35,1 \mathrm{H}-\mathrm{C}\left(8^{\prime}\right)\right) . \mathrm{NOE}: 2.53(8.03,1.83)$, $1.61(16.15,1.83), 1.48(2.08,1.57), 1.30$ (5.04, 1.57), 2.43 (3.63, 1.48), 1.57 (4.34, 1.48), $1.30(4.35,1.48), 1.57$ $(5.50,1.30), 1.48(4.48,1.30), 2.53(0.65,1.20), 2.43(0.97,1.20), 0.81(12.41,1.20), 2.53(2.57,0.81), 2.43(3.93$, 0.81), 1.20 (25.47, 0.81). ${ }^{13} \mathrm{C}-\mathrm{NMR}\left(50.3 \mathrm{MHz} \mathrm{CDCl}_{3}\right): 172.17(\mathrm{CO}) ; 117.17\left(\mathrm{C}\left(6^{\prime}\right)\right) ; 64.59,64.01\left(\mathrm{OCH}_{2} \mathrm{CH}_{2} \mathrm{O}\right)$; $60.69\left(\mathrm{CH}_{2} \mathrm{O}\right) ; 43.51\left(\mathrm{C}\left(7^{\prime}\right)\right) ; 43.04\left(\mathrm{C}\left(5^{\prime}\right)\right) ; 35.47\left(\mathrm{C}\left(1^{\prime}\right)\right) ; 28.16\left(\mathrm{C}\left(8^{\prime}\right)\right) ; 23.82\left(\mathrm{C}\left(3^{\prime}\right)\right) ; 22.19\left(\mathrm{C}\left(2^{\prime}\right)\right) ; 16.65$ $\left(\mathrm{C}\left(4^{\prime}\right)\right) ; 14.03(\mathrm{Me})$. CI-MS $\left(\mathrm{CH}_{4}\right): 267\left(7,[M+29]^{+}\right), 239\left(52,[M+1]^{+}\right), 238\left(6, M^{+}\right), 193(100), 177(7), 165$ (6), 149 (10), 131 (1), 121 (4), 105 (3), 73 (7). Anal. calc. for $\mathrm{C}_{13} \mathrm{H}_{18} \mathrm{O}_{4}$ : C 65.53, H 7.61; found: C 65.70, 7.66.

Data of anti-21: Colorless oil. $[\alpha]_{\mathrm{D}}^{22}=+54.6\left(c=0.80, \mathrm{CHCl}_{3}\right)$. IR $\left(\mathrm{CHCl}_{3}\right): 1719 .{ }^{1} \mathrm{H}-\mathrm{NMR}(500.13 \mathrm{MHz}$, $\left.\mathrm{CDCl}_{3}\right): 4.10\left(q, J=7.12, \mathrm{MeCH}_{2} \mathrm{O}\right) ; 3.98-3.83\left(m, \mathrm{OCH}_{2} \mathrm{CH}_{2} \mathrm{O}\right) ; 2.39\left(m, \mathrm{H}-\mathrm{C}\left(1^{\prime}\right)\right) ; 2.29\left(m, \mathrm{H}-\mathrm{C}\left(5^{\prime}\right)\right) ; 1.78$ $\left(d d, J=12.79,4.00, \mathrm{H}-\mathrm{C}\left(7^{\prime}\right)\right) ; 1.77\left(d d, J=2.58,2.58, \mathrm{H}-\mathrm{C}\left(3^{\prime}\right)\right) ; 1.70\left(d m, J=7.26, \mathrm{H}-\mathrm{C}\left(4^{\prime}\right)\right) ; 1.65(d d, J=$ $\left.12.79,3.71,1 \mathrm{H}-\mathrm{C}\left(7^{\prime}\right)\right) ; 1.54\left(d m, J=7.26, \mathrm{H}-\mathrm{C}\left(2^{\prime}\right)\right) ; 1.24\left(t, J=7.12, \mathrm{MeCH}_{2} \mathrm{O}\right) ; 1.15 \quad(d m, J=11.33$, $\left.1 \mathrm{H}-\mathrm{C}\left(8^{\prime}\right)\right) ; 0.98\left(d m, J=11.33,1 \mathrm{H}-\mathrm{C}\left(8^{\prime}\right)\right) . \mathrm{NOE}: 1.78(5.13,2.39), 1.54(3.54,2.39), 1.70(4.41,2.29), 2.39$ (4.47, 1.78), 1.65 (18.89, 1.78), 2.29 (3.04, 1.70), 1.54 (3.44, 1.70), 2.39 (2.36, 1.65), 2.39 (3.18, 1.54), 2.39 (3.24, 1.15), 2.29 (3.21, 1.15$), 0.97(28.24,1.15), 2.39(2.64,0.98), 1.77(23.51,0.98), 1.15(25.71,0.98) .{ }^{13} \mathrm{C}-\mathrm{NMR}$ $\left(50.3 \mathrm{MHz}, \mathrm{CDCl}_{3}\right): 173.12(\mathrm{CO}) ; 116.89(\mathrm{C}(6)) ; 64.63,64.00\left(\mathrm{OCH}_{2} \mathrm{CH}_{2} \mathrm{O}\right) ; 60.30\left(\mathrm{CH}_{2} \mathrm{O}\right) ; 43.00\left(\mathrm{C}\left(5^{\prime}\right)\right) ; 42.79$ $\left(\mathrm{C}\left(7^{\prime}\right)\right) ; 35.14\left(\mathrm{C}\left(1^{\prime}\right)\right) ; 27.42\left(\mathrm{C}\left(8^{\prime}\right)\right) ; 25.75\left(\mathrm{C}\left(2^{\prime}\right)\right) ; 20.69\left(\mathrm{C}\left(4^{\prime}\right)\right) ; 18.80\left(\mathrm{C}\left(3^{\prime}\right)\right) ; 14.29(\mathrm{Me})$. CI-MS $\left(\mathrm{CH}_{4}\right): 267(8$, $\left.[M+29]^{+}\right), 239\left(69,[M+1]^{+}\right), 238\left(14, M^{+}\right), 193(100), 165(6), 149(6), 112(5), 99(7), 87(27), 73(18)$. Anal. calc. for $\mathrm{C}_{13} \mathrm{H}_{18} \mathrm{O}_{4}$ : C 65.53, $\mathrm{H} 7.61$; found: C 65.68, H 7.76.

(1'R,2'R,3'R,4'S,5'R)-Spiro[1,3-dioxolane-2,6'-tricyclo[3.2.1.0 , $\left.^{2,4}\right]$ octane]-3'-methanol (syn-25a). A soln. of

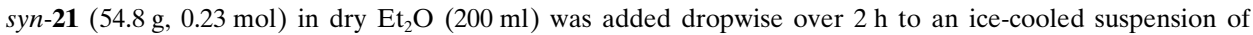
$\mathrm{LiAlH}_{4}(8.73 \mathrm{~g}, 0.23 \mathrm{~mol})$ in dry Et $2 \mathrm{O}(600 \mathrm{ml})$, and the mixture was stirred at r.t. for $24 \mathrm{~h}$. Thereafter, the excess $\mathrm{LiAlH}_{4}$ was decomposed by very slow addition of $\mathrm{H}_{2} \mathrm{O}$ before the soln. was filtered. The aq. layer was extracted 
with AcOEt $(4 \times 100 \mathrm{ml})$, the combined org. extract washed with brine $(2 \times 100 \mathrm{ml})$, dried $\left(\mathrm{Na}_{2} \mathrm{SO}_{4}\right)$; and evaporated, and the residue purified by $\mathrm{CC}\left(\mathrm{AcOEt} / \mathrm{CH}_{2} \mathrm{Cl}_{2} 1: 1\right): 41.98 \mathrm{~g}(93 \%)$ of syn-25a $\left(R_{\mathrm{f}} 0.39\right)$. Colorless oil. $[\alpha]_{\mathrm{D}}^{24}=+16.5\left(c=0.71, \mathrm{CHCl}_{3}\right) .{ }^{1} \mathrm{H}-\mathrm{NMR}\left(360 \mathrm{MHz}, \mathrm{CDCl}_{3}\right): 3.97-3.85\left(m, \mathrm{OCH}_{2} \mathrm{CH}_{2} \mathrm{O}, \mathrm{CH}_{2} \mathrm{OH}\right) ; 2.43$ $\left(m, \mathrm{H}-\mathrm{C}\left(1^{\prime}\right)\right) ; 2.35\left(m, \mathrm{H}-\mathrm{C}\left(5^{\prime}\right)\right) ; 1.82\left(d d, J=12.55,4.00,1 \mathrm{H}-\mathrm{C}\left(7^{\prime}\right)\right) ; 1.61\left(d d, J=12.55,3.71,1 \mathrm{H}-\mathrm{C}\left(7^{\prime}\right)\right)$; 1.43 (br. $s, \mathrm{OH}) ; 1.25\left(d d m, J=7.70,7.42, \mathrm{H}-\mathrm{C}\left(3^{\prime}\right)\right) ; 1.20\left(d m, J=11.69,1 \mathrm{H}-\mathrm{C}\left(8^{\prime}\right)\right) ; 1.11-1.04\left(m, \mathrm{H}-\mathrm{C}\left(2^{\prime}\right)\right.$, $\left.\mathrm{H}-\mathrm{C}\left(4^{\prime}\right)\right) ; 0.98\left(d m, J=11.69,1 \mathrm{H}-\mathrm{C}\left(8^{\prime}\right)\right) .{ }^{13} \mathrm{C}-\mathrm{NMR}\left(50.3 \mathrm{MHz}, \mathrm{CDCl}_{3}\right): 117.50\left(\mathrm{C}\left(6^{\prime}\right)\right) ; 64.42,63.78$ $\left(\mathrm{OCH}_{2} \mathrm{CH}_{2} \mathrm{O}\right) ; 60.63\left(\mathrm{CH}_{2} \mathrm{OH}\right) ; 43.83\left(\mathrm{C}\left(7^{\prime}\right)\right) ; 43.13\left(\mathrm{C}\left(5^{\prime}\right)\right) ; 35.44\left(\mathrm{C}\left(1^{\prime}\right)\right) ; 29.22\left(\mathrm{C}\left(8^{\prime}\right)\right) ; 25.01\left(\mathrm{C}\left(3^{\prime}\right)\right) ; 22.20$ $\left(\mathrm{C}\left(2^{\prime}\right)\right) ; 16.08\left(\mathrm{C}\left(4^{\prime}\right)\right)$. CI-MS $\left(\mathrm{CH}_{4}\right): 198\left(5,[M+2]^{+}\right), 197\left(40,[M+1]^{+}\right), 196\left(1, M^{+}\right), 195\left(5,[M-1]^{+}\right), 180$ (11), 179 (100), 153 (4), 135 (2), 118 (1), 117 (12), 99 (2), 87 (20), 86 (12), 73 (7). Anal. calc. for $\mathrm{C}_{11} \mathrm{H}_{16} \mathrm{O}_{3}$ : C 67.32, H 8.22; found: C 67.09, H 8.14

$\left(1^{\prime} \mathrm{R}, 2^{\prime} \mathrm{R}, 3^{\prime} \mathrm{S}, 4^{\prime} \mathrm{R}, 5^{\prime} \mathrm{R}\right)$-Spiro[1,3-dioxolane-2,6'-tricyclo[3.2.1.0 $\left.0^{2,4}\right]$ octane]-3'-methanol (anti-25a). As described for syn-25a, with anti-21 $(59.6 \mathrm{~g}, 0.25 \mathrm{~mol})$ : anti-25a $(46.12 \mathrm{~g}, 94 \%)$. Colorless oil. $R_{\mathrm{f}} 0.33$ : $[\alpha]_{\mathrm{D}}^{24}=$ $+31.1\left(c=0.37, \mathrm{CHCl}_{3}\right) .{ }^{1} \mathrm{H}-\mathrm{NMR}\left(500.13 \mathrm{MHz}, \mathrm{CDCl}_{3}\right): 3.97-3.85\left(m, \mathrm{OCH}_{2} \mathrm{CH}_{2} \mathrm{O}\right) ; 3.43(d d, J=11.00$, $\left.7.05,1 \mathrm{H}, \mathrm{CH}_{2} \mathrm{OH}\right) ; 3.39\left(d d, J=11.00,7.15,1 \mathrm{H}, \mathrm{CH}_{2} \mathrm{OH}\right) ; 2.33\left(m, \mathrm{H}-\mathrm{C}\left(1^{\prime}\right)\right) ; 2.24\left(m, \mathrm{H}-\mathrm{C}\left(5^{\prime}\right)\right) ; 1.77$ $\left(d d, J=12.80,4.05,1 \mathrm{H}-\mathrm{C}\left(7^{\prime}\right)\right) ; 1.58\left(d d, J=12.80,3.65,1 \mathrm{H}-\mathrm{C}\left(7^{\prime}\right)\right) ; 1.45$ (br. $\left.s, \mathrm{OH}\right) ; 1.33\left(m, \mathrm{H}-\mathrm{C}\left(3^{\prime}\right)\right) ; 1.11$ $\left(d m, J=11.10,1 \mathrm{H}-\mathrm{C}\left(8^{\prime}\right)\right) ; 1.03\left(d m, J=11.10,1 \mathrm{H}-\mathrm{C}\left(8^{\prime}\right)\right) ; 0.99\left(d m, J=7.15, \mathrm{H}-\mathrm{C}\left(4^{\prime}\right)\right) ; 0.83(d m, J=7.15$, $\left.\mathrm{H}-\mathrm{C}\left(2^{\prime}\right)\right) \cdot{ }^{13} \mathrm{C}-\mathrm{NMR}\left(50.3 \mathrm{MHz}, \mathrm{CDCl}_{3}\right): 117.08\left(\mathrm{C}\left(6^{\prime}\right)\right) ; 64.78,64.30\left(\mathrm{OCH}_{2} \mathrm{CH}_{2} \mathrm{O}\right) ; 63.72\left(\mathrm{CH}_{2} \mathrm{OH}\right) ; 43.26$ $\left(\mathrm{C}\left(7^{\prime}\right)\right) ; 42.73\left(\mathrm{C}\left(5^{\prime}\right)\right) ; 34.86\left(\mathrm{C}\left(1^{\prime}\right)\right) ; 27.28\left(\mathrm{C}\left(8^{\prime}\right)\right) ; 20.99\left(\mathrm{C}\left(3^{\prime}\right)\right) ; 19.02\left(\mathrm{C}\left(2^{\prime}\right)\right) ; 15.20\left(\mathrm{C}\left(4^{\prime}\right)\right)$. CI-MS $\left(\mathrm{CH}_{4}\right): 198$ $\left(4,[M+2]^{+}\right), 197\left(35,[M+1]^{+}\right), 196\left(1, M^{+}\right), 195\left(7,[M-1]^{+}\right), 180(11), 179(100), 153(4), 135(4), 117(14)$, 99 (2), 87 (14). Anal. calc. for $\mathrm{C}_{11} \mathrm{H}_{16} \mathrm{O}_{3}$ : C 67.32, H 8.22; found: C 67.06, H 8.49.

S-Methyl O-[(1'R, $\left.2^{\prime} \mathrm{R}, 3^{\prime} \mathrm{R}, 4^{\prime} \mathrm{R}, 5^{\prime} \mathrm{R}\right)$-Spiro[1,3-dioxolane-2,6'-tricyclo[3.2.1.0 $\left.0^{2,4}\right]$ octane]-3'-yl] Carbonodithioate (syn-25b). To a soln. of syn-25a $(42.00 \mathrm{~g}, 0.214 \mathrm{~mol})$ and DBN $(53.16 \mathrm{~g}, 0.43 \mathrm{~mol})$ in dry $\mathrm{MeCN}$ $(150 \mathrm{ml}), \mathrm{CS}_{2}(40 \mathrm{ml})$ was added, and the mixture was stirred for $2 \mathrm{~h}$ at r.t. Thereafter, MeI $(78 \mathrm{ml})$ was added, and stirring was continued for a further $3 \mathrm{~h}$ at r.t. before the excess reactants and most of the solvent were evaporated to yield an oily residue, which was poured into $\mathrm{H}_{2} \mathrm{O}(200 \mathrm{ml})$ and extracted with AcOEt $(4 \times$ $150 \mathrm{ml})$. The combined org. extract was washed with brine $(100 \mathrm{ml})$, dried $\left(\mathrm{Na}_{2} \mathrm{SO}_{4}\right)$, and evaporated and the residue purified by CC (AcOEt/petroleum ether 1:8): $58.84 \mathrm{~g}(96 \%)$ of $s y n-\mathbf{2 5 b}\left(R_{\mathrm{f}} 0.5\right)$. Yellow oil. $[\alpha]_{\mathrm{D}}^{25}=$ $+1.4\left(c=0.84, \mathrm{CHCl}_{3}\right)$. IR $\left(\mathrm{CHCl}_{3}\right): 1198 s, 1080 \mathrm{vs}, 1065 \mathrm{~s} .{ }^{1} \mathrm{H}-\mathrm{NMR}\left(200 \mathrm{MHz}, \mathrm{CDCl}_{3}\right): 4.84(d, J=5.86$, $\left.\mathrm{CH}_{2} \mathrm{O}\right) ; 3.98-3.85\left(m, \mathrm{OCH}_{2} \mathrm{CH}_{2} \mathrm{O}\right) ; 2.57(s, \mathrm{MeS}) ; 2.48\left(m, \mathrm{H}-\mathrm{C}\left(1^{\prime}\right)\right) ; 2.36\left(m, \mathrm{H}-\mathrm{C}\left(5^{\prime}\right)\right) ; 1.83(d d, J=12.47$, $\left.3.99,1 \mathrm{H}-\mathrm{C}\left(7^{\prime}\right)\right) ; 1.60\left(d d, J=12.47,3.71,1 \mathrm{H}-\mathrm{C}\left(7^{\prime}\right)\right) ; 1.40-1.08\left(m, \mathrm{H}-\mathrm{C}\left(2^{\prime}\right), \mathrm{H}-\mathrm{C}\left(3^{\prime}\right), \mathrm{H}-\mathrm{C}\left(4^{\prime}\right)\right.$, $\left.1 \mathrm{H}-\mathrm{C}\left(8^{\prime}\right)\right) ; 0.88\left(d m, J=11.91,1 \mathrm{H}-\mathrm{C}\left(8^{\prime}\right)\right) .{ }^{13} \mathrm{C}-\mathrm{NMR}\left(50.3 \mathrm{MHz}, \mathrm{CDCl}_{3}\right): 215.24(\mathrm{CS}) ; 117.11\left(\mathrm{C}\left(6^{\prime}\right)\right)$; $72.45\left(\mathrm{CH}_{2} \mathrm{O}\right)$; 64.33, $63.72\left(\mathrm{OCH}_{2} \mathrm{CH}_{2} \mathrm{O}\right) ; 43.59\left(\mathrm{C}\left(7^{\prime}\right)\right) ; 42.89\left(\mathrm{C}\left(5^{\prime}\right)\right) ; 35.18\left(\mathrm{C}\left(1^{\prime}\right)\right) ; 29.10\left(\mathrm{C}\left(8^{\prime}\right)\right) ; 22.44$ $(\mathrm{MeS}) ; 20.14\left(\mathrm{C}\left(2^{\prime}\right)\right) ; 18.74\left(\mathrm{C}\left(3^{\prime}\right)\right) ; 16.58\left(\mathrm{C}\left(4^{\prime}\right)\right)$. CI-MS $\left(\mathrm{CH}_{4}\right): 288\left(2,[M+2]^{+}\right), 287\left(15,[M+1]^{+}\right), 285(2$, $\left.[M-1]^{+}\right), 243(4), 239(4), 211(2), 181(3), 180(21), 179(100), 167$ (1), 135 (5), 119 (6), 118 (4), 118 (34), 99 (7), 93 (8), 91 (7), 87 (12), 73 (8), 41 (8). Anal. calc. for $\mathrm{C}_{13} \mathrm{H}_{18} \mathrm{O}_{3} \mathrm{~S}_{2}$ : C 54.52, H 6.33, S 22.39; found: C 54.72, H 6.48, S 22.51 .

S-Methyl O-[ ( $\left.1^{\prime} \mathrm{R}, 2^{\prime} \mathrm{R}, 3^{\prime} \mathrm{S}, 4^{\prime} \mathrm{R}, 5^{\prime} \mathrm{R}\right)$-Spiro[1,3-dioxolane-2,6'-tricyclo[3.2.1.0 $\left.0^{2,4}\right]$ octane]-3'-yl] Carbonodithioate (anti-25b): As described for syn-25b, with anti-25a (46.12 g, $0.235 \mathrm{~mol})$ : anti-25b $(64.61 \mathrm{~g}, 96 \%)$. Slightly yellow oil. $R_{\mathrm{f}} 0.5 .[\alpha]_{\mathrm{D}}^{25}=+26.6\left(c=0.73, \mathrm{CHCl}_{3}\right)$. IR $\left(\mathrm{CHCl}_{3}\right): 1196 m, 1098 m, 1063 s .{ }^{1} \mathrm{H}-\mathrm{NMR}(200 \mathrm{MHz}$, $\left.\mathrm{CDCl}_{3}\right): 4.43\left(d d, J=11.29,7.42,1 \mathrm{H}, \mathrm{CH}_{2} \mathrm{O}\right) ; 4.36\left(d d, J=11.29,7.42,1 \mathrm{H}, \mathrm{CH}_{2} \mathrm{O}\right) ; 3.99-3.81\left(m, \mathrm{OCH}_{2}\right.$ $\left.\mathrm{CH}_{2} \mathrm{O}\right) ; 2.57(s, \mathrm{MeS}) ; 2.37\left(m, \mathrm{H}-\mathrm{C}\left(1^{\prime}\right)\right) ; 2.27\left(m, \mathrm{H}-\mathrm{C}\left(5^{\prime}\right)\right) ; 1.78\left(d d, J=12.77,4.00,1 \mathrm{H}-\mathrm{C}\left(7^{\prime}\right)\right) ; 1.60$ $\left(d d, J=12.77,3.22,1 \mathrm{H}-\mathrm{C}\left(7^{\prime}\right)\right) ; 1.57-1.45(m, 1 \mathrm{H}) ; 1.19-0.94(m, 4 \mathrm{H}) .{ }^{13} \mathrm{C}-\mathrm{NMR}\left(50.3 \mathrm{MHz}, \mathrm{CDCl}_{3}\right): 216.09$ (CS); $117.09\left(\mathrm{C}\left(6^{\prime}\right)\right) ; 76.36\left(\mathrm{CH}_{2} \mathrm{O}\right) ; 64.56,63.99\left(\mathrm{OCH}_{2} \mathrm{CH}_{2} \mathrm{O}\right) ; 43.31\left(\mathrm{C}\left(7^{\prime}\right)\right) ; 42.90\left(\mathrm{C}\left(5^{\prime}\right)\right) ; 35.01\left(\mathrm{C}\left(1^{\prime}\right)\right) ; 27.34$ $\left(\mathrm{C}\left(8^{\prime}\right)\right) ; 21.68\left(\mathrm{C}\left(2^{\prime}\right)\right) ; 19.06(\mathrm{MeS}) ; 16.13\left(\mathrm{C}\left(3^{\prime}\right)\right) ; 14.92\left(\mathrm{C}\left(4^{\prime}\right)\right)$. CI-MS $\left(\mathrm{CH}_{4}\right): 288\left(2,[M+2]^{+}\right), 287(11,[M+$ $\left.1]^{+}\right), 286\left(2, M^{+}\right), 285\left(2,[M-1]^{+}\right), 271(1), 239(2), 211(1), 180(18), 179$ (100), 135 (1), $119(2), 117(11), 99$ (3), 91 (1), 87 (3). Anal. calc. for $\mathrm{C}_{13} \mathrm{H}_{18} \mathrm{O}_{3} \mathrm{~S}_{2}$ : C 54.52, H 6.33, S 22.39; found: C 54.74, H 6.23, S 22.38.

(1RS,2RS,3RS,4RS,5RS)-3-(Hydroxymethyl)tricyclo[3.2.1.0 $0^{2,4}$ ]octan-6-one (rac-syn-26a). A soln. of racsyn-25a $(2.94 \mathrm{~g}, 15 \mathrm{mmol})$ in $\mathrm{AcOH} / \mathrm{H}_{2} \mathrm{O} 3: 7(20 \mathrm{ml})$ was stirred for $1 \mathrm{~d}$ at r.t. The mixture was then carefully neutralized adding dropwise $10 \%$ aq. $\mathrm{NaOH}$ soln., and the aq. phase was extracted with AcOEt $(4 \times 100 \mathrm{ml})$. The combined extracts were washed with brine $(2 \times 50 \mathrm{ml})$, dried $\left(\mathrm{Na}_{2} \mathrm{SO}_{4}\right)$, and evaporated and the residue purified by $\mathrm{FC}\left(\mathrm{AcOEt} / \mathrm{CH}_{2} \mathrm{Cl}_{2} 1: 1\right)$ : rac-syn-26a $(2.15 \mathrm{~g}, 94 \%)$. Colorless oil. IR $\left(\mathrm{CHCl}_{3}\right): 1740 .{ }^{1} \mathrm{H}-\mathrm{NMR}$ (200 MHz, $\left.\mathrm{CDCl}_{3}\right): 3.98-3.92\left(m, \mathrm{CH}_{2} \mathrm{OH}\right) ; 2.81-2.73(m, 2 \mathrm{H}-\mathrm{C}(1), \mathrm{H}-\mathrm{C}(5)) ; 2.14-1.91(m, 2 \mathrm{H}-\mathrm{C}(7))$; 1.80 (br. $s, \mathrm{OH}) ; 1.37-1.22(m, 2 \mathrm{H}-\mathrm{C}(8), \mathrm{H}-\mathrm{C}(3), \mathrm{H}-\mathrm{C}(4)) ; 1.12(d m, J=7.08, \mathrm{H}-\mathrm{C}(2)) .{ }^{13} \mathrm{C}-\mathrm{NMR}$ $\left(50.3 \mathrm{MHz}, \mathrm{CDCl}_{3}\right): 213.93(\mathrm{C}(6)) ; 59.33\left(\mathrm{CH}_{2} \mathrm{OH}\right) ; 48.03(\mathrm{C}(5)) ; 44.25(\mathrm{C}(7)) ; 34.36(\mathrm{C}(1)) ; 28.30(\mathrm{C}(8)) ; 27.28$ $(\mathrm{C}(3)) ; 23.24(\mathrm{C}(2)) ; 15.10(\mathrm{C}(4))$. CI-MS $\left(\mathrm{CH}_{4}\right): 193\left(4,[M+41]^{+}\right), 181\left(9,[M+29]^{+}\right), 154\left(9,[M+2]^{+}\right), 153$ $\left(100,[M+1]^{+}\right), 135(31), 117(14), 109(25), 107(47), 95(10), 93(39), 79(21), 61(14), 55(7), 43(7), 41(35)$. 
(1RS,2RS,3SR,4RS,5RS)-3-(Hydroxymethyl)tricyclo[3.2.1.0 2,4 $]$ octan-6-one (rac-anti-26a). As described for rac-syn-26a, with rac-anti-25a $(2.36 \mathrm{~g}, 12 \mathrm{mmol})$; rac-anti-26a $(1.74 \mathrm{~g}, 95 \%)$. Colorless oil. IR $\left(\mathrm{CHCl}_{3}\right)$ : 1742. ${ }^{1} \mathrm{H}-\mathrm{NMR}\left(500.13 \mathrm{MHz}, \mathrm{CDCl}_{3}\right): 3.48\left(d d, J=11.28,6.92,1 \mathrm{H}, \mathrm{CH}_{2} \mathrm{OH}\right) ; 3.45(d d, J=11.28,6.92,1 \mathrm{H}$, $\left.\mathrm{CH}_{2} \mathrm{OH}\right) ; 2.66(m, \mathrm{H}-\mathrm{C}(1)) ; 2.64(m, \mathrm{H}-\mathrm{C}(5)) ; 2.03(d d, J=16.78,3.54,1 \mathrm{H}-\mathrm{C}(7)) ; 1.97(d d, J=16.78,4.23$, $1 \mathrm{H}-\mathrm{C}(7)) ; 1.85\left(m, \mathrm{CH}_{2} \mathrm{OH}\right) ; 1.66(m, \mathrm{H}-\mathrm{C}(3)) ; 1.34(d m, J=11.60, \mathrm{H}-\mathrm{C}(8)) ; 1.17 \quad(d m, J=11.60$, $1 \mathrm{H}-\mathrm{C}(8)) ; 1.10(d m, J=6.95, \mathrm{H}-\mathrm{C}(4)) ; 0.89(d m, J=6.95, \mathrm{H}-\mathrm{C}(2)) .{ }^{13} \mathrm{C}-\mathrm{NMR}\left(50.3 \mathrm{MHz}, \mathrm{CDCl}_{3}\right): 214.24$ $(\mathrm{C}(6)) ; 64.14\left(\mathrm{CH}_{2} \mathrm{OH}\right) ; 48.07(\mathrm{C}(5)) ; 44.32(\mathrm{C}(7)) ; 34.43(\mathrm{C}(1)) ; 26.80(\mathrm{C}(8)) ; 22.15(\mathrm{C}(3)) ; 20.77(\mathrm{C}(2)) ; 14.87$ $(\mathrm{C}(4))$. CI-MS $\left(\mathrm{CH}_{4}\right): 193\left(3,[M+41]^{+}\right), 181\left(6,[M+29]^{+}\right), 154\left(10,[M+2]^{+}\right), 153\left(100,[M+1]^{+}\right), 152(9$, $\left.M^{+}\right), 135$ (66), $117(17), 107(56), 79(15), 55(2)$.

S-Methyl O-[(1RS,2RS,3RS,4RS,5RS)-6-Oxotricyclo[3.2.1.0.4 $0^{2,4}$ oct-3-yl] Carbonodithioate (rac-syn-26b). To a soln. of rac-syn-26a (883 mg, $5.80 \mathrm{mmol})$ and DBN $(1.44 \mathrm{~g}, 11.6 \mathrm{mmol})$ in dry MeCN $(20 \mathrm{ml}), \mathrm{CS}_{2}(3 \mathrm{ml})$ was added, and the mixture was stirred for $1 \mathrm{~h}$ at r.t. After addition of MeI $(7 \mathrm{ml})$, stirring was continued for a further $90 \mathrm{~min}$ at r.t. The solvent was evaporated, the residue diluted with $\mathrm{H}_{2} \mathrm{O}(25 \mathrm{ml})$ and extracted with AcOEt $(4 \times 25 \mathrm{ml})$, the combined org. extract washed with brine $(25 \mathrm{ml})$, dried $\left(\mathrm{Na}_{2} \mathrm{SO}_{4}\right)$, and evaporated, and the residue purified by CC (AcOEt/petroleum ether $1: 8)$ : rac-syn-26b $(1.27 \mathrm{mg}, 90 \%)$. Yellow oil. ${ }^{1} \mathrm{H}-\mathrm{NMR}$ $\left(200 \mathrm{MHz}, \mathrm{CDCl}_{3}\right): 4.93\left(d d, J=11.57,6.25,1 \mathrm{H}, \mathrm{CH}_{2} \mathrm{O}\right) ; 4.85\left(d d, J=11.57,5.91,1 \mathrm{H}, \mathrm{CH}_{2} \mathrm{O}\right) ; 2.84-2.76$ $(m, \mathrm{H}-\mathrm{C}(1), \mathrm{H}-\mathrm{C}(5)) ; 2.58(s, \mathrm{MeS}) ; 2.08-1.98(m, 2 \mathrm{H}-\mathrm{C}(7)) ; 1.62-1.14(m, \mathrm{H}-\mathrm{C}(2), \mathrm{H}-\mathrm{C}(3), \mathrm{H}-\mathrm{C}(4)$, $2 \mathrm{H}-\mathrm{C}(8)) .{ }^{13} \mathrm{C}-\mathrm{NMR}\left(50.3 \mathrm{MHz}, \mathrm{CDCl}_{3}\right): 215.67,213.05(\mathrm{CO}, \mathrm{CS}) ; 71.61\left(\mathrm{CH}_{2} \mathrm{O}\right) ; 48.40(\mathrm{C}(5)) ; 44.58(\mathrm{C}(7))$; $34.90(\mathrm{C}(1)) ; 28.88(\mathrm{C}(8)) ; 24.12(\mathrm{C}(2)) ; 23.27(\mathrm{C}(3)) ; 19.05(\mathrm{MeS}) ; 16.29(\mathrm{C}(4))$. CI-MS $\left(\mathrm{CH}_{4}\right): 271(3,[M+$ $\left.29]^{+}\right), 263(11), 245\left(10,[M+3]^{+}\right), 244\left(11,[M+2]^{+}\right), 243\left(100,[M+1]^{+}\right), 215(9), 195(23), 167(35), 153(6)$, 151 (3), 136 (8), 135 (60), 117 (27), 107 (61), 93 (40), 91 (21), 79 (24), 75 (9), 41 (42).

S-Methyl O-[(1RS,2RS,3SR,4RS,5RS)-3-Oxotricyclo[3.2.1.0 2,4]oct-3-yl] Carbonodithioate (rac-anti-26b). As described for rac-syn-26b, with rac-anti-26b, $(535 \mathrm{mg}, 3.51 \mathrm{mmol})$ : rac-anti-26b $(762 \mathrm{mg}, 90 \%)$. Yellow solid. M.p. $73-75^{\circ}$. IR $\left(\mathrm{CHCl}_{3}\right)$ : $1746 .{ }^{1} \mathrm{H}-\mathrm{NMR}\left(200 \mathrm{MHz}, \mathrm{CDCl}_{3}\right): 4.41\left(d, J=7.22, \mathrm{CH}_{2} \mathrm{O}\right) ; 2.69-2.63(m, \mathrm{H}-\mathrm{C}(1)$, $\mathrm{H}-\mathrm{C}(5)) ; 2.55(s, \mathrm{MeS}) ; 2.04-1.93(m, 2 \mathrm{H}-\mathrm{C}(7)) ; 1.82(m, \mathrm{H}-\mathrm{C}(3)) ; 1.39-0.97(m, \mathrm{H}-\mathrm{C}(2), \mathrm{H}-\mathrm{C}(3)$, $2 \mathrm{H}-\mathrm{C}(8)) .{ }^{1} \mathrm{H}-\mathrm{NMR}\left(50.3 \mathrm{MHz}, \mathrm{CDCl}_{3}\right): 215.95,213.40(\mathrm{CO}, \mathrm{CS}) ; 74.77\left(\mathrm{CH}_{2} \mathrm{O}\right) ; 47.93(\mathrm{C}(5)) ; 44.01(\mathrm{C}(7))$; $34.35(\mathrm{C}(1)) ; 26.60(\mathrm{C}(8)) ; 22.53(\mathrm{C}(2)) ; 19.08(\mathrm{MeS}) ; 16.53(\mathrm{C}(3)) ; 15.43(\mathrm{C}(4))$. CI-MS $\left(\mathrm{CH}_{4}\right): 271(4,[M+$ $\left.29]^{+}\right), 263(18), 245\left(11,[M+3]^{+}\right), 244(19), 243\left(100,[M+1]^{+}\right), 214(6), 195(12), 167(7), 151(4), 136(14)$, 135 (98), 117 (42), 107 (70), 93 (66), 91 (24), 79 (16), 75 (7), 55 (8), 41 (35).

(1RS,4RS,6RS)-6-Ethenylbicyclo[2.2.1]heptan-2-one (rac-27a) and (1RS,4RS,5RS)-5-Ethenylbicyclo[2.2.1]heptan-2-one (rac-27b). To a soln. of rac-syn or rac-anti-26b $(651 \mathrm{mg}, 2.69 \mathrm{mmol})$ in toluene $(30 \mathrm{ml}), \mathrm{Bu}_{3} \mathrm{SnH}(1.07 \mathrm{ml}, 4.04 \mathrm{mmol})$ and AIBN $(89 \mathrm{mg}, 0.54 \mathrm{mmol})$ were added. The soln. was purged of air by bubbling $\mathrm{N}_{2}$ for $2 \mathrm{~h}$ and thereafter heated at $100^{\circ}$ (oil-bath temp.) for $5 \mathrm{~h}$. After evaporation, the residue was purified by CC (silica gel (230 - 430 mesh), AcOEt/petroleum ether 1:16): $r a c-27 \mathbf{a} / \mathrm{rac}-27 \mathbf{b} 1: 0.72$ (by ${ }^{1} \mathrm{H}-\mathrm{NMR}$; $322 \mathrm{mg}, 88 \%)$. Colorless oil. The isomers were separated by CC (Merck silica gel $60(0.015-0.040 \mathrm{~mm}), \mathrm{AcOEt} /$ petroleum ether $1: 32)$.

Data of rac-27a (first eluted): IR $\left(\mathrm{CHCl}_{3}\right): 1740 .{ }^{1} \mathrm{H}-\mathrm{NMR}\left(500.13 \mathrm{MHz}, \mathrm{CDCl}_{3}\right): 5.78($ ddd, $J=17.14,10.53$, 6.54, $\left.\mathrm{CH}_{2}=\mathrm{CH}\right) ; 5.18\left(d m, J=17.14,1 \mathrm{H}, \mathrm{CH}_{2}=\mathrm{CH}\right) ; 5.13\left(d m, J=10.53,1 \mathrm{H}, \mathrm{CH}_{2}=\mathrm{CH}\right) ; 2.62(d m, J=6.54$, $\mathrm{H}-\mathrm{C}(6)) ; 2.55-2.52(m, \mathrm{H}-\mathrm{C}(1), \mathrm{H}-\mathrm{C}(4)) ; 2.18(d m, J=17.90,1 \mathrm{H}) ; 2.02-1.85(m, 3 \mathrm{H}) ; 1.51(m, 1 \mathrm{H}) ; 1.43$ $(m, 1 \mathrm{H}) \cdot{ }^{13} \mathrm{C}-\mathrm{NMR}\left(50.3 \mathrm{MHz}, \mathrm{CDCl}_{3}\right): 216.55(\mathrm{C}(2)) ; 134.67\left(\mathrm{Ch}_{2}=\mathrm{CH}\right) ; 117.04\left(\mathrm{CH}_{2}=\mathrm{CH}\right) ; 53.82(\mathrm{C}(1))$; $51.28(\mathrm{C}(6))$; $46.64(\mathrm{C}(3)) ; 39.46(\mathrm{C}(4)) ; 24.98,21.52(\mathrm{C}(5), \mathrm{C}(7))$. CI-MS $\left(\mathrm{CH}_{4}\right): 177\left(4,[M+41]^{+}\right), 165(10$, $\left.[M+29]^{+}\right), 138\left(10,[M+2]^{+}\right), 137\left(100,[M+1]^{+}\right), 136\left(3, M^{+}\right), 135\left(1,[M-1]^{+}\right), 123(3), 119(20), 109(21)$, 108 (4), 107 (2), 95 (13), 94 (4), 93 (14), 91 (5), 79 (4), 67 (8), 55 (2).

Data of rac-27b: IR $\left(\mathrm{CHCl}_{3}\right): 1734 .{ }^{1} \mathrm{H}-\mathrm{NMR}\left(500.13 \mathrm{MHz}, \mathrm{CDCl}_{3}\right): 5.85(d d d, J=17.27,10.18,7.22$, $\left.\mathrm{CH}_{2}=\mathrm{CH}\right) ; 5.05-4.99\left(m, \mathrm{CH}_{2}=\mathrm{CH}\right) ; 2.61(m, \mathrm{H}-\mathrm{C}(5)) ; 2.51(m, \mathrm{H}-\mathrm{C}(4)) ; 2.38(m, \mathrm{H}-\mathrm{C}(1)) ; 2.11(d d, J=$ $17.80,4.60,1 \mathrm{H}-\mathrm{C}(3)) ; 1.91(d d, J=17.80,4.25 \mathrm{~Hz}, 1 \mathrm{H}-\mathrm{C}(3)) ; 1.81(d d d, J=13.28,8.54,2.20,1 \mathrm{H}-\mathrm{C}(6)) ; 1.74$ $(d m, J=10.70,1 \mathrm{H}-\mathrm{C}(7)) ; 1.68-1.61(m, 1 \mathrm{H}-\mathrm{C}(6), 1 \mathrm{H}-\mathrm{C}(7))$. NOE: $2.11(4.12,2.51), 1.90(1.53,2.51), 2.38$ $(6.44,1.81) .{ }^{13} \mathrm{C}-\mathrm{NMR}\left(50.3 \mathrm{MHz}, \mathrm{CDCl}_{3}\right): 217.20(\mathrm{C}(2)) ; 142.00\left(\mathrm{CH}_{2}=\mathrm{CH}\right) ; 113.41\left(\mathrm{CH}_{2}=\mathrm{CH}\right) ; 50.04(\mathrm{C}(5))$; $45.09(\mathrm{C}(3)) ; 43.45(\mathrm{C}(1)) ; 40.94(\mathrm{C}(4)) ; 34.68,30.89$ (C(6), C(7)). CI-MS $\left(\mathrm{CH}_{4}\right): 177\left(6,[M+41]^{+}\right), 165(6$, $\left.[M+29]^{+}\right), 138\left(11,[M+2]^{+}\right), 137\left(100,[M+1]^{+}\right), 136\left(33, M^{+}\right), 135\left(1,[M-1]^{+}\right), 119(20), 118(7), 109(16)$, 108 (8), 107 (4), 95 (8), 94 (8), 93 (15), 92 (26), 91 (10), 79 (5), 67 (5).

(1R,4R)-6-Ethenylspiro[bicyclo[2.2.1] heptane-2,2'-[1,3]dioxolane] (28a) and (1R,4R,5R)-5-Ethenylspiro[bicyclo[2.2.1] heptane-2,2'-[1,3]dioxolane] (28b). As described for rac-27a/b, with syn- or anti-25b $(64.61 \mathrm{~g}$, $0.226 \mathrm{~mol})$, dry toluene $(1.5 \mathrm{l}), \mathrm{Bu}_{3} \mathrm{SnH}(120 \mathrm{ml}, 0.452 \mathrm{~mol})$, and AIBN $(1.86 \mathrm{~g}, 11.3 \mathrm{mmol})\left(8 \mathrm{~h}\right.$ at $\left.120^{\circ}\right): 39.11 \mathrm{~g}$ (96\% ) 28a/28b $1: 3.2$, which were separated as described above. Further purification was achieved by CC (Merck silica gel $60(0.015-0.040 \mathrm{~mm})$, AcOEt/hexane 1:32). 
Data of 28a (first eluted): Colorless oil. $[\alpha]_{\mathrm{D}}^{23}=-2.54\left(c=0.63, \mathrm{CHCl}_{3}\right) .{ }^{1} \mathrm{H}-\mathrm{NMR}\left(500.13 \mathrm{MHz}, \mathrm{CDCl}_{3}\right)$ : $5.76\left(d d d, J=17.26,10.02,7.41, \mathrm{CH}_{2}=\mathrm{CH}\right) ; 4.98\left(d m, J=17.26,1 \mathrm{H}, \mathrm{CH}_{2}=\mathrm{CH}\right) ; 4.90(d m, J=10.02,1 \mathrm{H}$, $\left.\mathrm{CH}_{2}=\mathrm{CH}\right) ; 3.96-3.83\left(m, \mathrm{OCH}_{2} \mathrm{CH}_{2} \mathrm{O}\right) ; 2.70(m, 1 \mathrm{H}-\mathrm{C}(6)) ; 2.29(m, \mathrm{H}-\mathrm{C}(4)) ; 2.01(m, \mathrm{H}-\mathrm{C}(1)) ; 1.81$ $(d d d, J=13.13,4.55,3.03,1 \mathrm{H}-\mathrm{C}(3)) ; 1.60(d d d, J=11.96,8.93,2.70,1 \mathrm{H}-\mathrm{C}(5)) ; 1.55(d m, J=10.11$, $1 \mathrm{H}-\mathrm{C}(7)) ; 1.46(d d, J=13.13,3.37,1 \mathrm{H}-\mathrm{C}(3)) ; 1.41(d m, J=10.11,1 \mathrm{H}-\mathrm{C}(7)) ; 1.36(d m, J=11.96$, $1 \mathrm{H}-\mathrm{C}(5))$. NOE: $2.01(2.92,2.70), 1.60(3.34,2.70), 1.81(3.79,2.29), 1.60-1.36(9.20,2.29), 3.96-3.83$ $(4.44,2.01), 2.70(3.40,2.01), 1.55(1.76,2.01), 1.41(2.07,2.01), 2.29(4.54,1.81), 1.46(17.55,1.81), 2.70(11.12$, $1.60), 2.29(2.37,1.60), 1.36(24.65,1.60), 2.29(3.55,1.55), 2.01(4.29,1.55), 1.41(15.31,1.55), 2.29(2.26,1.46)$, $1.80(17.68,1.46), 2.70(1.54,1.36), 2.29(4.64,1.36), 1.60(19.53,1.36) .{ }^{13} \mathrm{C}-\mathrm{NMR}\left(50.3 \mathrm{MHz}, \mathrm{CDCl}_{3}\right): 142.99$ $\left(\mathrm{CH}_{2}=\mathrm{CH}\right) ; 116.02\left(\mathrm{CH}_{2}=\mathrm{CH}\right) ; 112.30(\mathrm{C}(2)) ; 64.48,63.76\left(\mathrm{OCH}_{2} \mathrm{CH}_{2} \mathrm{O}\right) ; 49.49(\mathrm{C}(1)) ; 43.11(\mathrm{C}(3)) ; 38.62$, $35.96(\mathrm{C}(4), \mathrm{C}(6)) ; 35.90,34.93(\mathrm{C}(5), \mathrm{C}(7))$. CI-MS $\left(\mathrm{CH}_{4}\right): 209\left(3,[M+29]^{+}\right), 182\left(11,[M+2]^{+}\right), 181(100$, $\left.[M+1]^{+}\right), 180\left(45, M^{+}\right), 179\left(18,[M-1]^{+}\right), 165(1), 153(2), 152(2), 151(3), 137(5), 126(7), 125(4), 113(4)$, 112 (4), 99 (7), 93 (7), 92 (11), 87 (4), 73 (8). HR-EI-MS (pos.): $180.1149\left(\mathrm{C}_{11} \mathrm{H}_{16} \mathrm{O}_{2}^{+}\right.$; calc. 180.1145).

Data of 28b: Colorless oil. $[\alpha]_{\mathrm{D}}^{24}=+49.9\left(c=1.33, \mathrm{CHCl}_{3}\right) .{ }^{1} \mathrm{H}-\mathrm{NMR}\left(500.13 \mathrm{MHz}, \mathrm{CDCl}_{3}\right): 5.77(d d d, J=$ $\left.17.33,10.13,7.35, \mathrm{CH}_{2}=\mathrm{CH}\right) ; 4.95\left(d m, J=17.33,1 \mathrm{H}, \mathrm{CH}_{2}=\mathrm{CH}\right) ; 4.89\left(d m, J=10.13,1 \mathrm{H}, \mathrm{CH}_{2}=\mathrm{CH}\right) ; 3.95-$ $3.81\left(m, \mathrm{OCH}_{2} \mathrm{CH}_{2} \mathrm{O}\right) ; 2.22(m, \mathrm{H}-\mathrm{C}(5)) ; 2.15(m, \mathrm{H}-\mathrm{C}(1)) ; 2.11(m, \mathrm{H}-\mathrm{C}(4)) ; 1.97(d d d, J=12.80,8.59$, $2.27,1 \mathrm{H}-\mathrm{C}(6)) ; 1.85(d d, J=13.31,4.89,1 \mathrm{H}-\mathrm{C}(3)) ; 1.54(d m, J=10.19,1 \mathrm{H}-\mathrm{C}(7)) ; 1.50(d d, J=13.31,3.40$, $1 \mathrm{H}-\mathrm{C}(3)) ; 1.43(d m, J=10.19,1 \mathrm{H}-\mathrm{C}(7)) ; 1.22(d d d, J=12.80,4.57,4.55,1 \mathrm{H}-\mathrm{C}(6))$. NOE: $1.97(3.11,2.22)$, $2.22(5.20,1.97), 1.22(16.05,1.97), 2.15(1.91,1.54), 2.11(1.59,1.54), 1.43(17.63,1.54), 2.15(3.59,1.43), 2.11$ $(1.99,1.43), 1.54(14.40,1.43), 2.22(5.55,1.22), 2.15(7.70,1.22), 1.97(15.11,1.22) .{ }^{13} \mathrm{C}-\mathrm{NMR}(50.3 \mathrm{MHz}$, $\left.\mathrm{CDCl}_{3}\right): 143.57\left(\mathrm{CH}_{2}=\mathrm{CH}\right) ; 116.02\left(\mathrm{CH}_{2}=\mathrm{CH}\right) ; 112.20(\mathrm{C}(2)) ; 64.44,63.82\left(\mathrm{OCH}_{2} \mathrm{CH}_{2} \mathrm{O}\right) ; 44.28,44.17,41.44$ $(\mathrm{C}(1), \mathrm{C}(4), \mathrm{C}(5)) ; 43.85,34.88,29.57(\mathrm{C}(3), \mathrm{C}(6), \mathrm{C}(7))$. CI-MS $\left(\mathrm{CH}_{4}\right): 209\left(3,[M+29]^{+}\right), 183\left(1,[M+3]^{+}\right)$; $182\left(14,[M+2]^{+}\right), 181\left(100,[M+1]^{+}\right), 180\left(13, M^{+}\right), 179\left(15,[M-1]^{+}\right), 165(2), 153(2), 137(36), 126(39)$, $125(6), 112(6), 109(6), 99(8), 91(4), 87$ (9), 73 (22), 55 (3), 45 (11), 41 (24). Anal. calc. for $\mathrm{C}_{11} \mathrm{H}_{16} \mathrm{O}_{2}: \mathrm{C} 73.30$, $\mathrm{H}$ 8.95; found: C 73.14, H 8.82 .

(1R,4R,5R)-Spiro[bicyclo[2.2.1] heptane-2,2'-[1,3]dioxolane]-5-ethanol (29). To a soln. of $\mathbf{2 8 b}(9.55 \mathrm{~g}$, $53 \mathrm{mmol})$ in dry THF $(100 \mathrm{ml}), 0.5 \mathrm{M} 9$-BBN . THF complex soln. $(233 \mathrm{ml}, c a .116 .6 \mathrm{mmol})$ was added dropwise at $0^{\circ}$ under $\mathrm{N}_{2}$. After the addition was complete $(3 \mathrm{~h})$, the mixture was stirred for $5 \mathrm{~h}$ at r.t. and then cooled to $9^{\circ}$ before $3 \mathrm{M}$ aq. $\mathrm{NaOH}(180 \mathrm{ml})$ was added. The thus obtained trialkylborane was oxidized by slow dropwise addition of $30 \% \mathrm{H}_{2} \mathrm{O}_{2}$ soln. $(180 \mathrm{ml})$ at $0^{\circ}$. After stirring overnight at r.t., the mixture was extracted with AcOEt $(4 \times 200 \mathrm{ml})$, the combined extract washed with sat. $\mathrm{Na}_{2} \mathrm{~S}_{2} \mathrm{O}_{3}$ soln. $(3 \times 80 \mathrm{ml})$ and brine $(2 \times 80 \mathrm{ml})$, dried $\left(\mathrm{Na}_{2} \mathrm{SO}_{4}\right)$, and evaporated, and the residue purified by CC $\left(\mathrm{AcOEt} / \mathrm{CH}_{2} \mathrm{Cl}_{2} 1: 2\right): 10.19 \mathrm{~g}(97 \%)$ of $\mathbf{2 9}\left(R_{\mathrm{f}} 0.39\right)$. Colorless oil. $[\alpha]_{\mathrm{D}}^{23}=+36.3\left(c=0.54, \mathrm{CHCl}_{3}\right) .{ }^{1} \mathrm{H}-\mathrm{NMR}\left(500.13 \mathrm{MHz}, \mathrm{CDCl}_{3}\right): 3.96-3.82\left(m, \mathrm{OCH}_{2} \mathrm{CH}_{2} \mathrm{O}\right)$; $3.67-3.63\left(m, \mathrm{CH}_{2} \mathrm{CH}_{2} \mathrm{OH}\right) ; 2.13(m, \mathrm{H}-\mathrm{C}(1)) ; 2.03(m, \mathrm{H}-\mathrm{C}(4)) ; 1.93(d d d, J=12.64,8.09,2.11,1 \mathrm{H}-\mathrm{C}(6))$; $1.84(d d, J=13.13,4.80,1 \mathrm{H}-\mathrm{C}(3)) ; 1.65-1.58(m, 3 \mathrm{H}) ; 1.55(d m, J=10.11,1 \mathrm{H}-\mathrm{C}(7)) ; 1.47-1.43(m, 2 \mathrm{H})$; $1.41(d m, J=10.19,1 \mathrm{H}-\mathrm{C}(7)) ; 0.97(d d d, J=12.64,4.38,4.38,1 \mathrm{H}-\mathrm{C}(6)) \cdot{ }^{13} \mathrm{C}-\mathrm{NMR}\left(50.3 \mathrm{MHz}, \mathrm{CDCl}_{3}\right)$ : $115.98(\mathrm{C}(2)) ; 64.48,63.86\left(\mathrm{OCH}_{2} \mathrm{CH}_{2} \mathrm{O}\right) ; 61.64\left(\mathrm{CH}_{2} \mathrm{CH}_{2} \mathrm{OH}\right) ; 44.32(\mathrm{C}(3)) ; 44.17(\mathrm{C}(1)) ; 40.53(\mathrm{C}(4)) ; 39.73$ $\left(\mathrm{CH}_{2} \mathrm{CH}_{2} \mathrm{OH}\right) ; 37.14(\mathrm{C}(5)) ; 34.78,30.41(\mathrm{C}(6), \mathrm{C}(7))$. CI-MS $\left(\mathrm{CH}_{4}\right): 239\left(1,[M+41]^{+}\right), 227\left(1,[M+29]^{+}\right), 200$ $\left(10,[M+2]^{+}\right), 199\left(86,[M+1]^{+}\right), 198\left(27, M^{+}\right), 197\left(17,[M-1]^{+}\right), 183(2), 182(11), 181(100), 167(1), 153$ (12), 137 (5), 126 (6), 119 (4), 99 (5), 87 (3), 73 (3). Anal. calc. for $\mathrm{C}_{11} \mathrm{H}_{18} \mathrm{O}_{3}$ : C 66.64, $\mathrm{H}$ 9.15; found: $\mathrm{C} 66.62$, H 9.34 .

(1R,4R,5R)-5-(2-Hydroxyethyl)bicyclo[2.2.1]heptan-2-one (30). As described for rac-syn-26a, with 29 $(9.93 \mathrm{~g}, 50.1 \mathrm{mmol})$. Purification of the product $\left(R_{\mathrm{f}} 0.34\right)$ by CC (silica gel, $\left.\mathrm{AcOEt} / \mathrm{CH}_{2} \mathrm{Cl}_{2} 1: 2\right)$ yielded $\mathbf{3 0} 7.26 \mathrm{~g}$ $(94 \%)$. Colorless oil. $[\alpha]_{\mathrm{D}}^{23}=+53.2\left(c=0.44, \mathrm{CHCl}_{3}\right)$. IR $\left(\mathrm{CHCl}_{3}\right): 1740 .{ }^{1} \mathrm{H}-\mathrm{NMR}\left(500.13 \mathrm{MHz}, \mathrm{CDCl}_{3}\right): 3.74-$ $3.65\left(m, \mathrm{CH}_{2} \mathrm{CH}_{2} \mathrm{OH}\right) ; 2.58(m, \mathrm{H}-\mathrm{C}(1)) ; 2.44(m, \mathrm{H}-\mathrm{C}(4)) ; 2.09(d d, J=17.69,4.70,1 \mathrm{H}-\mathrm{C}(3)) ; 1.85$ $(d d, J=17.69,2.96,1 \mathrm{H}-\mathrm{C}(3)) ; 1.83-1.71(m, 4 \mathrm{H}) ; 1.70(m, 1 \mathrm{H}) ; 1.66(d m, J=10.61,1 \mathrm{H}-\mathrm{C}(7)) ; 1.56$ $\left.(m, 1 \mathrm{H}) ; 1.38(d m, J=12.29,2 \mathrm{H}-\mathrm{C}(6)) .{ }^{13} \mathrm{C}-\mathrm{NMR}(50.3 \mathrm{MHz}, \mathrm{CDCl})_{3}\right): 217.88(\mathrm{C}(2)) ; 61.34\left(\mathrm{CH}_{2} \mathrm{CH}_{2} \mathrm{OH}\right)$; $50.19(\mathrm{C}(1)) ; 45.61(\mathrm{C}(4)) ; 39.99(\mathrm{C}(3)) ; 39.38\left(\mathrm{CH}_{2} \mathrm{CH}_{2} \mathrm{OH}\right) ; 36.74(\mathrm{C}(5)) ; 34.72,31.82(\mathrm{C}(6), \mathrm{C}(7))$. CI-MS $\left(\mathrm{CH}_{4}\right): 195\left(4,[M+41]^{+}\right), 183\left(9,[M+29]^{+}\right), 156\left(16,[M+2]^{+}\right), 155\left(100,[M+1]^{+}\right), 154\left(10, M^{+}\right), 137(25)$, 119 (12), 111 (13), 110 (14), 109 (27), 108 (9), 107 (7), 93 (39), 79 (6), 67 (8), 55 (3). Anal. calc. for $\mathrm{C}_{9} \mathrm{H}_{14} \mathrm{O}_{2}$ : C 70.10, H 9.15; found: C 69.96, H 9.40 .

(1R,2S,4R)-Spiro[bicyclo[2.2.1]hept-5-ene-2,2'-oxirane] (18). To a soln. of 17 [17] (185 g, $0.911 \mathrm{~mol})$ in $\mathrm{MeOH}(480 \mathrm{ml}), \mathrm{K}_{2} \mathrm{CO}_{3}(252 \mathrm{~g}, 1.822 \mathrm{~mol})$ was added at r.t. After $10 \mathrm{~h}$ stirring, ice-cold $\mathrm{H}_{2} \mathrm{O}(960 \mathrm{ml})$ was added, and the mixture was extracted with $\mathrm{Et}_{2} \mathrm{O}(4 \times 200 \mathrm{ml})$. The combined extract was washed with brine $(4 \times$ $100 \mathrm{ml})$ and dried $\left(\mathrm{MgSO}_{4}\right)$, the solvent distilled off through a short Vigreux column, and the residue purified by $\mathrm{CC}$ (pentane/ $\left.\mathrm{Et}_{2} \mathrm{O} 6: 1\right)$ : $102.4 \mathrm{~g}$ (92\%) of $\mathbf{1 8}$ besides the 2-O-methyl ether corresponding to $\mathbf{1 9}(2.81 \mathrm{~g}, 2 \%)$. 
Data of 18: Colorless oil. $R_{\mathrm{f}}$ 0.76. $[\alpha]_{\mathrm{D}}^{20}=+156\left(c=1.16, \mathrm{CHCl}_{3}\right) .{ }^{1} \mathrm{H}-\mathrm{NMR}\left(500.13 \mathrm{MHz}, \mathrm{CDCl}_{3}\right): 6.32$ $(d d, J=5.72,2.92, \mathrm{H}-\mathrm{C}(5)) ; 6.09(d d, J=5.72,3.20, \mathrm{H}-\mathrm{C}(6)) ; 2.95(m, \mathrm{H}-\mathrm{C}(4)) ; 2.84(d, J=4.57,1 \mathrm{H}$, $\left.\mathrm{CH}_{2} \mathrm{O}\right) ; 2.81\left(d, J=4.57,1 \mathrm{H}, \mathrm{CH}_{2} \mathrm{O}\right) ; 2.32(m, \mathrm{H}-\mathrm{C}(1)) ; 1.92(d m, J=8.51,1 \mathrm{H}-\mathrm{C}(7)) ; 1.77(d m, J=8.51$, $1 \mathrm{H}-\mathrm{C}(7)) ; 1.69(d d, J=12.53,3.48,1 \mathrm{H}-\mathrm{C}(3)) ; 1.56(d d, J=12.53,2.83,1 \mathrm{H}-\mathrm{C}(3)) .{ }^{13} \mathrm{C}-\mathrm{NMR}(50.3 \mathrm{MHz}$, $\left.\mathrm{CDCl}_{3}\right)$ : $140.47(\mathrm{C}(5)) ; 133.12(\mathrm{C}(6)) ; 66.30(\mathrm{C}(2)) ; 50.97\left(\mathrm{CH}_{2} \mathrm{O}\right) ; 49.33(\mathrm{C}(7)) ; 48.91(\mathrm{C}(1)) ; 41.57(\mathrm{C}(4))$; $33.97(\mathrm{C}(3))$. CI-MS $\left(\mathrm{CH}_{4}\right): 151\left(5,[M+29]^{+}\right), 137\left(1,[M+15]^{+}\right), 124\left(5,[M+2]^{+}\right), 123\left(60,[M+1]^{+}\right), 122$ $\left(15, M^{+}\right), 121\left(11,[M-1]^{+}\right), 113(4), 105(10), 95(15), 91(15), 85(9), 81(8), 80(20), 79$ (21), 67 (100), 66 (13), $57(10)$.

Data of (1R,2S,4R)-2-Methoxybicyclo[2.2.1]hept-5-ene-2-methanol: Colorless oil. $R_{\mathrm{f}} 0.25 .[\alpha]_{\mathrm{D}}^{22}=+21.6$ $\left(c=3.25, \mathrm{CHCl}_{3}\right) .{ }^{1} \mathrm{H}-\mathrm{NMR}\left(200 \mathrm{MHz}, \mathrm{CDCl}_{3}\right): 6.15(d d, J=5.72,2.92, \mathrm{H}-\mathrm{C}(5)) ; 6.02(d d, J=5.72,3.20$, $\mathrm{H}-\mathrm{C}(6)) ; 3.38(s, \mathrm{MeO}) ; 3.27\left(d, J=9.09,1 \mathrm{H}, \mathrm{CH}_{2} \mathrm{OH}\right) ; 3.21\left(d, J=9.09,1 \mathrm{H}, \mathrm{CH}_{2} \mathrm{OH}\right) ; 2.83(m, \mathrm{H}-\mathrm{C}(4))$; $2.69(m, \mathrm{H}-\mathrm{C}(1)) ; 2.66(s, \mathrm{OH}) ; 1.92(d m, J=8.50,1 \mathrm{H}-\mathrm{C}(7)) ; 1.62(d d, J=12.31,3.72,1 \mathrm{H}-\mathrm{C}(3)) ; 1.59$ $(d m, J=8.50,1 \mathrm{H}-\mathrm{C}(7)) ; 1.11(d d, J=12.31,2.73,1 \mathrm{H}-\mathrm{C}(3)) .{ }^{13} \mathrm{C}-\mathrm{NMR}\left(50.3 \mathrm{MHz}, \mathrm{CDCl}_{3}\right): 138.98(\mathrm{C}(5))$; $134.10(\mathrm{C}(6)) ; 80.99(\mathrm{C}(2)) ; 78.66\left(\mathrm{CH}_{2} \mathrm{OH}\right) ; 59.19(\mathrm{MeO}) ; 51.25(\mathrm{C}(1)) ; 47.80(\mathrm{C}(7)) ; 41.25(\mathrm{C}(4)) ; 38.86$ $(\mathrm{C}(3))$. CI-MS $\left(\mathrm{CH}_{4}\right): 155\left(2,[M+1]^{+}\right), 154\left(16, M^{+}\right), 138\left(3,[(M+2)-18]^{+}\right), 137\left(29,[(M+1)-18]^{+}\right), 136$ $\left(1,[M-18]^{+}\right), 123(3), 122(5), 121(2), 109(5), 105(4), 95(7), 89(2), 88(3), 87$ (3), $81(4), 72(5), 71(100)$, 66 (11).

(1R,2S,4R)-2-Hydroxybicyclo[2.2.1]hept-5-ene-2-methanol (19). To a stirred soln. of $\mathbf{1 8}$ (102 g, $0.835 \mathrm{~mol})$ in dioxane $(700 \mathrm{ml})$, a soln. of $\mathrm{KOH}(281 \mathrm{~g})$ in $\mathrm{H}_{2} \mathrm{O}(700 \mathrm{ml})$ was added, and stirring was continued for $48 \mathrm{~h}$ at $105^{\circ}$. After cooling to r.t., the mixture was extracted by $\mathrm{Et}_{2} \mathrm{O}$, washed with brine, dried $\left(\mathrm{MgSO}_{4}\right)$, and evaporated and the residue purified by CC ( $\left.\mathrm{AcOEt} / \mathrm{Et}_{2} \mathrm{O} 1: 1\right)$ : $114.7 \mathrm{~g}(98 \%)$ of $\mathbf{1 9}$ besides $1.6 \mathrm{~g}(1.5 \%)$ of the corresponding [oxybis(methylene)]bis[bicyclo[2.2.1]heptene].

Data of 19. $R_{\mathrm{f}}$ 0.54. White solid. M.p. $82-84^{\circ}$ (hexane). $[\alpha]_{\mathrm{D}}^{23}=+26\left(c=0.3, \mathrm{CHCl}_{3}\right) .{ }^{1} \mathrm{H}-\mathrm{NMR}(200 \mathrm{MHz}$, $\left.\mathrm{CDCl}_{3}\right): 6.17(d d, J=5.71,2.92, \mathrm{H}-\mathrm{C}(5)) ; 6.06(d d, J=5.71,3.13, \mathrm{H}-\mathrm{C}(6)) ; 3.50\left(d, J=11.00,1 \mathrm{H}, \mathrm{CH}_{2} \mathrm{OH}\right)$; $3.42\left(d, J=11.00,1 \mathrm{H}, \mathrm{CH}_{2} \mathrm{OH}\right) ; 2.87(m, \mathrm{H}-\mathrm{C}(4)) ; 2.72(m, \mathrm{H}-\mathrm{C}(1)) ; 2.24($ br., $2 \mathrm{OH}) ; 1.92(d m, J=8.55$, $1 \mathrm{H}-\mathrm{C}(7)) ; 1.63(d m, J=8.55,1 \mathrm{H}-\mathrm{C}(7)) ; 1.62(d d, J=12.30,3.72,1 \mathrm{H}-\mathrm{C}(3)) ; 1.18(d d, J=12.30,2.79$, $1 \mathrm{H}-\mathrm{C}(3)) .{ }^{13} \mathrm{C}-\mathrm{NMR}\left(50.3 \mathrm{MHz}, \mathrm{CDCl}_{3}\right): 139.06(\mathrm{C}(5)) ; 133.79(\mathrm{C}(6)) ; 82.33(\mathrm{C}(2)) ; 68.60\left(\mathrm{CH}_{2} \mathrm{OH}\right) ; 50.59$ $(\mathrm{C}(1)) ; 47.81(\mathrm{C}(7)) ; 41.37(\mathrm{C}(4)) ; 39.14(\mathrm{C}(3))$. CI-MS $\left(\mathrm{CH}_{4}\right): 141\left(2,[M+1]^{+}\right), 140\left(6, M^{+}\right), 123(44), 113(3)$, 109 (6), 105 (3), 95 (12), 85 (11), 81 (6), 79 (7), 67 (100), 66 (14), 57 (10). Anal. calc. for $\mathrm{C}_{8} \mathrm{H}_{12} \mathrm{O}_{2}$ : $\mathrm{C} 68.55$, H 8.63; found: C $68.32, \mathrm{H} 8.74$.

Data of (1R, $\left.1^{\prime} \mathrm{R}, 4 \mathrm{R}, 4^{\prime} \mathrm{R}, 5 \mathrm{~S}, 5^{\prime} \mathrm{S}\right)-5,5^{\prime}$-[Oxybis(methylene)]bis[bicyclo[2.2.1]hept-2-ene]: $R_{\mathrm{f}} 0.78$. White solid. M.p. $117-118^{\circ}$ (hexane). $[\alpha]_{\mathrm{D}}^{20}=+50.2\left(c=0.54, \mathrm{CHCl}_{3}\right) .{ }^{1} \mathrm{H}-\mathrm{NMR}\left(200 \mathrm{MHz}, \mathrm{CDCl}_{3}\right): 6.16(d d, J=$ $\left.5.70,2.94, \mathrm{H}-\mathrm{C}(2), \mathrm{H}-\mathrm{C}\left(2^{\prime}\right)\right) ; 6.01\left(d d, J=5.70,3.17, \mathrm{H}-\mathrm{C}(3), \mathrm{H}-\mathrm{C}\left(3^{\prime}\right)\right) ; 3.37\left(d, J=9.33,2 \mathrm{H}, \mathrm{CH}_{2} \mathrm{OCH}_{2}\right)$; $3.19\left(d, J=9.33,2 \mathrm{H}, \mathrm{CH}_{2} \mathrm{OCH}{ }_{2}\right) ; 2.85\left(m, \mathrm{H}-\mathrm{C}(1), \mathrm{H}-\mathrm{C}\left(1^{\prime}\right)\right) ; 2.71\left(m, \mathrm{H}-\mathrm{C}(4), \mathrm{H}-\mathrm{C}\left(4^{\prime}\right)\right) ; 2.67($ br., $2 \mathrm{OH})$; $1.94\left(d m, J=8.36,2 \mathrm{H}, \mathrm{H}-\mathrm{C}(7), \mathrm{H}-\mathrm{C}\left(7^{\prime}\right)\right) ; 1.66\left(d m, J=8.55,2 \mathrm{H}, \mathrm{H}-\mathrm{C}(7), \mathrm{H}-\mathrm{C}\left(7^{\prime}\right)\right) ; 1.65(d d, J=12.30$, $\left.3.71,2 \mathrm{H}, \mathrm{H}-\mathrm{C}(6), \mathrm{H}-\mathrm{C}\left(6^{\prime}\right)\right) ; 1.12\left(d d, J=12.30,2.66,2 \mathrm{H}, \mathrm{H}-\mathrm{C}(6), \mathrm{H}-\mathrm{C}\left(6^{\prime}\right)\right) .{ }^{13} \mathrm{C}-\mathrm{NMR}\left(50.3 \mathrm{MHz}, \mathrm{CDCl}_{3}\right)$ : $139.16\left(2 \mathrm{C}, \mathrm{C}(2), \mathrm{C}\left(2^{\prime}\right)\right) ; 133.96\left(2 \mathrm{C}, \mathrm{C}(3), \mathrm{C}\left(3^{\prime}\right)\right) ; 81.27\left(2 \mathrm{C}, \mathrm{C}(5), \mathrm{C}\left(5^{\prime}\right)\right) ; 77.43\left(2 \mathrm{C}, \mathrm{CH}_{2} \mathrm{OCH}_{2}\right) ; 51.31(2 \mathrm{C}$, $\left.\mathrm{C}(4), \mathrm{C}\left(4^{\prime}\right)\right) ; 47.78\left(2 \mathrm{C}, \mathrm{C}(7), \mathrm{C}\left(7^{\prime}\right)\right) ; 41.25\left(2 \mathrm{C}, \mathrm{C}(1), \mathrm{C}\left(1^{\prime}\right)\right) ; 38.82\left(2 \mathrm{C}, \mathrm{C}(6), \mathrm{C}\left(6^{\prime}\right)\right)$. CI-MS $\left(\mathrm{CH}_{4}\right): 263(2$, $\left.[M+1]^{+}\right), 246\left(7,[(M+2)-18]^{+}\right), 245\left(34,[(M+1)-18]^{+}\right), 244\left(22,[M-18]^{+}\right), 227(7), 180(11), 179(100)$, $178(29), 177$ (9), $161(19), 133(6), 124$ (6), $123(57), 122$ (13), $113(17), 105$ (18), 95 (11), 79 (8), 67 (13). Anal. calc. for $\mathrm{C}_{16} \mathrm{H}_{22} \mathrm{O}_{3}$ : C 73.25, H 8.45; found: C 73.25, H 8.64 .

$(1 \mathrm{R}, 4 \mathrm{R}, 5 \mathrm{~S})$-Spiro[bicyclo[2.2.1]heptane-2,2'-[1,3]dioxolane]-5-methanol (31). Ozone was bubbled into a soln. of $28 \mathbf{b}(9.91 \mathrm{~g}, 55 \mathrm{mmol})$ in $\mathrm{CH}_{2} \mathrm{Cl}_{2} / \mathrm{MeOH} 2: 1(300 \mathrm{ml})$ at $-78^{\circ}$ until a blue color persisted. Thereafter, the mixture was purged of ozone with $\mathrm{N}_{2}$ until the soln. became colorless, and $\mathrm{NaBH}_{4}(5.20 \mathrm{~g}, 137.5 \mathrm{mmol})$ was added. The mixture was allowed to warm to r.t. and then stirred for $2 \mathrm{~h}$ before most of the solvent was evaporated. Then, $\mathrm{H}_{2} \mathrm{O}(100 \mathrm{ml})$ was added, the aq. layer extracted with AcOEt $(5 \times 100 \mathrm{ml})$, the combined extract washed with brine $(2 \times 50 \mathrm{ml})$, dried $\left(\mathrm{Na}_{2} \mathrm{SO}_{4}\right)$, and evaporated, and the residue purified by CC (AcOEt/ $\left.\mathrm{CH}_{2} \mathrm{Cl}_{2} 1: 2\right): 9.71 \mathrm{~g}(96 \%)$ of 31. $R_{\mathrm{f}}$ 0.36. Colorless oil. $[\alpha]_{\mathrm{D}}^{23}=+17.2\left(c=0.46, \mathrm{CHCl}_{3}\right) .{ }^{1} \mathrm{H}-\mathrm{NMR}(500.13 \mathrm{MHz}$, $\left.\mathrm{CDCl}_{3}\right): 3.96-3.81\left(m, \mathrm{OCH}_{2} \mathrm{CH}_{2} \mathrm{O}\right) ; 3.44\left(d d, J=10.51,6.23,1 \mathrm{H}, \mathrm{CH}_{2} \mathrm{OH}\right) ; 3.40(d d, J=10.51,8.59,1 \mathrm{H}$, $\left.\mathrm{CH}_{2} \mathrm{OH}\right) ; 2.24(m, \mathrm{H}-\mathrm{C}(1)) ; 2.13(m, \mathrm{H}-\mathrm{C}(4)) ; 1.89(d d, J=13.30,4.88, \mathrm{H}-\mathrm{C}(3)) ; 1.86(d d d, J=12.43,8.44$, $2.26,1 \mathrm{H}-\mathrm{C}(6)) ; 1.78(m, \mathrm{H}-\mathrm{C}(5)) ; 1.65$ (br. $\left.s, \mathrm{CH}_{2} \mathrm{OH}\right) ; 1.55(d m, J=10.44,1 \mathrm{H}-\mathrm{C}(7)) ; 1.47(d d, J=13.30$, $3.53,1 \mathrm{H}-\mathrm{C}(3)) ; 1.36(d m, J=10.44,1 \mathrm{H}-\mathrm{C}(7)) ; 0.91(d d d, J=12.43,4.55,4.55,1 \mathrm{H}-\mathrm{C}(6)) .{ }^{13} \mathrm{C}-\mathrm{NMR}$ $\left(50.3 \mathrm{MHz}, \mathrm{CDCl}_{3}\right): 116.05(\mathrm{C}(2)) ; 66.59\left(\mathrm{CH}_{2} \mathrm{OH}\right) ; 64.52,63.88\left(\mathrm{OCH}_{2} \mathrm{CH}_{2} \mathrm{O}\right) ; 44.06(\mathrm{C}(3)) ; 43.77(\mathrm{C}(1))$; $43.55(\mathrm{C}(4)) ; 37.47(\mathrm{C}(5)) ; 34.56,26.44(\mathrm{C}(6), \mathrm{C}(7))$. CI-MS $\left(\mathrm{CH}_{4}\right): 186\left(5,[M+2]^{+}\right), 185\left(42,[M+1]^{+}\right), 184$ $\left(10, M^{+}\right), 183\left(12,[M-1]^{+}\right), 168(10), 167(100), 153(3), 141(26), 123(21), 113(3), 105(4), 99(5), 95$ (12), 79 (6), 73 (10), 67 (2), 55 (2). Anal. calc. for $\mathrm{C}_{10} \mathrm{H}_{10} \mathrm{O}_{3}$ : C 65.19, H 8.75; found: $\mathrm{C} 65.10, \mathrm{H} 8.92$. 
(1R,4R,5S)-5-(Hydroxymethyl)bicyclo[2.2.1]heptan-2-one (32). A soln. of $\mathbf{3 1}(9.55 \mathrm{~g}, 51.83 \mathrm{mmol})$ in $\mathrm{AcOH} / \mathrm{H}_{2} \mathrm{O} 3: 7(100 \mathrm{ml})$ was stirred for $2 \mathrm{~d}$ at r.t. The mixture was then carefully neutralized by adding dropwise $10 \%$ aq. $\mathrm{NaOH}$ soln. and then extracted with AcOEt $(5 \times 150 \mathrm{ml})$. The combined extract was washed with brine $(2 \times 50 \mathrm{ml})$ and dried $\left(\mathrm{Na}_{2} \mathrm{SO}_{4}\right)$ and the residue purified by $\mathrm{FC}\left(\mathrm{AcOEt} / \mathrm{CH}_{2} \mathrm{Cl}_{2} 1: 1\right): 6.78 \mathrm{~g}(93 \%)$ of 32. $R_{\mathrm{f}}$ 0.33. Colorless oil. $[\alpha]_{\mathrm{D}}^{23}=+25.3\left(c=0.85, \mathrm{CHCl}_{3}\right)$. IR $\left(\mathrm{CHCl}_{3}\right): 1742 .{ }^{1} \mathrm{H}-\mathrm{NMR}\left(500.13 \mathrm{MHz}, \mathrm{CDCl}_{3}\right)$ : $3.56\left(d d, J=10.61,6.40,1 \mathrm{H}, \mathrm{CH}_{2} \mathrm{OH}\right) ; 3.53\left(d d, J=10.61,8.59,1 \mathrm{H}, \mathrm{CH}_{2} \mathrm{OH}\right) ; 2.65(m, \mathrm{H}-\mathrm{C}(1)) ; 2.59$ $(m, \mathrm{H}-\mathrm{C}(4)) ; 2.14(d d, J=17.69,4.72,1 \mathrm{H}-\mathrm{C}(3)) ; 1.93(m, \mathrm{H}-\mathrm{C}(5)) ; 1.89(d m, J=17.69,1 \mathrm{H}-\mathrm{C}(3)) ; 1.71$ $(d d, J=13.14,8.59,1 \mathrm{H}-\mathrm{C}(6)) ; 1.69-1.65\left(m, 2 \mathrm{H}-\mathrm{C}(7), \mathrm{CH}_{2} \mathrm{OH}\right) ; 1.35(d d d, J=13.14,4.88,4.88,1 \mathrm{H}-\mathrm{C}(6))$. ${ }^{13} \mathrm{C}-\mathrm{NMR}\left(50.3 \mathrm{MHz}, \mathrm{CDCl}_{3}\right)$ : $217.60(\mathrm{C}(2)) ; 66.04\left(\mathrm{CH}_{2} \mathrm{OH}\right) ; 49.77$ (C(1)); $45.46(\mathrm{C}(3)) ; 42.90$ (C(4)); 37.16 $(\mathrm{C}(5)) ; 34.59,28.08(\mathrm{C}(6), \mathrm{C}(7))$. CI-MS $\left(\mathrm{CH}_{4}\right): 181\left(2,[M+41]^{+}\right), 169\left(5,[M+29]^{+}\right), 142\left(8,[M+2]^{+}\right), 141$ $\left(100,[M+1]^{+}\right), 140\left(8, M^{+}\right), 123(26), 122(4), 105(5), 96(3), 95(24), 94(3), 93(6), 81$ (7), 80 (3), 79 (15), 69 (1), 67 (4). Anal. calc. for $\mathrm{C}_{8} \mathrm{H}_{12} \mathrm{O}_{2}$ : C 68.55, $\mathrm{H} 8.63$; found: $\mathrm{C} 68.23, \mathrm{H} 8.93$.

(1R,5R,6S)-6-(Hydroxymethyl)-2-oxabicyclo[3.2.1]octan-3-one (33). As described for 14, procedure $b$ ), with $32(6.64 \mathrm{~g}, 47.4 \mathrm{mmol}), \mathrm{NaHCO}_{3}(7.97 \mathrm{~g}, 94.8 \mathrm{mmol}), c a .55 \%$ MCPBA $(29.82 \mathrm{~g}, 94.8 \mathrm{mmol})$, and $\mathrm{CH}_{2} \mathrm{Cl}_{2}$ $(650 \mathrm{ml}): 6.29 \mathrm{~g}(85 \%)$ of 33. $R_{\mathrm{f}}$ 0.34. Colorless oil. $[\alpha]_{\mathrm{D}}^{23}=+13.7\left(c=1.02, \mathrm{CHCl}_{3}\right)$. IR $\left(\mathrm{CHCl}_{3}\right): 1726 .{ }^{1} \mathrm{H}-\mathrm{NMR}$ $\left(500.13 \mathrm{MHz}, \mathrm{CDCl}_{3}\right): 4.87(m, \mathrm{H}-\mathrm{C}(1)) ; 3.55\left(d d, J=10.52,5.90,1 \mathrm{H}, \mathrm{CH}_{2} \mathrm{OH}\right) ; 3.44(d d, J=10.52,8.16,1 \mathrm{H}$, $\left.\mathrm{CH}_{2} \mathrm{OH}\right) ; 2.78(d d, J=18.53,4.96,1 \mathrm{H}-\mathrm{C}(4)) ; 2.56(d d d, J=18.53,2.27,1.94,1 \mathrm{H}-\mathrm{C}(4)) ; 2.45(m, \mathrm{H}-\mathrm{C}(5))$; $2.35(d d d, J=14.90,8.72,2.61,1 \mathrm{H}-\mathrm{C}(7)) ; 2.21(m, \mathrm{H}-\mathrm{C}(6)) ; 1.92(d m, J=13.06,1 \mathrm{H}-\mathrm{C}(8)) ; 1.80(d m, J=$ 13.06, $1 \mathrm{H}-\mathrm{C}(8)) ; 1.89-1.72$ (br., $\left.\mathrm{CH}_{2} \mathrm{OH}\right) ; 1.53(d d d, J=14.90,5.31,4.21,1 \mathrm{H}-\mathrm{C}(7)) .{ }^{13} \mathrm{C}-\mathrm{NMR}(50.3 \mathrm{MHz}$, $\left.\mathrm{CDCl}_{3}\right): 170.29(\mathrm{C}(3)) ; 81.15(\mathrm{C}(1))$; $65.60\left(\mathrm{CH}_{2} \mathrm{OH}\right) ; 44.90(\mathrm{C}(5))$; $41.15(\mathrm{C}(4))$; 36.27, $33.65(\mathrm{C}(7), \mathrm{C}(8))$; $34.05(\mathrm{C}(6))$. CI-MS $\left(\mathrm{CH}_{4}\right): 158\left(6,[M+2]^{+}\right), 157\left(63,[M+1]^{+}\right), 140(10), 139(100), 121(35), 111(14), 97$ (14), 95 (17), 94 (7), 93 (42), 81 (7), 79 (33), 67 (6), 61 (24). Anal. calc. for $\mathrm{C}_{8} \mathrm{H}_{12} \mathrm{O}_{3}: \mathrm{C} 61.52, \mathrm{H} 7.74$; found: C 61.14, H 8.00.

Methyl (1R,2S,4R)-4-Hydroxy-2-(hydroxymethyl)cyclopentaneacetate (34a). As described for 15a, with $\mathbf{3 3}$ $(5.3 \mathrm{~g}, 34 \mathrm{mmol}): 34 \mathrm{a}(5.76 \mathrm{~g}, 90 \%)$. The crude product was used without further purification for the next step. IR $\left(\mathrm{CHCl}_{3}\right)$ : 1726. ${ }^{1} \mathrm{H}-\mathrm{NMR}\left(500.13 \mathrm{MHz}, \mathrm{CDCl}_{3}\right): 4.32(\mathrm{~m}, \mathrm{H}-\mathrm{C}(4)) ; 3.68(s, \mathrm{MeO}) ; 3.57(d, J=5.81$, $\left.\mathrm{CH}_{2} \mathrm{OH}\right) ; 2.64\left(d d, J=16.15,6.72,1 \mathrm{H}, \mathrm{CH}_{2} \mathrm{COO}\right) ; 2.47\left(d d, J=16.15,6.71,1 \mathrm{H}, \mathrm{CH}_{2} \mathrm{COO}\right) ; 2.56-2.04$ $(m, 4 \mathrm{H}) ; 1.83(d d d d, J=13.47,7.59,3.15,1.66,1 \mathrm{H}) ; 1.62(d d d, J=13.47,9.08,5.68,1 \mathrm{H}) ; 1.42(d d d d, J=13.36$, 6.56, 4.01, 1.65, $1 \mathrm{H}) .{ }^{13} \mathrm{C}-\mathrm{NMR}\left(50.3 \mathrm{MHz}, \mathrm{CDCl}_{3}\right): 174.37(\mathrm{CO}) ; 72.49(\mathrm{C}(4)) ; 65.49\left(\mathrm{CH}_{2} \mathrm{OH}\right), 51.62(\mathrm{MeO})$; $45.59(\mathrm{C}(2)) ; 41.80\left(\mathrm{CH}_{2} \mathrm{CO}_{2} \mathrm{Me}\right) ; 39.95,39.14(\mathrm{C}(3), \mathrm{C}(5)) ; 36.65(\mathrm{C}(1))$. $\mathrm{CI}-\mathrm{MS}\left(\mathrm{CH}_{4}\right): 217\left(6,[M+29]^{+}\right), 190$ $\left(9,[M+2]^{+}\right), 189\left(77,[M+1]^{+}\right), 172(7), 171(70), 154(12), 153(100), 139(54), 121(34), 111(9), 93(37), 79$ (10), 75 (6), 61 (4).

Methyl (1R,2S,4R)-\{\{[(tert-Butyl)diphenylsilyl]oxy\}methyl\}-4-hydroxycyclopentaneacetate (34b). As described for 15b, with 34a $(5.84 \mathrm{~g}, 31 \mathrm{mmol})$ : $\mathbf{3 4 b}(9.30 \mathrm{~g}, 70 \%)$. Colorless syrup. $R$ ( $\left.\mathrm{AcOEt} / \mathrm{CH}_{2} \mathrm{Cl}_{2} 1: 8\right) 0.35$. $[\alpha]_{\mathrm{D}}^{23}=+12.8\left(c=0.75, \mathrm{CHCl}_{3}\right)$. IR $\left(\mathrm{CHCl}_{3}\right): 1730 .{ }^{1} \mathrm{H}-\mathrm{NMR}\left(360 \mathrm{MHz}, \mathrm{CDCl}_{3}\right): 7.68-7.61(m, 4$ arom. $\mathrm{H})$; $7.46-7.34(m, 6$ arom. $\mathrm{H}) ; 4.31(m, \mathrm{H}-\mathrm{C}(4)) ; 3.63(s, \mathrm{MeO}) ; 3.60\left(d, J=5.14, \mathrm{CH}_{2} \mathrm{O}\right) ; 2.60(d d, J=15.54,4.42$, $\left.1 \mathrm{H}, \mathrm{CH}_{2} \mathrm{COO}\right) ; 2.38\left(d d, J=15.54,8.11,1 \mathrm{H}, \mathrm{CH}_{2} \mathrm{COO} ; 2.30-2.08(m, 3 \mathrm{H}) ; 2.01\right.$ (br. $\left.s, \mathrm{OH}\right) ; 1.83-1.75$ $(m, 1 \mathrm{H}) ; 1.72-1.62(m, 1 \mathrm{H}) ; 1.44-1.36(m, 1 \mathrm{H}) ; 1.05\left(s,{ }^{\prime} \mathrm{Bu}\right) .{ }^{13} \mathrm{C}-\mathrm{NMR}\left(50.3 \mathrm{MHz}, \mathrm{CDCl}_{3}\right): 176.68(\mathrm{CO})$; 135.61, 133.76, 129.61, 127.64 (12 arom. C); $72.80(\mathrm{C}(4))$; $66.35\left(\mathrm{CH}_{2} \mathrm{O}\right) ; 51.33(\mathrm{MeO}) ; 45.14(\mathrm{C}(2)) ; 41.87$ $\left(\mathrm{CH}_{2} \mathrm{CO}_{2} \mathrm{Me}\right)$; 39.74, $39.10(\mathrm{C}(3), \mathrm{C}(5)) ; 36.80(\mathrm{C}(1)) ; 26.88\left(3 \mathrm{C}, \mathrm{Me}_{3} \mathrm{C}\right) ; 19.26\left(\mathrm{Me}_{3} \mathrm{C}\right)$. FAB-MS: 449 (13, $\left.[M+\mathrm{Na}]^{+}\right), 427\left(23,[M+1]^{+}\right), 409(7), 369(96), 343(36), 331(20), 239(15), 213(74), 199(100), 183(44)$, 153 (72), 135 (100), 121 (76). Anal. calc. for $\mathrm{C}_{25} \mathrm{H}_{34} \mathrm{O}_{4} \mathrm{Si}$ : C 70.38, H 8.03; found: C 69.98, $\mathrm{H} 8.06$.

Methyl (1R,2S,4R)-\{\{[(tert-Butyl)diphenylsilyl]oxy]methyl\}-4-[(methylsulfonyl)oxy]cyclopentaneacetate (35). Methanesulfonyl chloride $(1.77 \mathrm{~g}, 15.45 \mathrm{mmol})$ was added dropwise to a stirred, ice-cooled soln. of $\mathbf{3 4 b}$ $(5.07 \mathrm{~g}, 11.88 \mathrm{mmol})$ in $\mathrm{CH}_{2} \mathrm{Cl}_{2}(150 \mathrm{ml})$ containing DMAP $(2.90 \mathrm{~g}, 23.76 \mathrm{mmol})$, and then the mixture was stirred for $30 \mathrm{~min}$ before it was diluted with $\mathrm{CH}_{2} \mathrm{Cl}_{2}(150 \mathrm{ml})$. Then, the soln. was washed successively with sat. aq. $\mathrm{NaHCO}_{3}$ soln. $(80 \mathrm{ml})$ and brine $(80 \mathrm{ml})$, dried $\left(\mathrm{Na}_{2} \mathrm{SO}_{4}\right)$, and evaporated and the residue purified by $\mathrm{CC}$ (AcOEt/petroleum ether 1:2): $5.92 \mathrm{~g}(99 \%)$ of 35. $R_{\mathrm{f}} 0.79$. Colorless syrup. $[\alpha]_{\mathrm{D}}^{23}=+16.2\left(c=0.71, \mathrm{CHCl}_{3}\right)$. IR $\left(\mathrm{CHCl}_{3}\right)$ : 1732. ${ }^{1} \mathrm{H}-\mathrm{NMR}\left(500.13 \mathrm{MHz}, \mathrm{CDCl}_{3}\right): 7.66-7.62(m, 4$ arom. $\mathrm{H}) ; 7.46-7.36(m, 6$ arom. $\mathrm{H}) ; 5.13$ $(m, \mathrm{H}-\mathrm{C}(4)) ; 3.63(s, \mathrm{MeO}) ; 3.64\left(d d, J=10.28,4.90,1 \mathrm{H}, \mathrm{CH}_{2} \mathrm{O}\right) ; 3.59\left(d d, J=10.28,5.06,1 \mathrm{H}^{\left.-\mathrm{CH}_{2} \mathrm{O}\right) ; 2.99}\right.$ $\left(s, \mathrm{MeSO}_{2}\right) ; 2.60-2.53(m, 1 \mathrm{H}) ; 2.43(d d d, J=14.39,8.15,5.96,1 \mathrm{H}) ; 2.33-2.22(m, 2 \mathrm{H}) ; 2.12(d d d d, J=13.48$, $7.60,2.84,1.70,1 \mathrm{H}) ; 2.09-2.02(m, 1 \mathrm{H}) ; 1.89(d d d, J=13.28,8.80,5.76,1 \mathrm{H}) ; 1.72(d d d d, J=14.39,6.93,4.05$, 1.60, $1 \mathrm{H}) ; 1.05\left(s,{ }^{\mathrm{B} u}\right) .{ }^{13} \mathrm{C}-\mathrm{NMR}\left(125.76 \mathrm{MHz}, \mathrm{CDCl}_{3}\right): 172.96(\mathrm{CO}) ; 135.55,133.30,129.73,127.72$ (12 arom. C); $83.33(\mathrm{C}(4)) ; 65.13\left(\mathrm{CH}_{2} \mathrm{O}\right), 51.53(\mathrm{MeO}) ; 45.03\left(\mathrm{MeSO}_{2}\right) ; 39.57,39.52(\mathrm{C}(3), \mathrm{C}(5))$; 38.43, $36.14(\mathrm{C}(1), \mathrm{C}(2)) ; 36.57\left(\mathrm{CH}_{2} \mathrm{CO}_{2} \mathrm{Me}\right) ; 26.83\left(3 \mathrm{C}, \mathrm{Me}_{3} \mathrm{C}\right) ; 19.23\left(\mathrm{Me}_{3} \mathrm{C}\right)$. FAB-MS: $527\left(5,[\mathrm{M}+\mathrm{Na}]^{+}\right), 505(4$, 
$\left.[M+1]^{+}\right), 473(6), 447(51), 427(13), 409(25), 377$ (6), 351 (21), 331 (37), 277 (73), 257 (18), 239 (24), 213 (100), 183 (82), 153 (100), 121 (100). Anal. calc. for $\mathrm{C}_{26} \mathrm{H}_{36} \mathrm{O}_{6} \mathrm{SSi}$ : C 61.87, H 7.19; found: C 61.83, H 7.02. Methyl (1R,2S,4S)-4-(6-Amino-9H-purin-9-yl)-2-\{\{[(tert-butyl)diphenylsilyl]oxy\}methyl cyclopentaneacetate (36). Adenine $(1.21 \mathrm{~g}, 8.93 \mathrm{mmol})$ and $\mathrm{K}_{2} \mathrm{CO}_{3}(1.65 \mathrm{~g}, 11.90 \mathrm{mmol})$ were added to a soln. of $35(3.0 \mathrm{~g}$, $5.95 \mathrm{mmol})$ in dry DMSO $(30 \mathrm{ml})$, and the mixture was stirred at $85^{\circ}$ for $1 \mathrm{~d}$. After evaporation, the residue was dissolved in $\mathrm{CH}_{2} \mathrm{Cl}_{2}(1.2 \mathrm{l})$, the soln. washed successively with $\mathrm{H}_{2} \mathrm{O}(3 \times 100 \mathrm{ml})$ and brine $(3 \times 100 \mathrm{ml})$, dried $\left(\mathrm{Na}_{2} \mathrm{SO}_{4}\right)$, and evaporated, and the residue purified by $\mathrm{CC}\left(\mathrm{CH}_{2} \mathrm{Cl}_{2} / \mathrm{EtOH} 20: 1\right): 1.86 \mathrm{~g}(58 \%)$ of $36 . R_{\mathrm{f}} 0.22$. White solid. M.p. $134-135^{\circ}$ (from $\mathrm{CH}_{2} \mathrm{Cl}_{2}$ /petroleum ether). $[\alpha]_{\mathrm{D}}^{24}=+11.43\left(c=0.84, \mathrm{CHCl}_{3}\right) \cdot \mathrm{UV}\left(\mathrm{CHCl}_{3}\right): 262$ (21600). IR (KBr): 1740, 1667, 1599. ${ }^{1} \mathrm{H}-\mathrm{NMR}\left(500.13 \mathrm{MHz}, \mathrm{CDCl}_{3}\right): 8.35\left(s, \mathrm{H}-\mathrm{C}\left(2^{\prime}\right)\right) ; 7.88\left(s, \mathrm{H}-\mathrm{C}\left(8^{\prime}\right)\right)$; $7.68-7.62$ ( $m, 4$ arom. $\mathrm{H}) ; 7.46-7.36(m, 6$ arom. $\mathrm{H}) ; 5.99\left(s, \mathrm{NH}_{2}\right) ; 4.99\left(m, 1 \mathrm{H}-\mathrm{C}\left(4^{\prime}\right)\right) ; 3.76(d d, J=10.33$, $\left.4.67,1 \mathrm{H}, \mathrm{CH}_{2} \mathrm{O}\right) ; 3.71\left(d d, J=10.33,5.07,1 \mathrm{H}, \mathrm{CH}_{2} \mathrm{O}\right) ; 3.64(s, \mathrm{MeO}) ; 2.65-2.54(m, 2 \mathrm{H}) ; 2.51-2.45(m, 1 \mathrm{H})$; $2.39-2.26(m, 2 \mathrm{H}) ; 2.10(m, 1 \mathrm{H}) ; 2.04-1.94(m, 2 \mathrm{H}) ; 1.07\left(s,{ }^{t} \mathrm{Bu}\right) .{ }^{13} \mathrm{C}-\mathrm{NMR}\left(50.3 \mathrm{MHz}, \mathrm{CDCl}_{3}\right): 172.80$ $(\mathrm{CO}) ; 155.48\left(\mathrm{C}\left(6^{\prime}\right)\right) ; 152.70\left(\mathrm{C}\left(2^{\prime}\right)\right) ; 150.07\left(\mathrm{C}\left(4^{\prime}\right)\right) ; 138.42\left(\mathrm{C}\left(8^{\prime}\right)\right) ; 135.56,133.31,129.76,127.72$ (12 arom. C); $119.95\left(\mathrm{C}\left(5^{\prime}\right)\right) ; 65.21\left(\mathrm{CH}_{2} \mathrm{O}\right) ; 53.62(\mathrm{C}(4)) ; 51.59(\mathrm{MeO}) ; 46.29(\mathrm{C}(1)) ; 39.11,38.47(\mathrm{C}(3), \mathrm{C}(5))$; 36.42 $\left(\mathrm{CH}_{2} \mathrm{CO}_{2} \mathrm{Me}\right) ; 36.09(\mathrm{C}(2)) ; 26.88\left(3 \mathrm{C}, \mathrm{Me}_{3} \mathrm{C}\right)$; $19.25\left(\mathrm{Me}_{3} \mathrm{C}\right)$. FAB-MS: $546\left(13,[M+2]^{+}\right), 545\left(34,[M+1]^{+}\right)$, $544\left(79, M^{+}\right), 486(10), 466(9), 288$ (40), 255 (8), 213 (44), 197 (44), 183 (31), 136 (100), 121 (50). Anal. calc. for $\mathrm{C}_{30} \mathrm{H}_{37} \mathrm{~N}_{5} \mathrm{O}_{3} \mathrm{Si}$ : C 66.27, H 6.86, N 12.88; found: C 66.17, H 7.00, N 12.85 .

Methyl (1R,2S,4S)-2-\{\{[(tert-Butyl)diphenylsilyl]oxy\}methyl\}-4-(1,2,3,4-tetrahydro-5-methyl-2,4-dioxopyrimidin-1-yl)cyclopentaneacetate (37). A mixture of $\mathbf{3 5}(1.45 \mathrm{~g}, 2.87 \mathrm{mmol})$ and thymine $(906 \mathrm{mg}, 7.18 \mathrm{mmol})$ in dry DMF $(20 \mathrm{ml})$ containing [18]crown-6 $(1.14 \mathrm{~g}, 4.31 \mathrm{mmol})$ as phase-transfer catalyst, and $\mathrm{K}_{2} \mathrm{CO}_{3}(992 \mathrm{mg}$, $7.18 \mathrm{mmol}$ ) was stirred at $85^{\circ}$ for $2 \mathrm{~d}$. After dilution with AcOEt $(1 \mathrm{l})$, the mixture was washed successively with $\mathrm{H}_{2} \mathrm{O}(4 \times 100 \mathrm{ml})$ and brine $(100 \mathrm{ml})$, dried $\left(\mathrm{Na}_{2} \mathrm{SO}_{4}\right)$, and evaporated and the residue purified by FC (AcOEt/ $\left.\mathrm{CH}_{2} \mathrm{Cl}_{2} / \mathrm{EtOH} 20: 40: 1\right): 599 \mathrm{mg}(39 \%)$ of 37. $R_{\mathrm{f}} 0.58$. White frothy solid. M.p. $48-51^{\circ}$. [ $\left.\alpha\right]_{\mathrm{D}}^{24}=-2.27(c=0.22$, $\left.\mathrm{CHCl}_{3}\right)$. UV $\left(\mathrm{CHCl}_{3}\right): 272$ (13100). IR (KBr): 1736, 1690. ${ }^{1} \mathrm{H}-\mathrm{NMR}\left(500.13 \mathrm{MHz}, \mathrm{CDCl}_{3}\right): 8.98\left(s, \mathrm{H}-\mathrm{N}\left(3^{\prime}\right)\right)$; $7.67-7.62$ ( $m, 4$ arom. $\mathrm{H}) ; 7.47-7.36(m, 6$ arom. $\mathrm{H}) ; 7.04\left(d, J=1.12, \mathrm{H}-\mathrm{C}\left(6^{\prime}\right)\right) ; 5.05\left(m, 1 \mathrm{H}-\mathrm{C}\left(4^{\prime}\right)\right) ; 3.72$ $\left(d d, J=10.44,4.58,1 \mathrm{H}, \mathrm{CH}_{2} \mathrm{O}\right) ; 3.69\left(d d, J=10.44,4.90,1 \mathrm{H}, \mathrm{CH}_{2} \mathrm{O}\right) ; 3.64(s, \mathrm{MeO}) ; 2.51(d d, J=15.45,4.58$, $1 \mathrm{H}) ; 2.48-2.41(m, 1 \mathrm{H}) ; 2.25-2.20(m, 1 \mathrm{H}) ; 2.19(d d, J=15.45,9.16,1 \mathrm{H}) ; 2.04-2.18(m, 1 \mathrm{H}) ; 1.91(d, J=$ $\left.1.12, \mathrm{Me}-\mathrm{C}\left(5^{\prime}\right)\right) ; 1.90-1.80(m, 2 \mathrm{H}) ; 1.63(\mathrm{~m}, 1 \mathrm{H}) ; 1.07\left(s,{ }^{t} \mathrm{Bu}\right) .{ }^{13} \mathrm{C}-\mathrm{NMR}\left(125.76 \mathrm{MHz}, \mathrm{CDCl}_{3}\right): 172.84$ $(\mathrm{CO}) ; 163.56\left(\mathrm{C}\left(4^{\prime}\right)\right) ; 151.08\left(\mathrm{C}\left(2^{\prime}\right)\right) ; 136.29\left(\mathrm{C}\left(6^{\prime}\right)\right) ; 135.53,133.26,129.79,127.73$ (12 arom. C); $111.27\left(\mathrm{C}\left(5^{\prime}\right)\right)$; $64.65\left(\mathrm{CH}_{2} \mathrm{O}\right) ; 53.62(\mathrm{C}(4)) ; 51.56(\mathrm{MeO}) ; 45.91(\mathrm{C}(1)) ; 38.92,37.00,36.13(\mathrm{C}(2)) ; 35.18,26.88\left(3 \mathrm{C}, M_{3} \mathrm{C}\right)$; $19.24\left(M e-\mathrm{C}\left(5^{\prime}\right)\right) ; 12.62\left(\mathrm{Me}_{3} C\right)$. FAB-MS: $559\left(3,[(M+1)+\mathrm{Na}]^{+}\right), 558\left(11,[M+\mathrm{Na}]^{+}\right), 557(27,[(M-1)+$ $\left.\mathrm{Na}]^{+}\right), 536\left(10,[M+1]^{+}\right), 535\left(26, M^{+}\right), 477(35), 457(16), 409(5), 369(4), 351(15), 331(14), 307(20), 287$

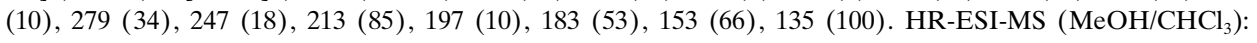
557.2432 $\left(\mathrm{C}_{30} \mathrm{H}_{38} \mathrm{~N}_{2} \mathrm{O}_{5} \mathrm{SiNa}^{+},[M+\mathrm{Na}]^{+}\right.$; calc. 557.2442). Anal. calc. for $\mathrm{C}_{30} \mathrm{H}_{38} \mathrm{~N}_{2} \mathrm{O}_{5} \mathrm{Si}: \mathrm{C} 67.39, \mathrm{H}$ 7.16, N 5.24; found: C 66.90, H 7.38, N 4.98 .

Ethyl (1R,2R,3R,4S,5R)-7-Oxo-6-oxatricyclo[3.3.1.0 2,4 nonane-3-carboxylate (syn-38). As described for 14, procedure $b$ ), with syn-11 (4.94 g, $25.43 \mathrm{mmol}), \mathrm{NaHCO}_{3}(4.27 \mathrm{~g}, 50.86 \mathrm{mmol}), \mathrm{CH}_{2} \mathrm{Cl}_{2}$, and MCPBA (15.96 g, $50.86 \mathrm{mmol})(20 \mathrm{~h})$. Purification by CC (AcOEt/petroleum ether $1: 1)$ yielded $5.19 \mathrm{~g}(97 \%)$ of syn-38. Colorless solid. M.p. $85-87^{\circ} .[\alpha]_{\mathrm{D}}^{22}=+67.1\left(c=0.83, \mathrm{CHCl}_{3}\right)$. IR $(\mathrm{KBr}): 1726 .{ }^{1} \mathrm{H}-\mathrm{NMR}\left(360 \mathrm{MHz}, \mathrm{CDCl}_{3}\right): 4.87$ $(m, \mathrm{H}-\mathrm{C}(5)) ; 4.14\left(d q, J=7.13,2.18, \mathrm{MeCH}_{2} \mathrm{O}\right) ; 2.79(d d, J=18.34,4.66, \mathrm{H}-\mathrm{C}(8)) ; 2.71-2.64(m, 1 \mathrm{H}-\mathrm{C}(8)$, $\mathrm{H}-\mathrm{C}(1)) ; 2.16(d d m, J=7.13,6.94, \mathrm{H}-\mathrm{C}(3)) ; 1.88(d d, J=8.32,8.12, \mathrm{H}-\mathrm{C}(4)) ; 1.76 \quad(d m, J=14.66$, $1 \mathrm{H}-\mathrm{C}(9)) ; 1.74(m, \mathrm{H}-\mathrm{C}(2)) ; 1.43(d m, J=14.66,1 \mathrm{H}-\mathrm{C}(9)) ; 1.26\left(t, J=7.1, M e \mathrm{CH}_{2} \mathrm{O}\right) .{ }^{13} \mathrm{C}-\mathrm{NMR}$ (50.3 MHz, $\left.\mathrm{CDCl}_{3}\right)$ : $169.96(\mathrm{CO}) ; 169.71(\mathrm{CO}) ; 79.40(\mathrm{C}(5)) ; 61.47\left(\mathrm{MeCH}_{2} \mathrm{O}\right) ; 41.19(\mathrm{C}(8)) ; 31.51(\mathrm{C}(1))$; $30.34(\mathrm{C}(9)) ; 26.48(\mathrm{C}(4)) ; 25.61(\mathrm{C}(3)) ; 24.95(\mathrm{C}(2)) ; 14.00\left(\mathrm{MeCH}_{2} \mathrm{O}\right) . \mathrm{CI}-\mathrm{MS}\left(\mathrm{CH}_{4}\right): 239\left(2,[M+29]^{+}\right), 212$ $\left(13,[M+2]^{+}\right), 211\left(100,[M+1]^{+}\right), 193(24), 183(6), 166(8), 165(60), 151(3), 138(7), 137(44) .119(10), 93$ (10), 91 (14), 79 (2), 57 (4), 43 (4). Anal. calc. for $\mathrm{C}_{11} \mathrm{H}_{14} \mathrm{O}_{4}$ : C 62.85, H 6.71; found: C 62.85, H 6.96.

Ethyl (1R,2R,3S,4S,5R)-7-Oxo-6-oxatricyclo[3.3.1.0 2,4]nonane-3-carboxylate (anti-38). As described for 33, with anti-11 $(8.71 \mathrm{~g}, 44.84 \mathrm{mmol}), \mathrm{NaHCO}_{3}(7.53 \mathrm{~g}, 89.69 \mathrm{mmol}), \mathrm{CH}_{2} \mathrm{Cl}_{2}$, and $\mathrm{MCPBA}(28.14 \mathrm{~g}, 89.69 \mathrm{mmol})$ $(20 \mathrm{~h})$. Purification as described for $s y n-38$ yielded $8.40 \mathrm{~g}(89 \%)$ of anti-38. White solid. M.p. $124-125^{\circ} \cdot[\alpha]_{\mathrm{D}}^{22}=$ $+23.2\left(c=0.93, \mathrm{CHCl}_{3}\right)$. IR (KBr): 1723. ${ }^{1} \mathrm{H}-\mathrm{NMR}\left(500.13 \mathrm{MHz}, \mathrm{CDCl}_{3}\right): 4.81(m, \mathrm{H}-\mathrm{C}(5)) ; 4.13(q, J=7.13$, $\left.\mathrm{MeCH}_{2} \mathrm{O}\right) ; 2.78(d d, J=18.36,4.41,1 \mathrm{H}-\mathrm{C}(8)) ; 2.71(d d d, J=18.36,1.97,1.97,1 \mathrm{H}-\mathrm{C}(8)) ; 2.57(m, \mathrm{H}-\mathrm{C}(1))$; $2.36(d m, J=6.36, \mathrm{H}-\mathrm{C}(4)) ; 1.99(d d m, J=6.30,2.99, \mathrm{H}-\mathrm{C}(2)) ; 1.72(d m, J=14.07,1 \mathrm{H}-\mathrm{C}(9)) ; 1.68(d d, J=$ 2.73, 2.73, $\mathrm{H}-\mathrm{C}(3)) ; 1.46(d m, J=14.07 \mathrm{~Hz}, 1 \mathrm{H}-\mathrm{C}(9)) ; 1.26\left(t, J=7.13, M e \mathrm{CH}_{2} \mathrm{O}\right) .{ }^{13} \mathrm{C}-\mathrm{NMR}(50.3 \mathrm{MHz}$, $\left.\mathrm{CDCl}_{3}\right)$ : $171.08(\mathrm{CO}) ; 169.37(\mathrm{C}(7)) ; 78.86(\mathrm{C}(5)) ; 60.94\left(\mathrm{MeCH}_{2} \mathrm{O}\right) ; 40.35(\mathrm{C}(8)) ; 31.69(\mathrm{C}(1)) ; 29.54(\mathrm{C}(4))$; $29.43(\mathrm{C}(9)) ; 28.59(\mathrm{C}(3)) ; 22.15(\mathrm{C}(2)) ; 14.11\left(\mathrm{MeCH}_{2} \mathrm{O}\right)$. CI-MS $\left(\mathrm{CH}_{4}\right): 251\left(1,[M+41]^{+}\right), 239(4,[M+$ 
$\left.29]^{+}\right), 212\left(13,[M+2]^{+}\right), 211\left(100,[M+1]^{+}\right), 210\left(8, M^{+}\right), 193(30), 183(5), 166(8), 165(69), 137(23), 119$ (5), 107 (2), 93 (5), 91 (7), 41 (4). Anal. calc. for $\mathrm{C}_{11} \mathrm{H}_{14} \mathrm{O}_{4}$ : C 62.85, H 6.71; found: C 62.88, H 6.83.

Ethyl 3-Oxo-2-oxabicyclo[3.2.1]octane-7-exo-acetate (rac-39). A soln. of rac-syn-38 (52 $\mathrm{mg}, 24.7 \mathrm{mmol})$ in $\mathrm{MeOH}(20 \mathrm{ml})$ was hydrogenated for $15 \mathrm{~h}$ at r.t./1 atm over $10 \% \mathrm{Pd} / \mathrm{C}(112 \mathrm{mg})$. The catalyst was filtered off, the filtrate evaporated, and the residue purified by CC (AcOEt/petroleum ether 1:1): $13 \mathrm{mg}(25 \%)$ of $\mathrm{rac}-\mathbf{3 9}$. Colorless oil. ${ }^{1} \mathrm{H}-\mathrm{NMR}\left(360 \mathrm{MHz}, \mathrm{CDCl}_{3}\right): 4.59(m, \mathrm{H}-\mathrm{C}(5)) ; 4.15 \quad\left(q, J=7.13, \mathrm{MeCH}_{2} \mathrm{O}\right) ; 2.85$ $(m, 1 \mathrm{H}-\mathrm{C}(6)) ; 2.75(d d d, J=18.54,5.13,2.57, \mathrm{H}-\mathrm{C}(2)) ; 2.57(m, \mathrm{H}-\mathrm{C}(1)) ; 2.51(d m, J=18.54, \mathrm{H}-\mathrm{C}(2))$; $2.36(d d, J=15.26,7.6,1 \mathrm{H}-\mathrm{C}(6)) ; 2.20(d d, J=15.26,8.42,1 \mathrm{H}-\mathrm{C}(6)) ; 2.09(d d d, J=13.69,8.56,2.28$, $1 \mathrm{H}-\mathrm{C}(7)) ; 1.96(d m, J=13.69,1 \mathrm{H}-\mathrm{C}(7)) ; 1.76(d m, J=13.12,1 \mathrm{H}-\mathrm{C}(8)) ; 1.49(d m, J=13.12,1 \mathrm{H}-\mathrm{C}(8))$; $1.27\left(t, J=7.13, \mathrm{MeCH}_{2} \mathrm{O}\right)$. NOE: 2.85 (2.8, 4.59), $2.36(2.9,4.59), 1.76(1.6,4.59), 4.59(2.3,2.85), 2.36(1.7$, 2.85), $2.20(1.63,2.85), 2.75(4.2,2.57), 1.76(1.9,2.57), 1.49(20,2.57) .{ }^{13} \mathrm{C}-\mathrm{NMR}\left(50.3 \mathrm{MHz}, \mathrm{CDCl}_{3}\right): 169.94$ $(\mathrm{CO}) ; 83.81(\mathrm{C}(5)) ; 60.73\left(\mathrm{CH}_{2} \mathrm{O}\right) ; 41.76(\mathrm{C}(6)) ; 40.24(\mathrm{C}(2)) ; 39.44\left(\mathrm{CH}_{2} \mathrm{COO}\right) ; 37.29,33.50(\mathrm{C}(7), \mathrm{C}(8))$; $32.41(\mathrm{C}(1)) ; 14.63\left(\mathrm{MeCH}_{2} \mathrm{O}\right)$. CI-MS $\left(\mathrm{CH}_{4}\right): 212\left(6,[M+2]^{+}\right), 213\left(45,[M+1]^{+}\right), 196(12), 195(100), 184$ (3), 167 (47), 154 (5), 153 (65), 139 (6), 121 (3), 93 (3), 41 (23).

Methyl (1R,2R,4R,5S,6S)-4-Hydroxy-6-(methoxycarbonyl)bicyclo[3.1.0]hexane-2-acetate (anti-40). A soln. of anti-38 $(8.30 \mathrm{~g}, 39.48 \mathrm{mmol})$ in $\mathrm{MeOH}(180 \mathrm{ml})$ containing $37 \%$ aq. $\mathrm{HCl}$ soln. $(9.87 \mathrm{ml}, 118.44 \mathrm{mmol})$ was refluxed for $48 \mathrm{~h}$ and then cooled and evaporated. The residual liquid was partitioned between AcOEt $(100 \mathrm{ml})$ and $\mathrm{H}_{2} \mathrm{O}(100 \mathrm{ml})$, the aq. layer extracted with $\mathrm{AcOEt}(4 \times 100 \mathrm{ml})$, the combined org. extract washed with $\mathrm{H}_{2} \mathrm{O}$ $(100 \mathrm{ml})$ and brine $(100 \mathrm{ml})$, dried $\left(\mathrm{Na}_{2} \mathrm{SO}_{4}\right)$, and evaporated: $8.74 \mathrm{~g}(97 \%)$ of anti-40 as a slightly yellow oil which was transformed into anti-41 without further purification. IR $\left(\mathrm{CDCl}_{3}\right): 1724 .{ }^{1} \mathrm{H}-\mathrm{NMR}(360 \mathrm{MHz}$, $\left.\mathrm{CDCl}_{3}\right): 4.35(d, J=5.25,1 \mathrm{H}-\mathrm{C}(4)) ; 3.69(s, \mathrm{MeO}) ; 3.66(s, \mathrm{MeO}) ; 2.69-2.53(m, 3 \mathrm{H}) ; 2.07(m, 1 \mathrm{H}) ; 1.97$ $(d d, J=5.81,3.00,1 \mathrm{H}) ; 1.64(d d d, J=15.32,6.93,5.43,1 \mathrm{H}) ; 1.50(d m, J=15.32,1 \mathrm{H}) ; 1.29(d d, J=3.18,3.00$, $1 \mathrm{H}) .{ }^{13} \mathrm{C}-\mathrm{NMR}\left(50.3 \mathrm{MHz}, \mathrm{CDCl}_{3}\right): 173.27(\mathrm{CO}) ; 172.97(\mathrm{CO}) ; 73.72(\mathrm{C}(4)) ; 51.76(\mathrm{MeO}) ; 51.56(\mathrm{MeO}) ; 40.39$ $\left(\mathrm{CH}_{2} \mathrm{CO}_{2} \mathrm{Me}\right) ; 37.11(\mathrm{C}(3)) ; 36.09 ; 34.48 ; 32.45 ; 22.22$. CI-MS $\left(\mathrm{CH}_{4}\right): 269\left(1,[M+41]^{+}\right), 258(2,[(M+29)+$ $\left.1]^{+}\right), 257\left(19,[M+29]^{+}\right), 229\left(11,[M+1]^{+}\right), 228\left(5, M^{+}\right), 212(15), 211(100), 197(12), 180(5), 179(51), 152$ (3), 151 (43), 137 (3), 119 (7), 91 (9)

rac-Methyl 6-(Methoxycarbonyl)-4-oxobicyclo[3.1.0]hexane-2-acetate (syn-41). As described for anti-40, with rac-syn-38 $(2.10 \mathrm{~g}, 10 \mathrm{mmol}), \mathrm{MeOH}(45 \mathrm{ml})$, and containing $37 \%$ aq. $\mathrm{HCl}$ soln. $(2.5 \mathrm{ml}, 30 \mathrm{mmol})$. The product, rac-syn-40, was added, without further purification, into a stirred suspension of PCC $(3.14 \mathrm{~g}$, $14.55 \mathrm{mmol})$ in $\mathrm{CH}_{2} \mathrm{Cl}_{2}(100 \mathrm{ml})$. After $2 \mathrm{~h}$, dry $\mathrm{Et}_{2} \mathrm{O}(100 \mathrm{ml})$ was added, and the supernatant liquid was decanted from a black gummy residue, which was washed with dry $\mathrm{Et}_{2} \mathrm{O}(3 \times 200 \mathrm{ml})$ until it became a black granular solid. The combined org. soln. was filtered through a short pad of Florisil, the filtrate evaporated, and the residue purified by CC (AcOEt/petroleum ether 1:2): $678.7 \mathrm{mg} \mathrm{(30 \% )} \mathrm{of} \mathrm{rac-syn-41.} \mathrm{Colorless} \mathrm{oil.}{ }^{1} \mathrm{H}-\mathrm{NMR}$ $\left(200 \mathrm{MHz}, \mathrm{CDCl}_{3}\right): 3.717(s, \mathrm{MeO}) ; 3.707(s, \mathrm{MeO}) ; 2.86-2.67(m, 2 \mathrm{H}) ; 2.63-2.56(m, 2 \mathrm{H}) ; 2.35-2.24$ $(m, 3 \mathrm{H}) ; 2.10-1.91(m, 1 \mathrm{H}) \cdot{ }^{13} \mathrm{C}-\mathrm{NMR}\left(50.3 \mathrm{MHz}, \mathrm{CDCl}_{3}\right): 210.80(\mathrm{C}(4)) ; 171.74(\mathrm{CO}) ; 169.77(\mathrm{CO}) ; 52.08$ $(\mathrm{MeO}) ; 51.52(\mathrm{MeO}) ; 44.68(\mathrm{C}(3)) ; 40.40\left(\mathrm{CH}_{2} \mathrm{COO}\right) ; 34.34 ; 34.12 ; 30.12 ; 27.94$. CI-MS $\left(\mathrm{CH}_{4}\right): 267$ (3, [M+ $\left.41]^{+}\right), 255\left(5,[M+29]^{+}\right), 228\left(7,[M+2]^{+}\right), 227\left(56,[M+1]^{+}\right), 196(12), 195(100), 167(10), 153(5), 135(5)$, $121(3), 107(4), 98(3)$.

Methyl (1R,2R,5S,6S)-6-(Methoxycarbonyl)-4-oxobicyclo[3.1.0]hexane-2-acetate (anti-41). Crude anti-40 $(8.74 \mathrm{~g}, 38.30 \mathrm{mmol})$ was added in one portion to a stirred suspension of PCC $(12.38 \mathrm{~g}, 57.45 \mathrm{mmol})$ in anh. $\mathrm{CH}_{2} \mathrm{Cl}_{2}(400 \mathrm{ml})$. After $2 \mathrm{~h}$, the product $\left(R_{\mathrm{f}} 0.33\right)$ was isolated and purified as described for $\operatorname{syn}-4 \mathbf{4 1}: 5.29 \mathrm{~g}(61 \%)$ of anti-41. White solid. M.p. 100.5-101.5 $.[\alpha]_{\mathrm{D}}^{23}=+2.04\left(c=1.03, \mathrm{CHCl}_{3}\right)$. IR $(\mathrm{KBr}): 1726 .{ }^{1} \mathrm{H}-\mathrm{NMR}$ $\left(360 \mathrm{MHz}, \mathrm{CDCl}_{3}\right)$ : $3.71(s, \mathrm{MeO}) ; 3.70(s, \mathrm{MeO}) ; 2.86(m, \mathrm{H}-\mathrm{C}(2)) ; 2.54\left(d d, J=16.26,7.41,1 \mathrm{H}, \mathrm{CH}_{2} \mathrm{COO}\right)$; $2.45\left(d d, J=16.26,7.13,1 \mathrm{H}, \mathrm{CH}_{2} \mathrm{COO}\right) ; 2.43(d d, J=5.56,3.57, \mathrm{H}-\mathrm{C}(5)) ; 2.32(m, \mathrm{H}-\mathrm{C}(1)) ; 2.31(d d, J=$ 19.11, 8.85, $1 \mathrm{H}-\mathrm{C}(3)) ; 2.08(m, \mathrm{H}-\mathrm{C}(6)) ; 1.88(d m, J=19.11,1 \mathrm{H}-\mathrm{C}(3))$. NOE: $2.54(2.07,2.86), 2.45(6.22$, 2.86), $2.31(4.77,2.86), 2.08(4.51,2.86), 2.86(4.33,2.08) .{ }^{13} \mathrm{C}-\mathrm{NMR}\left(50.3 \mathrm{MHz}, \mathrm{CDCl}_{3}\right): 209.46(\mathrm{C}(4)) ; 171.56$ $(\mathrm{CO}) ; 170.33(\mathrm{CO}) ; 52.26(\mathrm{MeO}) ; 51.70(\mathrm{MeO}) ; 39.73\left(\mathrm{CH}_{2} \mathrm{CO}_{2} \mathrm{Me}\right) ; 38.58(\mathrm{C}(3)) ; 35.00 ; 33.66 ; 31.90 ; 26.31$. CI-MS $\left(\mathrm{CH}_{4}\right): 267\left(2,[M+41]^{+}\right), 255\left(5,[M+29]^{+}\right), 228\left(5,[M+2]^{+}\right), 227\left(49,[M+1]^{+}\right), 196(10), 195(100)$, 181 (4), 167 (10), 153 (8), 135 (7), 107 (8), 98 (18), 79 (1), 45 (5). Anal. calc. for $\mathrm{C}_{11} \mathrm{H}_{14} \mathrm{O}_{5}$ : C 58.40, H 6.24; found: C $58.47, \mathrm{H} 6.25$.

Dimethyl (1R,2R)-4-Oxocyclopentane-1,2-diacetate (42). A soln. of anti-41 (3.51 g, $15.50 \mathrm{mmol})$ in $\mathrm{MeOH}$ $(160 \mathrm{ml})$ was hydrogenated for $15 \mathrm{~h}$ at r.t./1 atm over $10 \% \mathrm{Pd} / \mathrm{C}(1.05 \mathrm{~g})$. The catalyst was filtered off, the filtrate evaporated, and the residue purified by FC (AcOEt/petroleum ether 1:3): $3.22 \mathrm{~g}(91 \%)$ of $\mathbf{4 2}$. Colorless oil. $R_{\mathrm{f}}$ 0.32. $[\alpha]_{\mathrm{D}}^{23}=+136.2\left(c=0.52, \mathrm{CHCl}_{3}\right)$. IR $\left(\mathrm{CHCl}_{3}\right): 1740,1728 .{ }^{1} \mathrm{H}-\mathrm{NMR}\left(360 \mathrm{MHz}, \mathrm{CDCl}_{3}\right): 3.69$ $(s, 2 \mathrm{MeO}) ; 2.70-2.56\left(m, \mathrm{CH}_{2}(3), \mathrm{CH}_{2}(5)\right) ; 2.39-2.28\left(m, 2 \mathrm{CH}_{2} \mathrm{COO}\right) ; 2.06-1.96(m, \mathrm{H}-\mathrm{C}(1), \mathrm{H}-\mathrm{C}(2))$. 
${ }^{13} \mathrm{C}-\mathrm{NMR}\left(50.3 \mathrm{MHz}, \mathrm{CDCl}_{3}\right)$ : 215.31 (C(4)); 172.12 (2 C, $\left.2 \mathrm{CO}\right) ; 51.58$ (2 C, $\left.2 \mathrm{MeO}\right) ; 44.48$ (2 C, C(3), C(5)); $38.19(2 \mathrm{C}, \mathrm{C}(1), \mathrm{C}(2)) ; 37.53\left(2 \mathrm{C}, 2 \mathrm{CH}_{2} \mathrm{COO}\right)$. CI-MS $\left(\mathrm{CH}_{4}\right): 269\left(1,[M+41]^{+}\right), 257\left(2,[M+29]^{+}\right), 229(33$, $\left.[M+1]^{+}\right), 198(11), 197\left(100,[M-\mathrm{MeO}]^{+}\right), 183(11), 169(6), 168(4), 155(12)$. Anal. calc. for $\mathrm{C}_{11} \mathrm{H}_{16} \mathrm{O}_{5}$ : C 57.89, H 7.07; found: C 57.73, H 7.09.

Dimethyl (1R,2R)-4-Hydroxycyclopentane-1,2-diacetate (43). $\mathrm{NaBH}_{4}(481 \mathrm{mg}, 12.71 \mathrm{mmol})$ was added in one portion into a stirred soln. of $\mathbf{4 2}(2.90 \mathrm{~g}, 12.71 \mathrm{mmol})$ in $\mathrm{MeOH}(40 \mathrm{ml})$ at $0^{\circ}$. After $1 \mathrm{~h} \mathrm{stirring}$ at $0^{\circ}$, most of the solvent was evaporated before $\mathrm{H}_{2} \mathrm{O}(40 \mathrm{ml})$ was added. The mixture was extracted with AcOEt $(5 \times 40 \mathrm{ml})$, the combined extract washed with brine $(50 \mathrm{ml})$, dried $\left(\mathrm{Na}_{2} \mathrm{SO}_{4}\right)$, and evaporated, and the residue purified by $\mathrm{CC}$ (AcOEt/petroleum ether 1:1): $2.69 \mathrm{~g}(92 \%)$ of 43. Colorless oil. $R_{\mathrm{f}} 0.36 .[\alpha]_{\mathrm{D}}^{23}=+39.1\left(c=0.47, \mathrm{CHCl}_{3}\right)$. IR $\left(\mathrm{CHCl}_{3}\right)$ : 1728. ${ }^{1} \mathrm{H}-\mathrm{NMR}\left(360 \mathrm{MHz}, \mathrm{CDCl}_{3}\right): 4.33(\mathrm{~m}, \mathrm{H}-\mathrm{C}(4)) ; 3.674(s, \mathrm{MeO}) ; 3.671(s, \mathrm{MeO}) ; 2.58(d d, J=$ $15.76,5.05,1 \mathrm{H}) ; 2.51(d d, J=14.27,4.56,1 \mathrm{H}) ; 2.38(d d, J=15.76,8.62,1 \mathrm{H}) ; 2.23(d d, J=14.27,8.72,1 \mathrm{H})$; $2.33-2.25(m, 2 \mathrm{H}) ; 2.00-1.92(m, 2 \mathrm{H}) ; 1.76$ (br. $s, \mathrm{OH}) ; 1.53(d d d, J=13.72,9.91,5.75,1 \mathrm{H}) ; 1.40(d d d d, J=$ 13.72, 7.53, 3.57, 1.58, $1 \mathrm{H}) .{ }^{13} \mathrm{C}-\mathrm{NMR}\left(50.3 \mathrm{MHz}, \mathrm{CDCl}_{3}\right): 173.43(\mathrm{CO}) ; 173.11(\mathrm{CO}) ; 71.99(\mathrm{C}(4)) ; 51.45$ $(2 \mathrm{MeO}) ; 42.33,41.64(\mathrm{C}(3), \mathrm{C}(5)) ; 40.11,39.39(\mathrm{C}(1), \mathrm{C}(2)) ; 39.01,38.62\left(2 \mathrm{CH}_{2} \mathrm{COO}\right)$. CI-MS $\left(\mathrm{CH}_{4}\right): 259(6$, $\left.[M+29]^{+}\right), 231\left(18,[M+1]^{+}\right), 214(6), 213(50), 199(3), 182(11), 181(100), 167(3), 153$ (15), $152(2), 139$ (12). Anal. calc. for $\mathrm{C}_{11} \mathrm{H}_{18} \mathrm{O}_{5}: \mathrm{C} 57.38, \mathrm{H}$ 7.88; found: C 57.21, $\mathrm{H}$ 7.94.

Methyl (1R,2S,4S)-2-\{2-\{[(tert-Butyl)diphenylsilyl]oxy\}ethyl\}-4-[(methylsulfonyl)oxy]cyclopentaneacetate (44). To a stirred soln. of $\mathbf{1 5 b}(925 \mathrm{mg}, 2.10 \mathrm{mmol})$ in $\mathrm{CH}_{2} \mathrm{Cl}_{2}(35 \mathrm{ml}), \mathrm{Et}_{3} \mathrm{~N}(533 \mathrm{mg}, 5.26 \mathrm{mmol})$ and methanesulfonyl chloride $(602 \mathrm{mg}, 5.26 \mathrm{mmol}$ ) were successively added, and the mixture was stirred for $2 \mathrm{~d}$ at r.t. The residue obtained after evaporation was purified by CC (AcOEt/petroleum ether 1:2): $1.035 \mathrm{~g}(95 \%)$ of 44. Colorless syrup. $R_{\mathrm{f}} 0.49 .[\alpha]_{\mathrm{D}}^{23}=+29.8\left(c=0.47, \mathrm{CHCl}_{3}\right)$. $\mathrm{IR}\left(\mathrm{CHCl}_{3}\right): 1732 .{ }^{1} \mathrm{H}-\mathrm{NMR}\left(500.13 \mathrm{MHz}, \mathrm{CDCl}_{3}\right)$ : $7.67-7.63$ (m, 4 arom. $\mathrm{H}) ; 7.45-7.36(m, 6$ arom. $\mathrm{H}) ; 5.10(m, \mathrm{H}-\mathrm{C}(4)) ; 3.73-3.61\left(m, \mathrm{CH}_{2} \mathrm{CH}_{2} \mathrm{O}\right) ; 3.66$ $(s, \mathrm{MeO}) ; 2.95\left(s, \mathrm{MeSO}_{2}\right) ; 2.57(d d, J=15.56,3.94,1 \mathrm{H}) ; 2.44(d d d, J=14.65,7.84,6.50,1 \mathrm{H}) ; 2.25(d d, J=$ $15.56,9.48,1 \mathrm{H}) ; 2.17(m, 1 \mathrm{H}) ; 1.97-1.87(m, 2 \mathrm{H}) ; 1.81(m, 1 \mathrm{H}) ; 1.67(m, 1 \mathrm{H}) ; 1.51$ (ddd, $J=14.40,10.06$, 6.08, $1 \mathrm{H}) ; 1.37(\mathrm{~m}, 1 \mathrm{H}) ; 1.05\left(\mathrm{~s},{ }^{\mathrm{B}} \mathrm{Bu}\right) .{ }^{13} \mathrm{C}-\mathrm{NMR}\left(125.76 \mathrm{MHz}, \mathrm{CDCl}_{3}\right): 173.11(\mathrm{CO}) ; 135.51,133.65,129.66$, $127.68\left(12\right.$ arom. C); $83.00(\mathrm{C}(4)) ; 62.52\left(\mathrm{CH}_{2} \mathrm{CH}_{2} \mathrm{O}\right) ; 51.60(\mathrm{MeO}) ; 40.29\left(\mathrm{MeSO}_{2}\right) ; 39.95(\mathrm{C}(1)$ or $\mathrm{C}(2)) ; 39.83$, $39.31(\mathrm{C}(3), \mathrm{C}(5)) ; 38.88\left(\mathrm{CH}_{2} \mathrm{CH}_{2} \mathrm{O}\right) ; 38.42(\mathrm{C}(2)$ or $\mathrm{C}(1)) ; 36.51\left(\mathrm{CH}_{2} \mathrm{CO}_{2} \mathrm{Me}\right) ; 26.82\left(3 \mathrm{C}, \mathrm{Me}_{3} \mathrm{C}\right) ; 19.13$ $\left(\mathrm{Me}_{3} C\right)$. FAB-MS: $542\left(2,[M+\mathrm{Na}]^{+}\right), 520\left(4,[M+1]^{+}\right), 488(6), 461(37), 441(13), 421(7), 391(6), 365(33)$, $345(56), 277$ (56), $257(18), 239$ (26), 213 (100), 183 (100), 137 (100). Anal. calc. for $\mathrm{C}_{27} \mathrm{H}_{38} \mathrm{OSSi}: \mathrm{C} 62.52$, H 7.38; found: C $62.37, \mathrm{H} 7.49$.

Methyl (1R,2R,4R)-4-(6-Amino-9H-purin-9-yl)-2-\{2-\{[(tert-butyl)diphenylsilyl]oxy\}ethyl\}cyclopentaneacetate (45). As described for 36, with $44(220 \mathrm{mg}, 424 \mathrm{mmol}): 45(135 \mathrm{mg}, 57 \%)$. White solid. M.p. 126 $126.5^{\circ}$ (from $\mathrm{CH}_{2} \mathrm{Cl}_{2} /$ petroleum ether). $R_{\mathrm{f}}\left(\mathrm{CH}_{2} \mathrm{Cl}_{2} / \mathrm{EtOH} 20: 1\right)$ 0.20. $[\alpha]_{\mathrm{D}}^{24}=+23.86\left(c=0.44, \mathrm{CHCl}_{3}\right)$. IR (KBr): 1738, 1669, 1643, 1601. UV $\left(\mathrm{CHCl}_{3}\right): 262(15600) .{ }^{1} \mathrm{H}-\mathrm{NMR}\left(500.13 \mathrm{MHz}, \mathrm{CDCl}_{3}\right): 8.35\left(s, \mathrm{H}-\mathrm{C}\left(2^{\prime}\right)\right)$; $7.84\left(s, \mathrm{H}-\mathrm{C}\left(8^{\prime}\right)\right) ; 7.67-7.63(m, 4$ arom. $\mathrm{H}) ; 7.44-7.35(m, 6$ arom. $\mathrm{H}) ; 5.86\left(s, \mathrm{NH}_{2}\right) ; 4.90(m, \mathrm{H}-\mathrm{C}(4)) ; 3.77-$ $3.62\left(m, \mathrm{CH}_{2} \mathrm{CH}_{2} \mathrm{O}\right) ; 3.67(s, \mathrm{MeO}) ; 2.60(d d, J=15.10,3.48,1 \mathrm{H}) ; 2.42(m, 1 \mathrm{H}) ; 2.37-2.24(m, 3 \mathrm{H}) ; 2.13-$ $2.05(m, 1 \mathrm{H}) ; 1.94-1.80(m, 2 \mathrm{H}) ; 1.68(m, 1 \mathrm{H}) ; 1.52(m, 1 \mathrm{H}) ; 1.05\left(s,{ }^{t} \mathrm{Bu}\right) .{ }^{13} \mathrm{C}-\mathrm{NMR}\left(50.3 \mathrm{MHz}, \mathrm{CDCl}_{3}\right)$ : $172.98(\mathrm{CO})$; $155.18\left(\mathrm{C}\left(6^{\prime}\right)\right)$; $152.29\left(\mathrm{C}\left(2^{\prime}\right)\right) ; 150.01\left(\mathrm{C}\left(4^{\prime}\right)\right)$; $138.64\left(\mathrm{C}\left(8^{\prime}\right)\right)$; 135.50, 133.64, 129.67, 127.67 (12 arom. C); $119.95\left(\mathrm{C}\left(5^{\prime}\right)\right) ; 62.40\left(\mathrm{OCH}_{2} \mathrm{CH}_{2}\right) ; 53.78\left(\mathrm{C}\left(4^{\prime}\right)\right)$; $51.63(\mathrm{MeO}) ; 41.11,40.02(\mathrm{C}(1), \mathrm{C}(2))$; 39.52, 38.71, 38.07, 36.74, $26.87\left(3 \mathrm{C}, \mathrm{Me}_{3} \mathrm{C}\right) ; 19.16\left(\mathrm{Me}_{3} \mathrm{C}\right)$. FAB-MS: $560\left(11,[M+2]^{+}\right), 559\left(38,[M+1]^{+}\right), 558(87$, $M^{+}$), $500(23), 480(5), 302(10), 213(27), 197$ (34), $183(23), 136(100), 121$ (34). Anal. calc. for $\mathrm{C}_{31} \mathrm{H}_{39} \mathrm{~N}_{5} \mathrm{O}_{3} \mathrm{Si}$ : C 66.76, H 7.05, N 12.56; found: C 66.56, H 6.97, N 12.39.

Methyl (1R,2R,4R)-2-\{2-\{[(tert-Butyl)diphenylsilyl]oxy\}ethyl\}-4-(1,2,3,4-tetrahydro-5-methyl-2,4-dioxopyrimidin-1-yl)cyclopentaneacetate (46). As described for 37, with 44 (210 mg, $405 \mathrm{mmol})$ : 46 (77.8 mg, 35\%). White foamy solid. M.p. $43-45^{\circ}$. $R_{\mathrm{f}}\left(\mathrm{AcOEt} / \mathrm{CH}_{2} \mathrm{Cl}_{2} / \mathrm{EtOH} 20: 40: 1\right) 0.62 .[\alpha]_{\mathrm{D}}^{24}=+15.91\left(c=0.22, \mathrm{CHCl}_{3}\right)$. UV $\left(\mathrm{CHCl}_{3}\right): 272(13400)$. IR (KBr): 1738, 1688. ${ }^{1} \mathrm{H}-\mathrm{NMR}\left(500.13 \mathrm{MHz}, \mathrm{CDCl}_{3}\right): 8.81\left(s, \mathrm{H}-\mathrm{C}\left(3^{\prime}\right)\right) ; 7.66-7.62$ ( $m, 4$ arom. $\mathrm{H}) ; 7.45-7.36$ ( $m, 6$ arom. $\mathrm{H}) ; 7.00\left(d, J=1.17, \mathrm{H}-\mathrm{C}\left(6^{\prime}\right)\right) ; 4.92(m, \mathrm{H}-\mathrm{C}(4)) ; 3.75-3.60$ $\left(m, \mathrm{CH}_{2} \mathrm{CH}_{2} \mathrm{O}\right) ; 3.67(s, \mathrm{MeO}) ; 2.56(d d, J=15.02,3.30,1 \mathrm{H}) ; 2.19(d d, J=15.02,9.90,1 \mathrm{H}) ; 2.18-2.10$ $(m, 2 \mathrm{H}) ; 2.01-1.94(m, 1 \mathrm{H}) ; 1.93\left(d, J=1.17, \mathrm{Me}-\mathrm{C}\left(5^{\prime}\right)\right) ; 1.91-1.82(m, 2 \mathrm{H}) ; 1.75-1.65(m, 1 \mathrm{H}) ; 1.43$ $(m, 1 \mathrm{H}) ; 1.26(m, 1 \mathrm{H}) ; 1.05\left(s,{ }^{\prime} \mathrm{Bu}\right) .{ }^{13} \mathrm{C}-\mathrm{NMR}\left(125.76 \mathrm{MHz}, \mathrm{CDCl}_{3}\right): 173.07(\mathrm{CO}) ; 163.54\left(\mathrm{C}\left(4^{\prime}\right)\right) ; 150.93$ $\left(\mathrm{C}\left(2^{\prime}\right)\right) ; 136.52\left(\mathrm{C}\left(6^{\prime}\right)\right) ; 135.51,133.64,129.68,127.68(12$ arom. $\mathrm{C}) ; 111.12\left(\mathrm{C}\left(5^{\prime}\right)\right) ; 62.33\left(\mathrm{CH}_{2} \mathrm{O}\right) ; 54.03(\mathrm{C}(4))$; $51.61(\mathrm{MeO}) ; 40.79,40.30(\mathrm{C}(1), \mathrm{C}(2)) ; 38.58,38.46,36.49,36.43,26.85\left(3 \mathrm{C}, \mathrm{Me}_{3} \mathrm{C}\right) ; 19.13\left(\mathrm{Me}-\mathrm{C}\left(5^{\prime}\right)\right) ; 12.60$ $\left(\mathrm{Me}_{3} C\right)$. FAB-MS: $550\left(3,[M+1]^{+}\right), 549\left(8, M^{+}\right), 491(23), 471(23), 365(6), 345(11), 307(15), 287(10), 247$ (11), 213 (34), 197 (52), 167 (29), 135 (100), 127 (68). HR-ESI-MS ( $\mathrm{MeOH} / \mathrm{CHCl}_{3}$ ): 571.2596 $\left(\mathrm{C}_{31} \mathrm{H}_{40} \mathrm{~N}_{2} \mathrm{O}_{5} \mathrm{SiNa}^{+},[M+\mathrm{Na}]^{+}\right.$; calc. 571.2599). Anal. calc. for $\mathrm{C}_{31} \mathrm{H}_{40} \mathrm{~N}_{2} \mathrm{O}_{5} \mathrm{Si}: \mathrm{C} 67.85, \mathrm{H}$ 7.35, N 5.10; found: C 67.47, H 7.59, N 4.80 . 


\section{REFERENCES}

[1] P. C. Zamecnik, M. L. Stephenson, Proc. Natl. Acad. Sci. U.S.A. 1978, 75, 280

[2] M. L. Stephenson, P. C. Zamecnik, Proc. Natl. Acad. Sci. U.S.A. 1978, 75, 285.

[3] E. Uhlmann, A. Peyman, Chem. Rev. 1990, 90, 543.

[4] A. De Mesmaeker, R. Häner, P. Martin, H. E. Moser, Acc. Chem. Res. 1995, 28, 366.

[5] J. Temsamani, S. Agrawal, Adv. Antiviral Drug Design 1996, 2, 1.

[6] V. E. Marquez, M.-I. Lim, Med. Res. Rev. 1986, 6, 1.

[7] A. D. Borthwick, K. Biggadike, Tetrahedron 1992, 48, 571.

[8] L. Agrofoglio, E. Suhas, A. Farese, R. Condom, S. R. Challand, R. A. Earl, R. Guedj, Tetrahedron 1994, 50, 10611.

[9] V. E. Marquez, Adv. Antiviral Drug Design 1996, $2,89$.

[10] T. Kusaka, H. Yamamoto, M. Shibata, M. Muroi, T. Kishi, K. Mizuno, J. Antibiot. 1968, $21,255$.

[11] S. Yaginuma, N. Muto, M. Tsujino, Y. Sudate, M. Hayashi, M. Otani, J. Antibiot. 1981, 34, 359.

[12] J. Wang, A. Gossauer, Helv. Chim. Acta 1994, 77, 533.

[13] T. F. Jenny, Helv. Chim. Acta 1993, 76, 248.

[14] T. F. Jenny, S. A. Benner, Helv. Chim. Acta 1993, 76, 826.

[15] Å. Rosenquist, I. Kvarnström, S. C. T. Svensson, B. Classon, B. Samuelsson, Acta Chem. Scand. 1992, 46, 1127.

[16] E. J. Corey, T.-P. Loh, J. Am. Chem. Soc. 1991, 113, 8966

[17] E. J. Corey, T.-P. Loh, T. D. Roper, M. D. Azimioara, M. C. Noe, J. Am. Chem. Soc. 1992, $114,8290$.

[18] E. J. Corey, C. L. Cywin, J. Org. Chem. 1992, 57, 7372.

[19] G. Helmchen, A. Krotz, H.-P. Neumann, M. L. Ziegler, Liebigs Ann. Chem. 1993, 1313.

[20] A. J. Anciaux, A. J. Hubert, A. F. Noels, N. Petiniot, P. Teyssié, J. Org. Chem. 1980, 45, 695.

[21] H. Günther, 'NMR-Spektroskopie. Eine Einführung', Georg Thieme Verlag, Stuttgart, 1973.

[22] D. C. Nonhebel, Chem. Soc. Rev. 1993, 22, 347.

[23] D. H. R. Barton, W. B. Motherwell, A. Stange, Synthesis 1981, 743.

[24] J. R. Collins, G. H. Loew, J. Biol. Chem. 1988, 263, 3164.

[25] C. Gröger, H. Musso, Angew. Chem. 1976, 88, 415; Angew. Chem., Int. Ed. 1976, 15, 373.

[26] C. Gröger, H. Musso, I. Rossnagel, Chem. Ber. 1980, 113, 3621.

[27] C. H. DePuy, M. Isaks, K. L. Eilers, G. F. Morris, J. Org. Chem. 1964, 29, 3503.

[28] V. Osterthun, E. Winterfeldt, Chem. Ber. 1977, 110, 146.

[29] L. A. Paquette, C. W. Doecke, F. R. Kearney, A. F. Drake, S. F. Mason, J. Am. Chem. Soc. 1980, $102,7228$.

[30] J. Meinwald, B. C. Cadoff, J. Org. Chem. 1962, 27, 1539.

[31] S. A. Monti, S.-S. Yuan, J. Org. Chem. 1971, 36, 3350. 